University of Louisville

ThinkIR: The University of Louisville's Institutional Repository

Electronic Theses and Dissertations

$12-2008$

\title{
Viscoelastic properties of pediatric blood
}

Neema Nair 1983-

University of Louisville

Follow this and additional works at: https://ir.library.louisville.edu/etd

\section{Recommended Citation}

Nair, Neema 1983-, "Viscoelastic properties of pediatric blood" (2008). Electronic Theses and Dissertations. Paper 1037.

https://doi.org/10.18297/etd/1037

This Master's Thesis is brought to you for free and open access by ThinkIR: The University of Louisville's Institutional Repository. It has been accepted for inclusion in Electronic Theses and Dissertations by an authorized administrator of ThinkIR: The University of Louisville's Institutional Repository. This title appears here courtesy of the author, who has retained all other copyrights. For more information, please contact thinkir@louisville.edu. 


\title{
VISCOELASTIC PROPERTIES OF PEDIATRIC BLOOD
}

\author{
By
}

\author{
Neema Nair \\ B.E., Mumbai University, India, 2004
}

\begin{abstract}
A Thesis
Submitted to the Faculty of the

Graduate School of the University of Louisville

In Partial Fulfillment of the Requirements

For the Degree of

Master of Science

Department of Mechanical Engineering

University of Louisville

Louisville, Kentucky
\end{abstract}

December 2008 


\title{
VISCOELASTIC PROPERTIES OF PEDIATRIC BLOOD
}

\author{
By
}

Neema Nair

B.E., Mumbai University, India, 2004

A Thesis Approved on

November $20^{\text {th }}, 2008$

by the following Thesis Committee:

Dr. Keith Sharp, Thesi\& Director

Department of Mechanical Engineering

\begin{tabular}{c} 
Dr. Ellen Brehob \\
Department of Mechanical Engineering \\
\hline $\begin{array}{c}\text { Dr George Pantalos } \\
\text { Department of Suqgery Division of Cardiothoracic Surgery } \\
\text { Departiment of Bioengineering }\end{array}$
\end{tabular}




\section{DEDICATION}

I would like to dedicate this thesis to my parents, Capt. K. S. Nair and Mrs. Laila K. Nair, who are the corner stone of all my achievements and success; sister, Dr. Naina Nair, for being my friend and confidante; and husband, Milan Visaria, for his unconditional love and support. 


\section{ACKNOWLEDGEMENT}

My sincere thanks, to my advisor, Dr. Keith Sharp of the Department of Mechanical Engineering, and to Dr. George Pantalos of the Department of Surgery, at the University of Louisville, without whose support and continuous persistence, this research work and thesis would not have materialized. I would also like to thank Dr. Nancy Henderson of Vilastic Inc. for putting up with my thousand questions and inquiries, and also for being prompt and so helpful with any problems that we had with the Vilastic-3 and Haake DC30. I would like to acknowledge Dr. Akif Undar from the Department of Pediatrics, Penn State University, for providing the data from his pediatric viscoelasticity

study and Dr. G. B. Thurston from Vilastic Inc., for providing data from his adult viscoelasticity study. 


\section{ABSTRACT \\ VISCOELASTIC PROPERTIES OF PEDIATRIC BLOOD \\ Neema Nair \\ $20^{\text {th }}$ November, 2008}

The performance of pediatric circulatory support devices depends on the properties of pediatric blood. This study reports the measurement of the viscoelastic properties of pediatric blood at $37^{\circ} \mathrm{C}$ [body temperature]. The results were compared with adult viscoelastic properties at the same temperature and also to pediatric viscoelastic properties analyzed at $22^{\circ} \mathrm{C}$ [room temperature]. The measurements were made using a viscoelasticity analyzer Vilastic-3 on the blood at the hematocrit at which it was drawn. Each test produced results for viscoelastic parameters versus shear rate [stretch test] at a frequency of $2 \mathrm{~Hz}$. Samples were obtained with informed consent from 11 pediatric patients at Kosair Children's Hospital with body weight of $12.72 \pm 9.85 \mathrm{~kg}$ [3.60 kg to $34.8 \mathrm{~kg}$ ] and age of $2.72 \pm 3.42$ years [0.0301 years to 11.83 years]. The average spun hematocrit was $40.2 \pm 7.38 \%$ [ $30 \%$ to $51.5 \%]$ and the average density was $1.053 \pm$ $0.00492[1.047$ to 1.060$]$. Mean viscosity values were $0.091 \pm 0.022$ poise $[0.2$ strain], $0.08 \pm 0.021$ poise [ 1 strain] and $0.0696 \pm 0.016$ poise [ 5 strain]. Mean elasticity values were $0.056 \pm 0.028$ poise [0.2 strain], $0.053 \pm 0.024$ poise [ 1 strain] and $0.021 \pm 0.007$ poise [ 5 strain]. The results obtained by 2 way - ANOVA comparison showed significant variation $(p<0.05)$ between the adult and pediatric data at $37^{\circ} \mathrm{C}$. The comparison of the 
pediatric data at body temperature and room temperature showed dissimilar values in viscoelasticity with a significant variation $(\mathrm{p}<0.05)$. The results from this study can be used as base data for pediatric blood at normal body temperature for design of implants for pediatric patients. 


\section{TABLE OF CONTENTS}

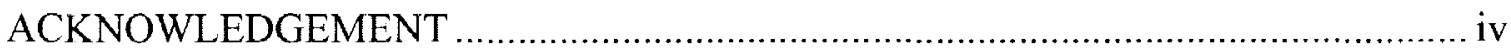

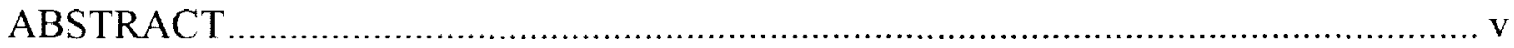

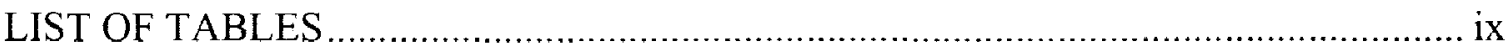

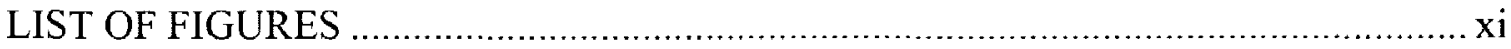

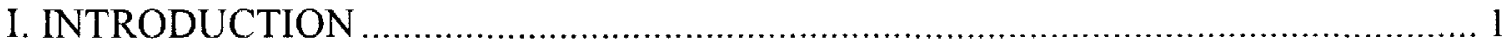

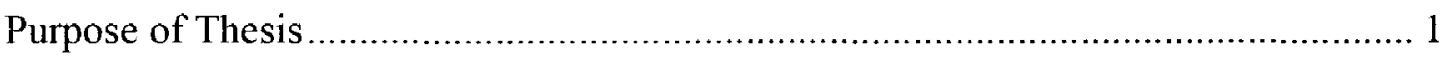

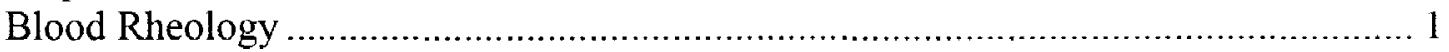

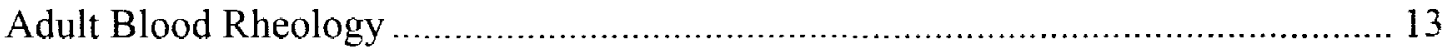

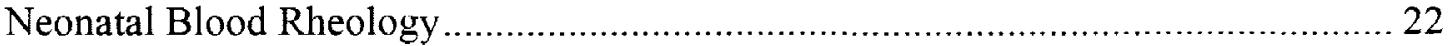

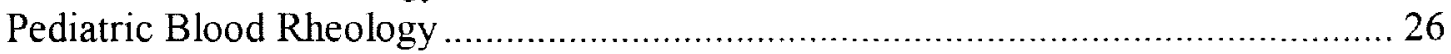

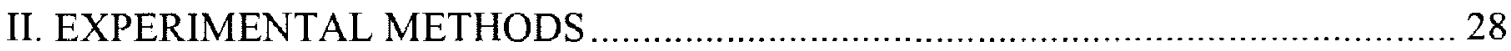

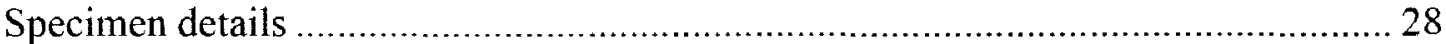

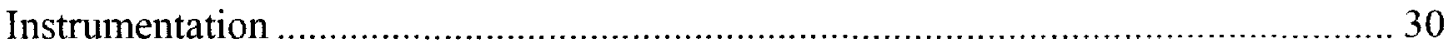

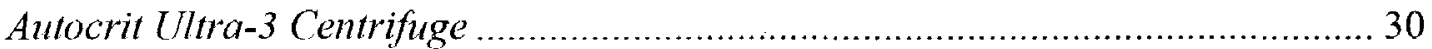

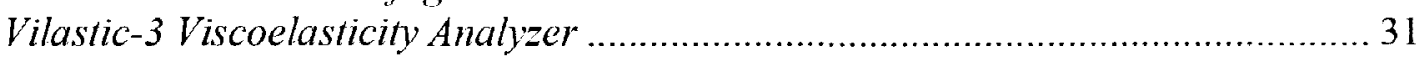

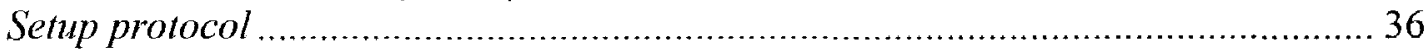

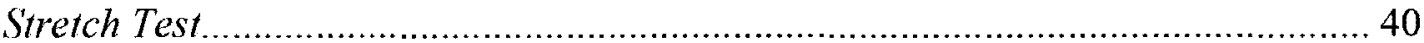

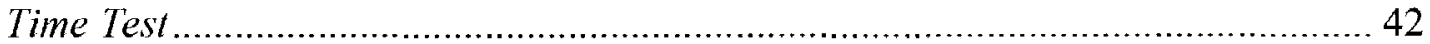

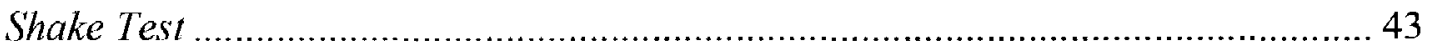

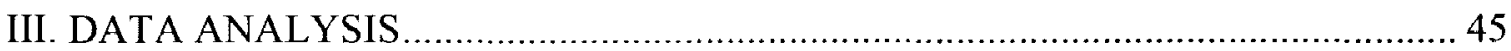

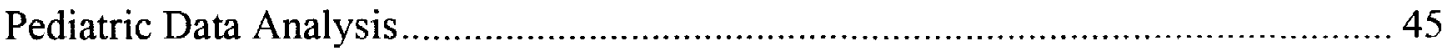

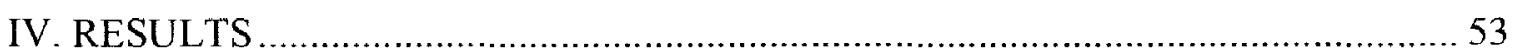

New Pediatric Viscoelasticity Data ..................................................................53

Comparison of Pediatric and Adult Blood .........................................................5 59

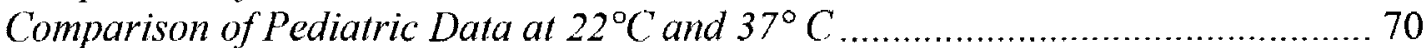

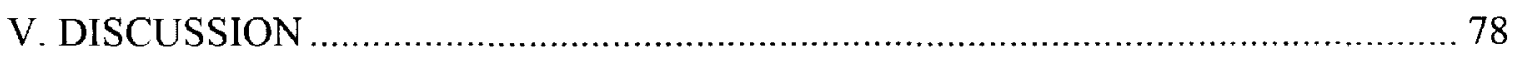

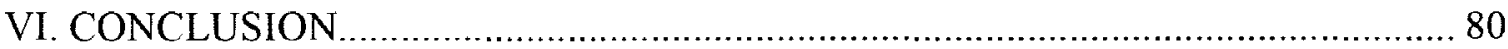

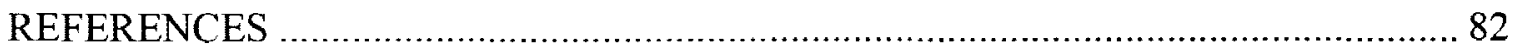




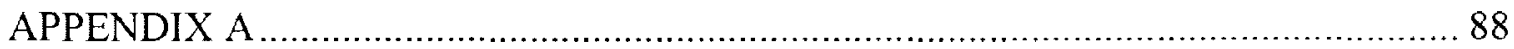

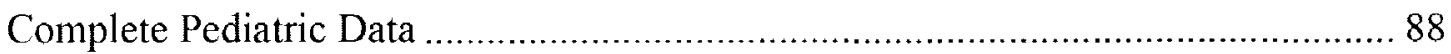

Trendlines for Hematocrit fit for Pediatric Data ................................................... 95

Statistical Test Analysis Results - Pediatric vs. Adult Data ................................... 98

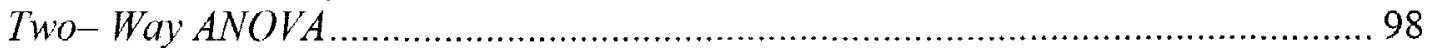

Statistical Test Analysis Results - Pediatric data at $37^{\circ} \mathrm{C}$ vs. $22^{\circ} \mathrm{C}$........................... 99

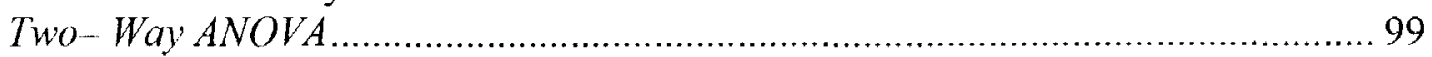

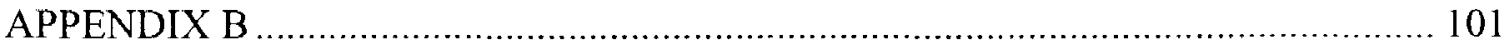

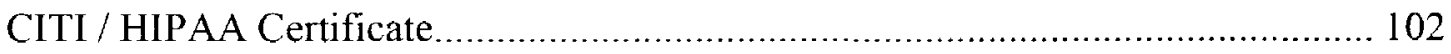

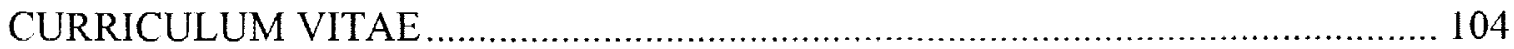




\section{LIST OF TABLES}

Table 1. Constituents of plasma [Germann, et al. 2002] .......................................... 8

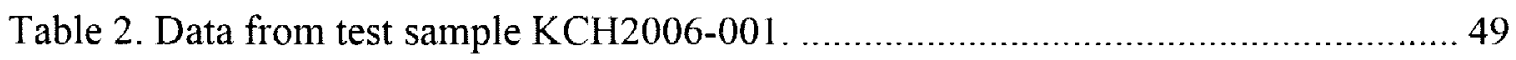

Table 3. Patient characteristics for the 11 pediatric samples........................................ 54

Table 4. Interpolated viscosity and elasticity values for the pediatric blood at the strains

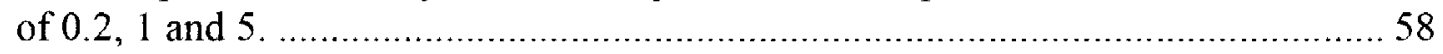

Table 5. Power curve fits for viscoelasticity versus hematocrit for all pediatric data, ,.... 62

Table 6. Viscoelastic adult data at shear rate of $10 \mathrm{~s}^{-1}$ [Kaber, et al.1988] ................... 66

Table 7. Averaged viscoelastic adult data at shear rate of $10 \mathrm{~s}^{-1}$ for analysis [Kaber, et

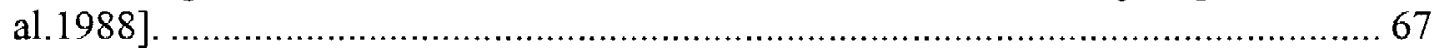

Table 8. Two-way ANOVA results for pediatric and adult blood result comparison at

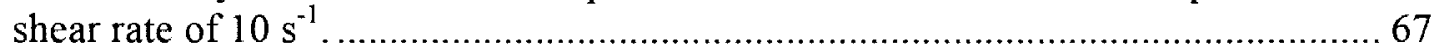

Table 9. Regression equations for pediatric and adult blood across the hematocrit range.

Table 10. Comparison of age of Penn State vs. UofL paired samples at the same hematocrit.

Table 11. Two-way ANOVA p-values for pediatric data at $22^{\circ} \mathrm{C}$ [Long et al.] and $37^{\circ} \mathrm{C}$.

Table 12. Regression equations for pediatric blood at $37^{\circ} \mathrm{C}$ and $22^{\circ} \mathrm{C}$ [Long et al. 2005].

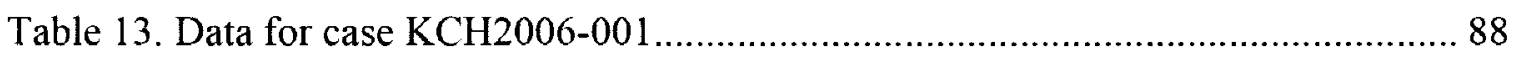

Table 14. Data for case KCH2006-002

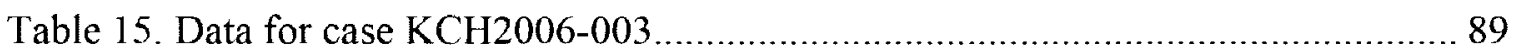

Table 16. Data for case KCH2006-004 
Table 17. Data for case KCH2006-005.

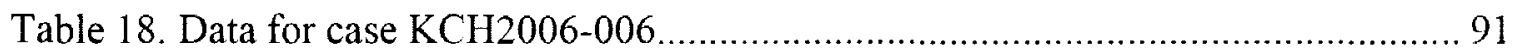

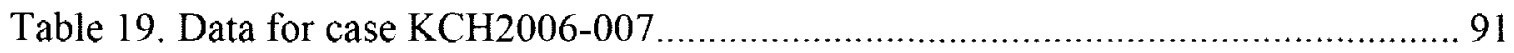

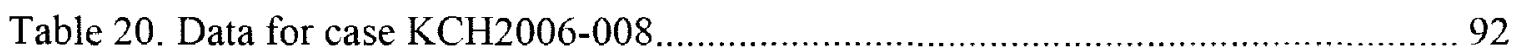

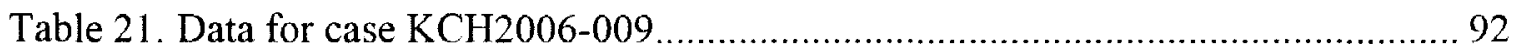

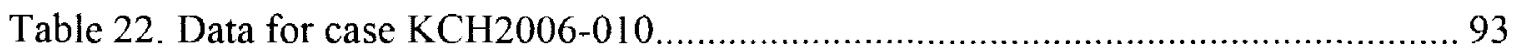

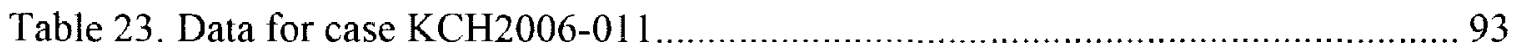

Table 24. Two-way ANOVA results for comparison of viscosity of pediatric and adult

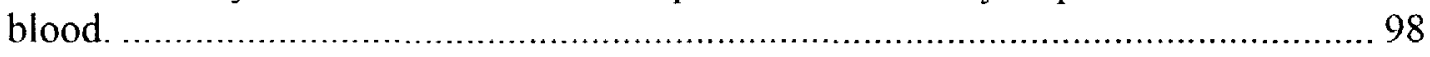

Table 25. Two-way ANOVA results for comparison of elasticity of pediatric and adult blood.

Table 26. Two-way ANOVA results for comparison of viscosity at 0.2 strain of pediatric data measured at $37^{\circ} \mathrm{C}$ vs. $22^{\circ} \mathrm{C}$

Table 27. Two-way ANOVA results for comparison of viscosity at 1 strain of pediatric

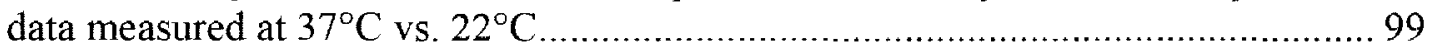

Table 28. Two-way ANOVA results for comparison of viscosity at 5 strain of pediatric

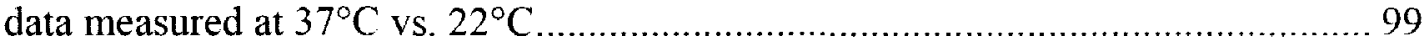

Table 29. Two-way ANOVA results for comparison of elasticity at 0.2 strain of pediatric data measured at $37^{\circ} \mathrm{C}$ vs. $22^{\circ} \mathrm{C}$. 100

Table 30. Two-way ANOVA results for comparison of elasticity at 1 strain of pediatric

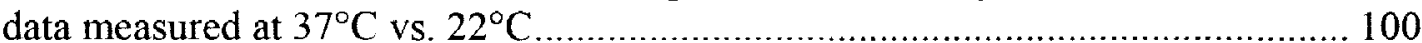

Table 31. Two-way ANOVA results for comparison of elasticity at 5 strain of pediatric data measured at $37^{\circ} \mathrm{C}$ vs. $22^{\circ} \mathrm{C}$. 100 


\section{LIST OF FIGURES}

Figure 1. Scanning electron microscope showing a human leukocyte, erythrocyte and several platelets [Lowe 1988].

Figure 2. Diagrammatic representation of the circulatory system................................. 10

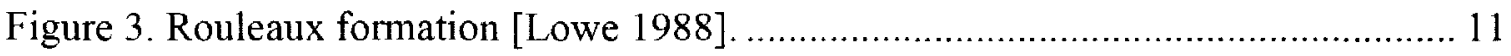

Figure 4. Reference ranges of viscosity of human blood.......................................... 15

Figure 5. Viscoelasticity plot for normal adult human blood [Thurston 1996].............. 16

Figure 6. Viscosity $\eta_{\varsigma}$ and elasticity $\eta_{\mathrm{E}}$, components of the complex coefficient of viscoelasticity, versus shear rate $\gamma$ for adult blood at different hematocrits $\mathrm{H}$ and frequency $2 \mathrm{~Hz}$ [Thurston 1989].

Figure 7. Steady flow viscosity for 0.43 hematocrit blood and oscillatory flow viscoelasticity for 0.46 hematocrit blood measured at frequencies of $0.1,0.3,1$ and 2 Hz. [Thurston 1989].

Figure 8. Viscosity vs. temperature at fixed shear rate $\left(45 \mathrm{~s}^{-1}\right)$ and hematocrit $(22.5 \%)$. Hemodilution was with $0.9 \% \mathrm{NaCl}(\cdot), 5 \%$ albumin(o), analogous plasma $(\Delta)$, or $6 \%$ hydroxyethyl starch $(\mathbf{\nabla})[$ Eckmann, et al. 2000].

Figure 9. Neonatal whole blood viscosity: shear rate relationships for two neonates illustrating extreme responses. Hematocrits were not reported for these cases [Anwar, et al. 1993].

Figure 10. Whole blood viscosity vs. shear rate plotted on log-log axes. The data represent mean \pm SEM for seven preterm, 18 term infants, and nine adult males. The mean hematocrits $( \pm S D)$ for each group were $46.8 \pm 2.1,52.8 \pm 6.1$ and $44.1 \pm 2.5 \%$, respectively [Rampling, et al. 1989].

Figure 11 . Comparison of adult and neonatal whole blood viscosity at hematocrit of A.

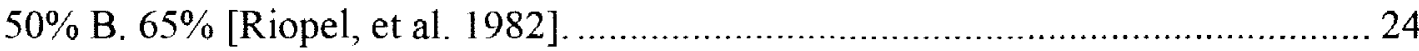

Figure 12. Relative viscosities of suspensions of washed erythrocytes in PBS containing increasing concentrations of fibrinogen. The neonatal data $(\bullet)$ was obtained from five subjects and the adult (x) from four [Rampling, et al. 1989]. 
Figure 13 . Viscosity of pediatric blood at $22^{\circ} \mathrm{C}$ [Long, et al. 2005].

Figure 14 . Elasticity of pediatric blood at $22^{\circ} \mathrm{C}$ [Long, et al. 2005].

Figure 15. Test tube with purple EDTA top. 29

Figure 16. Autocrit Ultra-3 centrifuge. 30

Figure 17. Capillary tubes with blood in place in the centrifuge.

Figure 18. Principle of measurement of Vilastic-3 [www.vilastic.com].

Figure 19. Vilastic-3 viscoelasticity analyzer. 34

Figure 20. HAAKE circulator connected to the Vilastic-3. 35

Figure 21. Complete experimental setup showing the circulator, viscoelastic analyzer and control computer. 35

Figure 22. Vmax software main screen. 36

Figure 23. Density entry screen on $V \max$. 37

Figure 24. Test of sensors and test of drive tests before filling begins 37

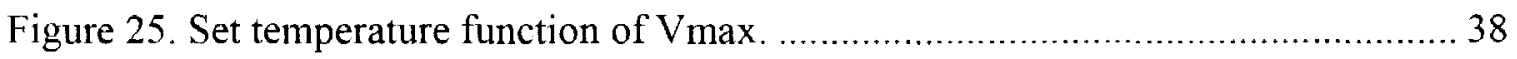

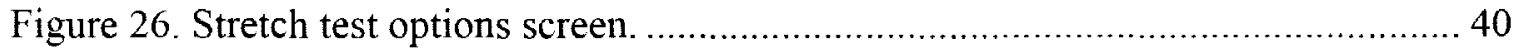

Figure 27. Evaluation test screen for stretch test [Vmax Operation Manual] ............... 41

Figure 28. Set up screen for the stretch test [Vmax Operation Manual]. ........................ 41

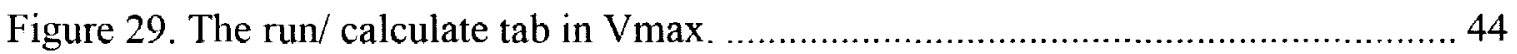

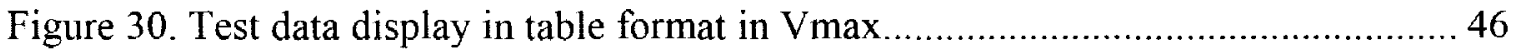

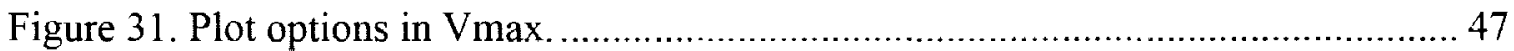

Figure 32. Sample log of viscoelasticity vs. log of shear rate plot using Vmax............. 47

Figure 33. Parameter selection screen for ASCII file ....................................... 48

Figure 34 . Viscosity, elasticity, relaxation time vs. shear rate ................................ 50

Figure 35 . Viscosity, elasticity, relaxation time vs. strain. .................................... 51 
Figure 36. Viscosity vs. shear rate for all samples.

Figure 37. Elasticity vs. shear rate for all samples. ................................................... 55

Figure 38. Viscosity vs. shear rate with standard deviation error bars........................ 56

Figure 39. Viscosity vs. strain with standard deviation error bars.................................. 57

Figure 40. Viscosity versus shear rate of pediatric samples (red) compared to adult (blue).

Figure 41. Elasticity versus shear rate of pediatric samples (red) compared to adult (blue).

Figure 42. Average pediatric (mean hematocrit $39.6 \%$ ) vs. adult viscosity at $47 \%$ hematocrit.

Figure 43. Average pediatric (mean hematocrit $39.6 \%$ ) vs. adult elasticity at $47 \%$ hematocrit.

Figure 44 . Viscosity vs. strain at $47 \%$ hematocrit.

Figure 45 . Elasticity vs. strain at $47 \%$ hematocrit.

Figure 46. Comparison of pediatric viscoelasticity with adult values [Kaber et al. 1988] at shear rate of $10 \mathrm{~s}^{-1}$.

Figure 47. Adult and pediatric viscosity vs. hematocrit showing the p-values from the 2way ANOVA analysis. 68

Figure 48. Adult and pediatric elasticity vs. hematocrit showing the p-values from the 2way ANOVA analysis. 68

Figure 49 . Average viscosity vs. shear rate for pediatric data at $22^{\circ} \mathrm{C}$ and $37^{\circ} \mathrm{C}$ with standard deviation.

Figure 50. Average elasticity vs. shear rate for pediatric data measured at $22^{\circ} \mathrm{C}$ and $37^{\circ} \mathrm{C}$ with standard deviation.

Figure 51. Age vs. hematocrit for the Penn State and UofL patients. (The patient with hematocrit of $42 \%$ measured at $37 \mathrm{C}$ was only 11 days old, so does not show well on this graph.)

Figure 52. Pediatric viscosity vs. hematocrit (comparison at $22^{\circ} \mathrm{C}$ vs. $37^{\circ} \mathrm{C}$ ) showing the p-values from the 2-way ANOVA analysis at 0.2 strain. 
Figure 53. Pediatric viscosity vs. hematocrit (comparison at $22^{\circ} \mathrm{C}$ vs. $37^{\circ} \mathrm{C}$ ) showing the p-values from the 2-way ANOVA analysis at 1 strain.

Figure 54. Pediatric viscosity vs. hematocrit (comparison at $22^{\circ} \mathrm{C}$ vs. $37^{\circ} \mathrm{C}$ ) showing the p-values from the 2-way ANOVA analysis at 5 strain.

Figure 55. Pediatric elasticity vs. hematocrit (comparison at $22^{\circ} \mathrm{C}$ vs. $37^{\circ} \mathrm{C}$ ) showing the p-values from the 2-way ANOVA analysis at 0.2 strain. 75

Figure 56. Pediatric elasticity vs. hematocrit (comparison at $22^{\circ} \mathrm{C}$ vs. $37^{\circ} \mathrm{C}$ ) showing the p-values from the 2-way ANOVA analysis at 1 strain.

Figure 57. Pediatric elasticity vs. hematocrit (comparison at $22^{\circ} \mathrm{C}$ vs. $37^{\circ} \mathrm{C}$ ) showing the p-values from the 2-way ANOVA analysis at 5 strain. 76

Figure 58 . Viscoelasticity vs. shear rate of all pediatric data. 94

Figure 59. Viscoelasticity vs. strain of all pediatric data. 94

Figure 60. Powercurve fit for viscosity vs. hematocrit at 0.2 strain.. 95

Figure 61. Powercurve fit for viscosity vs. hematocrit at 1 strain 95

Figure 62. Powercurve fit for viscosity vs. hematocrit at 5 strain. 96

Figure 63. Powercurve fit for elasticity vs. hematocrit at 0.2 strain. 96

Figure 64. Powercurve fit for elasticity vs. hematocrit at 1 strain 97

Figure 65. Powercurve fit for elasticity vs. hematocrit at 5 strain. 97 


\section{INTRODUCTION}

Rheology is the study of the deformation and flow of matter. The term Rheology was coined by Eugene Bingham, a professor at Lehigh University, in 1920, from a suggestion by Markus Reiner, inspired by Heraclitus's famous expression 'panta rhei', "everything flows". Perhaps the earliest attempts to study the flow properties of blood were made by Young and Poiseuille in the 17 th century, and simulating blood flow in complex corporeal and clinical environment is still a difficult problem.

\section{Purpose of Thesis}

The objective of this project is to quantify pediatric blood rheology and the progression of rheological properties from neonate toward adult along with justifying the significance of the temperature at which the measurements are made. Blood rheology has been extensively studied in adults. Limited data on neonates indicates several important differences that can influence flow patterns in surgically altered flow passages and in cardiovascular devices. Lacking, however, is information on the transition of rheological properties during the infant years. This project enhances this database, which is critical for refining surgical procedures and device design for efficacy and optimum performance. 


\section{Blood Rheology}

Blood rheology is the study of the flow behavior of blood. This field gained importance with the realization that blood flow did not depend only on the pumping action of the heart, but also on aspects of fluid flow imposed by the vascular geometry such as viscosity, elasticity, cell deformation, and so on.

Viscosity is the measure of the resistance of a fluid to flow. Blood flowing in the circulatory system has, in addition to viscosity, an elastic component. It is this elastic component that describes its unsteady flow due to the rhythmic beating of the heart. Hence viscoelasticity is known to be a basic rheological property of blood, which is amenable to measurement in any geometric confinement. The viscoelastic properties of blood depend primarily on the elastic behavior of the red blood cells. The cells are individually deformable; and cell interaction leads to aggregation of the cells, hence hematocrit values become important. The stress vs. strain curve for blood is not a linear curve. This means that blood is a non-Newtonian fluid because its flow properties cannot be described by the Newtonian equation of flow described as:

$$
\tau=\mu \frac{\mathrm{dv}}{\mathrm{dx}}
$$

where $\tau$ is the shear stress exerted by the fluid, $\mu$ is the fluid viscosity, and

$$
\frac{\mathrm{dv}}{\mathrm{dx}} \text { is the velocity gradient. }
$$


The viscosity of blood is dependant on the time for which shear is applied. This property of fluids is known as thixotropy. Along with this, blood viscosity decreases with an increase in the rate of shear. Such fluids are known as psuedoplastic fluids. Along with this parameter we summarize that human blood is viscoelastic, non-Newtonian, thixotropic, and psuedoplastic.

The flow resistance of blood becomes important as an indicator, in several disease states, not only of alterations in the structure or function of the heart or blood vessels, but also their interactions with the flow behavior of blood itself. Manipulation of blood flow properties is considered a useful tool for use in therapeutic strategies; not only for hematological disorders in which blood rheology is overtly abnormal, but also for several common circulatory disorders in which rheology plays a more subtle role. Blood rheology tests are also of diagnostic significance. A number of organic diseases result in alterations of blood rheology which can be measured by simple laboratory tests.

Blood rheology is an important factor in defining the flow of blood in the internal circulation. However, it is common in clinical practice that erythrocyte sedimentation rate or the plasma viscosity change is measured as an indication of changes that occur due to onset of organic diseases. More recently, work has been done to recognize the importance of rheology in adults and to some extent in neonates. This thesis represents one of the first investigations of the diagnostic use of rheology in pediatric blood. 
A brief list of diseases for which study of adult and neonatal blood rheology has been useful is as shown [Taber's Cyclopedic Medical Dictionary]:

A. Overtly abnormal rheology in hematological diseases

- Polycythemias - This is a condition in which there are an excessive number of erythrocytes present in the blood. The excessive number of erythrocytes is directly related to increased whole blood viscosity. Also the white blood cells (WBC) of newborns are larger and less deformable than the red blood cells (RBC), which increases viscosity in the microcirculation [Rosenkrantz 2003].

- Hemolytic Anemias - Anemia is the condition in which the mass of red blood cells or level of hemoglobin is below normal. Hemolytic anemia is a type of anemia that is caused by the destruction of red blood cells. Change in red cell membrane deformability is considered to be a probable cause for reduced red cell survival in various hemolytic anemias [Mohandas, et al. 1979].

- Paraproteinemias - This condition is marked with the presence of an excessive number of proteins in the blood. Presence of paraproteins is characterized with hyperviscosity [Somer 1966] and corresponding clinical condition is known as plasma hyperviscosity syndrome [Somer 1975].

- Hyperleukocytic Leukemias -This describes an abnormal intravascular leukocyte aggregation and clumping often seen in leukemia patients. The brain and lungs are the two most commonly affected organs. The abnormally large number of leukocytes present in the blood restils in fractional increase in viscosity in normal flow, but in the microcirculation the viscosity increases 
drastically as the leukocytes have lower deformability than erythrocytes [Marshall, et al.1982].

B. Covertly abnormal rheology in circulatory diseases

- Hypertension - Hypertension is a condition in which the blood pressure is higher than the normal systolic and diastolic pressure of blood at a given age.

- Circulatory Shock - Circulatory shock or failure exists when, despite a normal oxygen content of arterial blood, the oxygen delivery fails to meet the metabolic requirements of the tissues. A decrease in $\mathrm{RBC}$ deformability is seen in septic patients. WBC rheology may also affect the circulation in circulatory shock [Voerman, et al.1989].

- Venous thromboembolism - This describes a blockage in a vein by a thrombus that has become detached from its site of formation. There are a number of rheological factors that can lead to a thrombus formation. These include high RBC count, inherited RBC abnormalities, altered RBC membrane properties and any other RBC property that can alter blood viscosity [Andrews, et al. 1999]

- Ischemia of the heart, brain and limbs - This kind of ischemia is defined as a temporary deficiency of blood flow to the heart, brain or limbs. Plasma viscosity and $\mathrm{RBC}$ aggregation is indicated to be increased in this condition [Ernst, et al. 1988] leading to a Transient Ischemia Attack.

- Diabetes mellitus - Diabetes mellitus is a chronic metabolic disorder marked by hyperglycemia. This could be caused by either malfunctioning of the pancreas or from insulin resistance, with inadequate secretion of insulin to 
support normal metabolism. Red blood cell deformability and leukocyte filterability are both reduced in diabetes mellitus [Ernst, et al. 1986].

- Retinal vascular disorders - This is a generalized term for all disorders caused by vascular blockages occurring in the arteries or the veins of the retina.

- Pregnancy hypertension and fetal growth retardation - Pregnancy hypertension is hypertension induced by pregnancy. Whole blood viscosity is higher in pregnancies with hypertension [Zondervan, et al. 1988]. Fetal growth can be affected drastically in pregnancies with pregnancy-induced hypertension. The fetus tends to be smaller than normal for its age.

- Neonatal circulatory disorders - These are disorders associated with abnormal circulatory behavior in neonates. They can range from hypertension and hematological conditions to severe cardiac problems and heart diseases.

Although blood is a fluid, nearly half its volume is composed of cells (Figure 1). The most numerous cells are erythrocytes also known as red blood cells. These cells contain hemoglobin, a protein that carries oxygen and carbon dioxide. The remainder of the cells are leukocytes or white blood cells, which come in variety of types, and help the body defend against invading microorganisms. Also present are platelets, which are not cells but instead are cell fragments. They play an important role in blood clotting. 


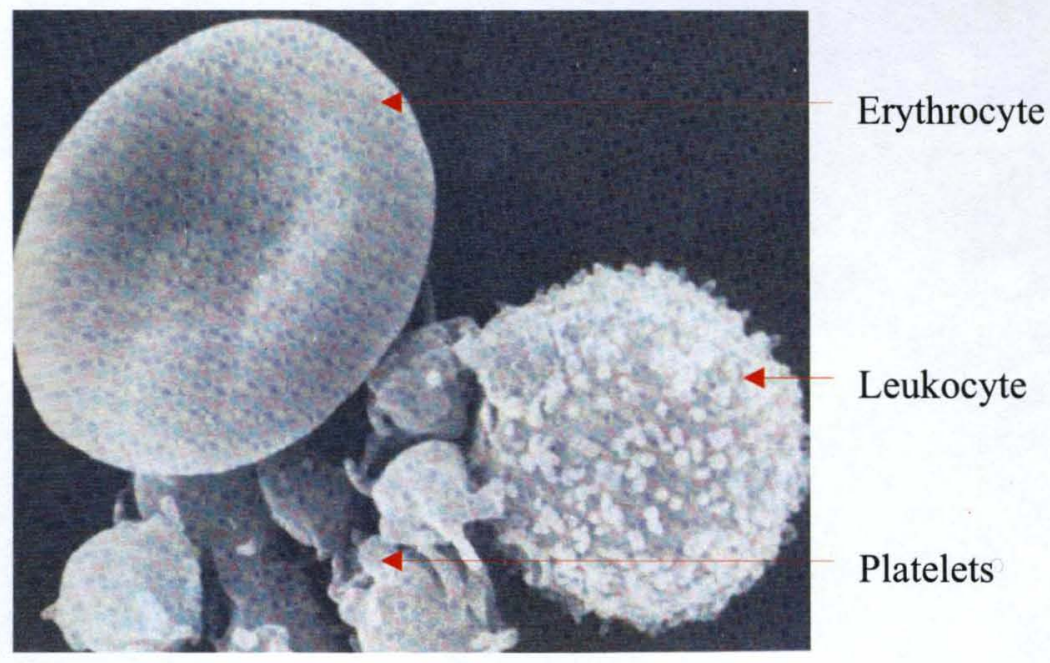

Figure 1. Scanning electron microscope showing a human leukocyte, erythrocyte and several platelets [Lowe 1988].

The liquid portion of the blood, called plasma, is made up of water containing dissolved proteins, electrolytes, and other solutes. A list of the components of plasma is as shown in Table 1. 


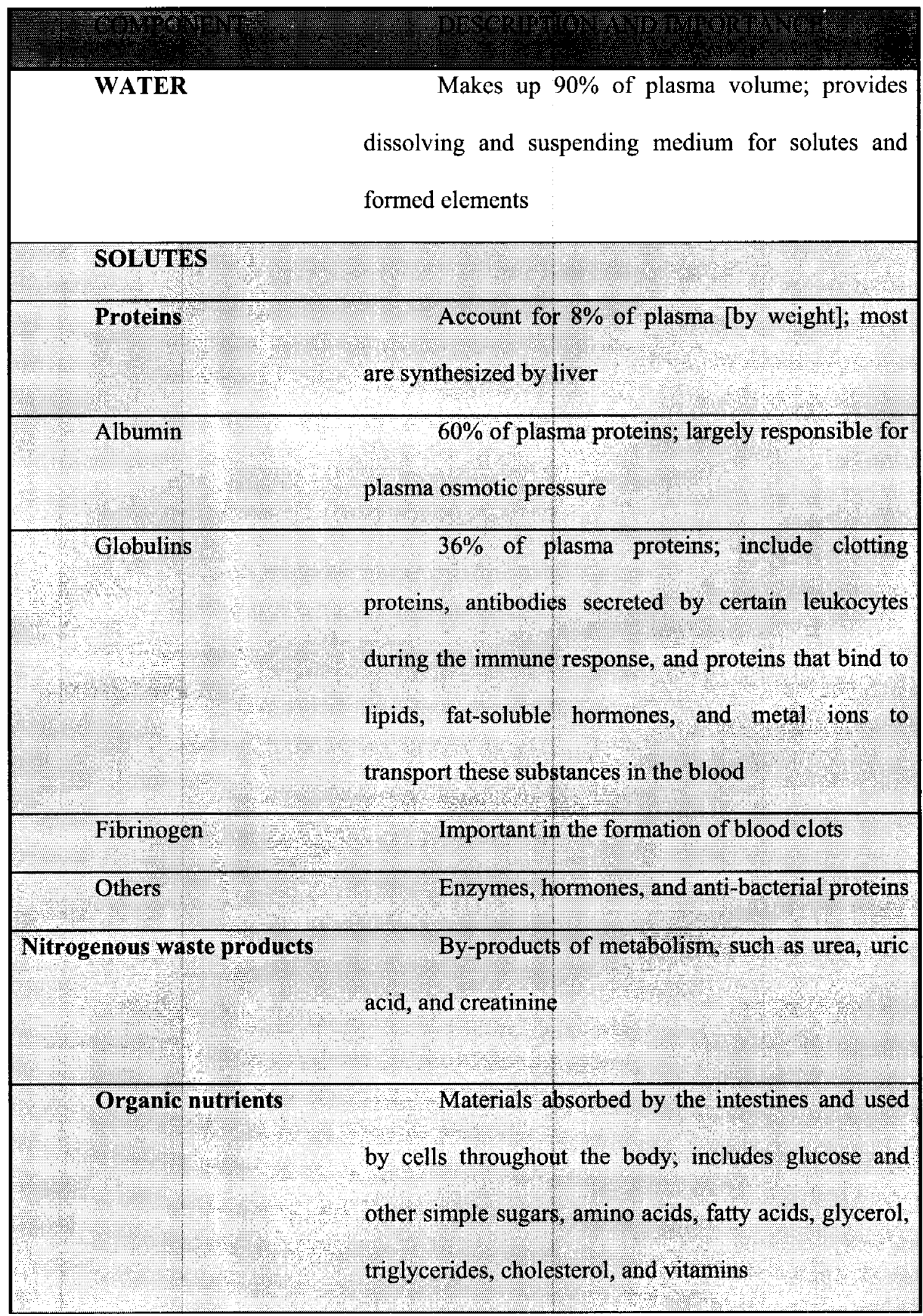




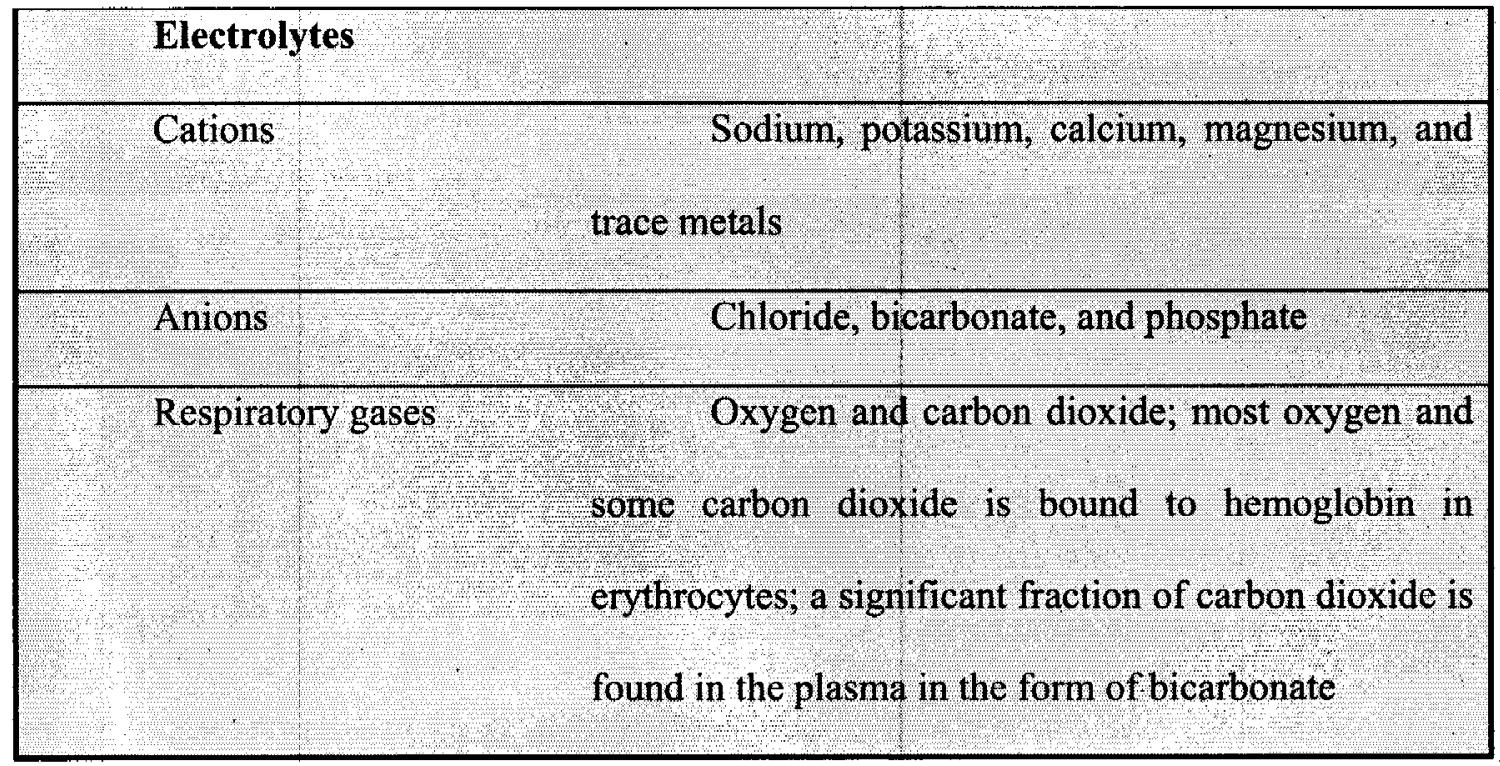

Table 1. Constituents of plasma [Germann, et al. 2002]. 
The blood flows through the circulatory system. The overall organization of the circulatory system is as shown in Figure 2. The chambers of the heart are connected through two vascular beds: the systemic and the pulmonary circulation. The left ventricle pumps oxygenated blood into the aorta, which is a long, arch-shaped vessel; from which smaller arteries and arterioles distribute it into a number of parallel vascular beds that form the systemic circulation. As the blood flows through the systemic circulation it exchanges oxygen, carbon dioxide, food stuffs, metabolites and water with the tissue cells. After this exchange across the capillary membrane, the blood leaves the capillaries with reduced oxygen saturation, an increased content of metabolites and carbon dioxide and a decreased $\mathrm{pH}$. It is collected by venules in the venous system and flows back from the venae cavae into the right atrium, from which it passes into the right ventricle. The right ventricle pumps the blood through the pulmonary arteries into the pulmonary capillaries, where the exchange of oxygen and carbon dioxide with the atmosphere takes place. The re-oxygenated blood flows through the pulmonary venous system into the left atrium and the left ventricle from where it is returned to the aorta. 


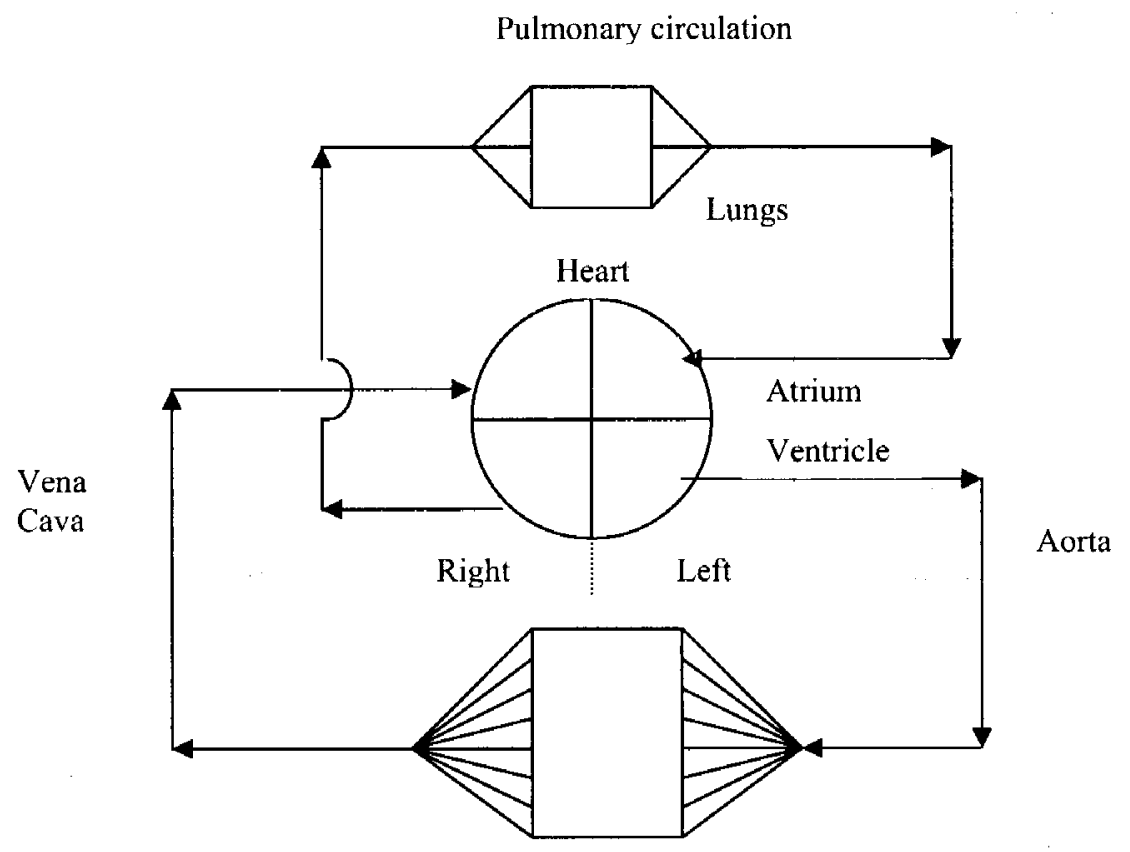

Systemic circulation

Figure 2. Diagrammatic representation of the circulatory system. 
Regions of low shear stress in blood flows present the potential for erythrocyte aggregation and flow stagnation. Erythrocyte aggregates, called rouleau, as shown in Figure 3, can significantly influence blood viscosity in vivo [Bishop, et al. 2001].

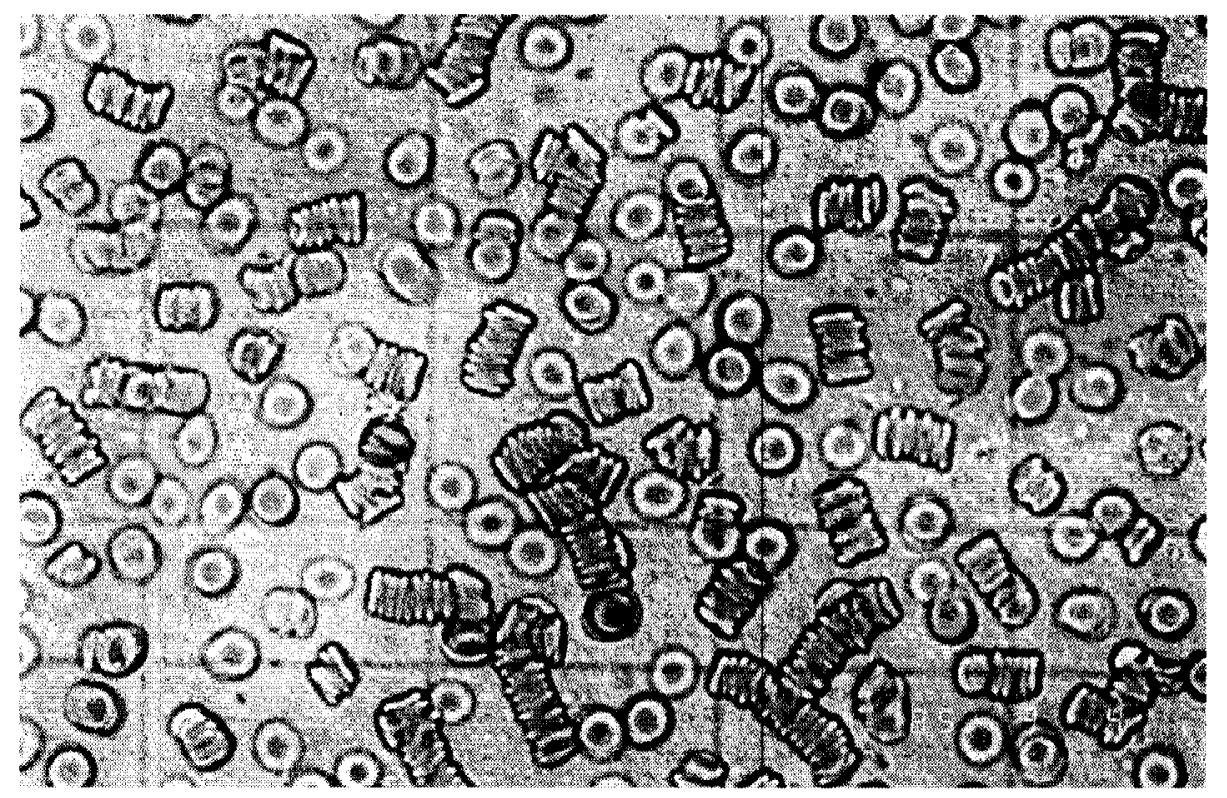

Figure 3. Rouleaux formation [Lowe 1988].

While regions with shear low enough to be problematic are rare in the normal circulation, in surgically modified vessels and in many cardiovascular devices, such regions are difficult to avoid. Without accurate rheological parameters, design criteria for vessel and device geometry to reduce low shear regions are uncertain. 
The rheology of adult blood is well documented and is summarized here, since it establishes the values that the pediatric blood may approach as patient age increases. Similarly, neonatal rheology marks the initial values of young pediatric patients, therefore, available neonatal data is also outlined. 


\section{Adult Blood Rheology}

Blood is a concentrated suspension of elastic red cells that aggregate at low shear rates to form rouleaux, which increases the apparent viscosity of the mixture. Fibrinogen is involved in the attachment of one cell to another. At high shear rates the deformability of the red cells influences blood viscosity, resulting in lower apparent viscosity than for a suspension of rigid particles of the same shape.

The red blood cell is the structural element primarily responsible for blood viscoelasticity. Calculations by G.B. Thurston show that the closest packing without cell deformation gives a hematocrit of $58 \%$, so in the range of normal hematocrit there is little plasma space available for free cell motion without deformation. The dependence on hematocrit of whole blood viscoelasticity must be considered in order to compare pathological blood samples to normal ones [Walitza, et al. 1988].

For unsteady flow, blood rheology is dependent not only on shear, but also on time, or in the case of oscillatory flow, frequency of oscillation. Viscosity can be represented with a complex viscoelasticity

$$
\eta^{*}=\eta_{\vee}-\mathrm{i} \eta_{\mathrm{E}}
$$

where, $\eta_{\mathrm{V}}$ and $\eta_{\mathrm{E}}$ are the viscous and elastic components (hereafter called viscosity and elasticity) [Thurston 1972].

The normal values for the adult blood rheological parameters have been established by various methods of testing. 
The results for a hydrodynamic test system [Thurston 1972] utilizing oscillatory tube flow at $10 \mathrm{~Hz}$ for mean values of velocity gradient less than $1-2 \mathrm{sec}^{-1}$ showed that the stress was directly proportional to the gradient. At higher gradients the blood became non-linear in its response.

Reference ranges using a oscillatory capillary rheo-densitymeter ${ }^{1}$ [Käber, et al. 1988] at native packed cell volumes are as shown in Figure 4. The oscillatory capillary rheo-densitymeter measures the viscosity by measuring the rheology and density of blood by the oscillating u-tube principle, based on the law of harmonic oscillation. The reference range of plasma viscosity at 2.5 and 97.5 percentile is 1.16 to $1.41 \mathrm{mPas}$.

\footnotetext{
I This rheometer was developed by Anton Paar in Austria.
} 


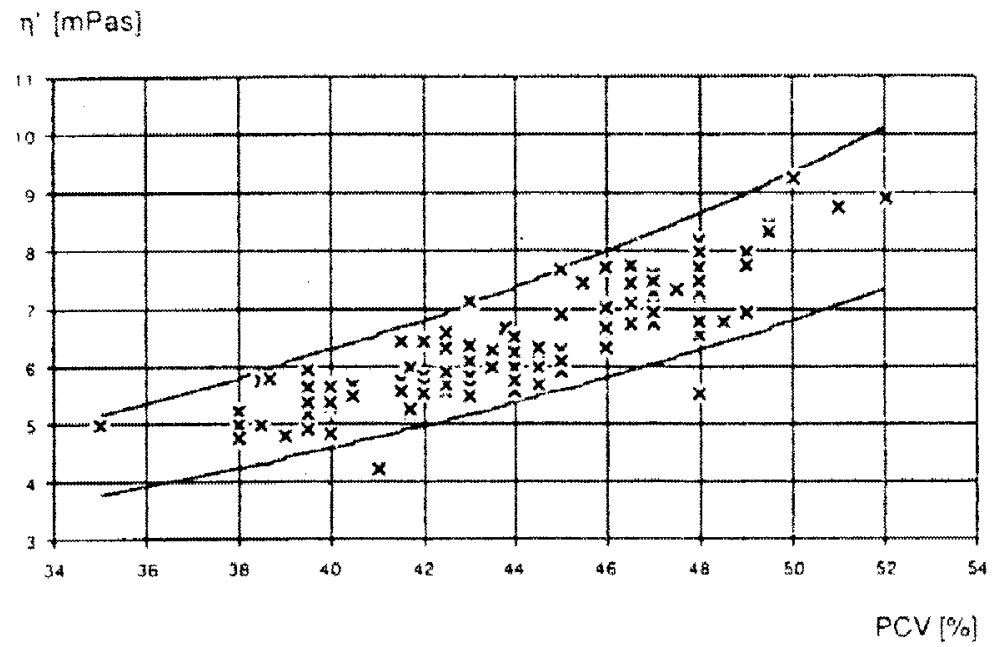

4a.

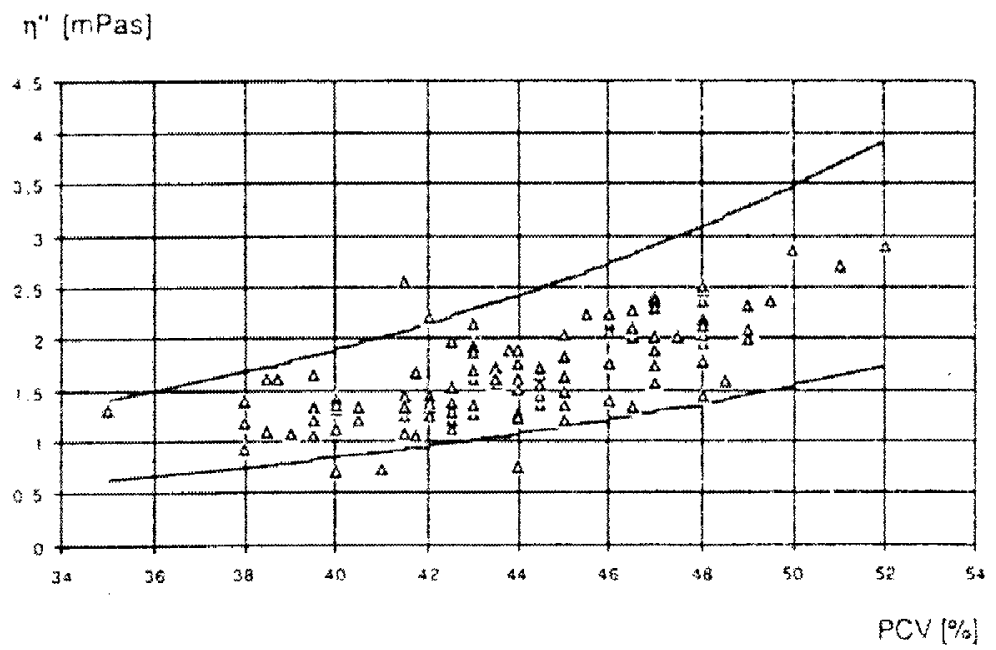

$4 b$.

Figure 4. Reference ranges of viscosity of human blood.

4a: Normal range of the viscous component $\left[\eta^{\prime}=x\right]$ of whole blood viscosity.

$4 \mathrm{~b}$ : Normal range of the elastic component $[\eta "=\Delta]$ of whole blood viscosity at its native packed cell volume $[\mathrm{PCV}]$. Shear rate $10 \mathrm{l} / \mathrm{s}$. The normal ranges are defined as the $96 \%$ range of 113 healthy donors [Kaber, et al. 1988]. 
The results obtained with an oscillatory capillary tube viscometer [Thurston 1989] were similar, as shown in Figure 5. Pulsatile flow is produced by superimposing oscillatory flow on steady flow, providing a closer approximation to blood flow in vivo.

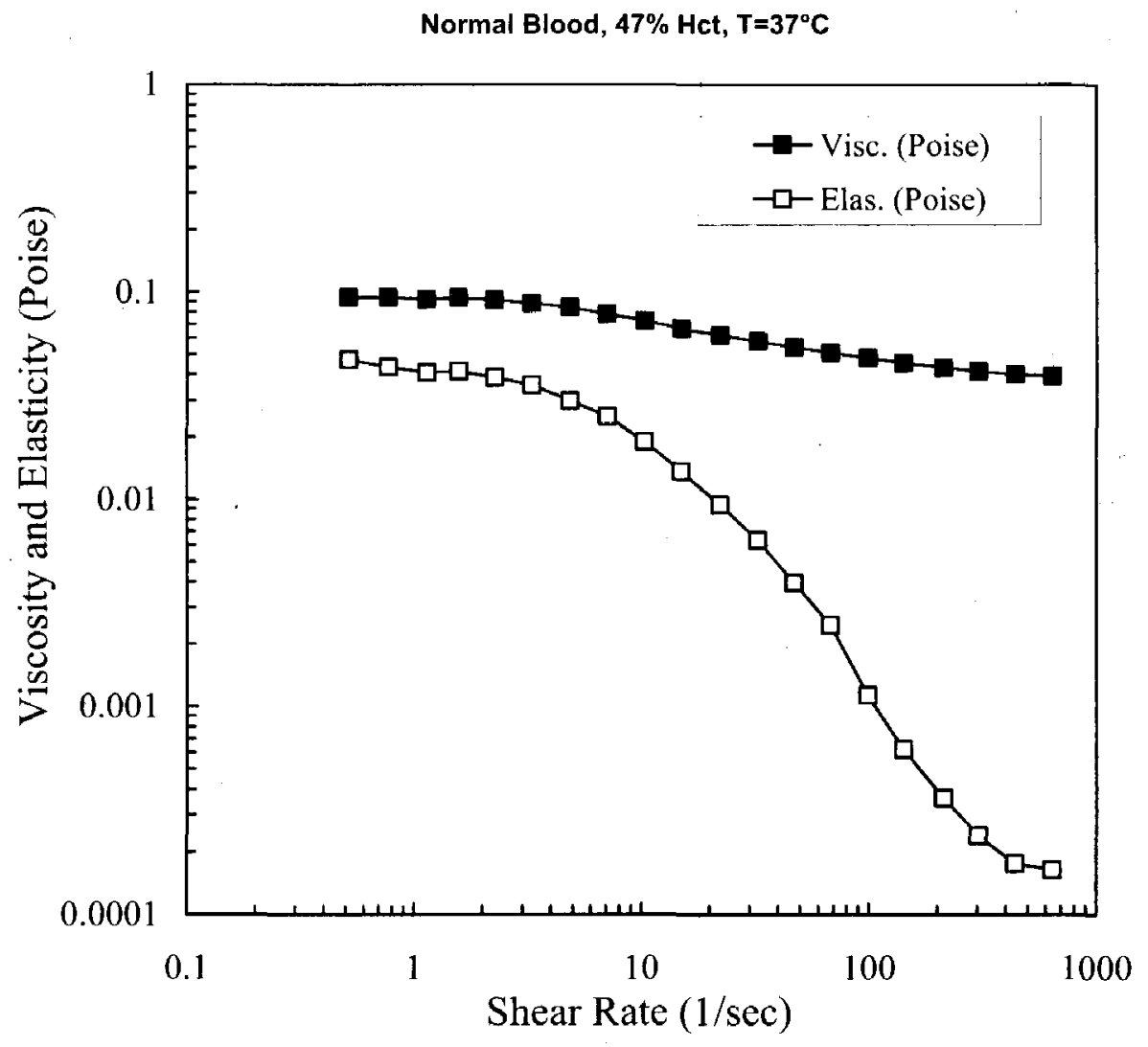

Figure 5. Viscoelasticity plot for normal adult human blood [Thurston 1996]. 
Measurements by Thurston [1996] were made by testing blood at $2 \mathrm{~Hz}$, which is very close to the frequency of the arterial waveform. Figure 6 and Figure 7 show the measurements made over a range of amplitudes of oscillation to cover the extreme conditions ranging from near stasis to the maximum shear rates in vivo.

Viscosity for normal blood is pseudoplastic (shear-thinning), with an increased value at low shear rates produced by red cell aggregation and a reduced value at high shear rates due to disaggregation, orientation and deformation of red blood cells. Elasticity is also normally pseudoplastic, with increased elasticity at low shear rates indicative of the elasticity of the red cells.

Viscosity and elasticity remain pseudoplastic for a wide range of hematocrit. The amount of shear thinning of both components decreases with decreasing hematocrit, since plasma is essentially Newtonian. 

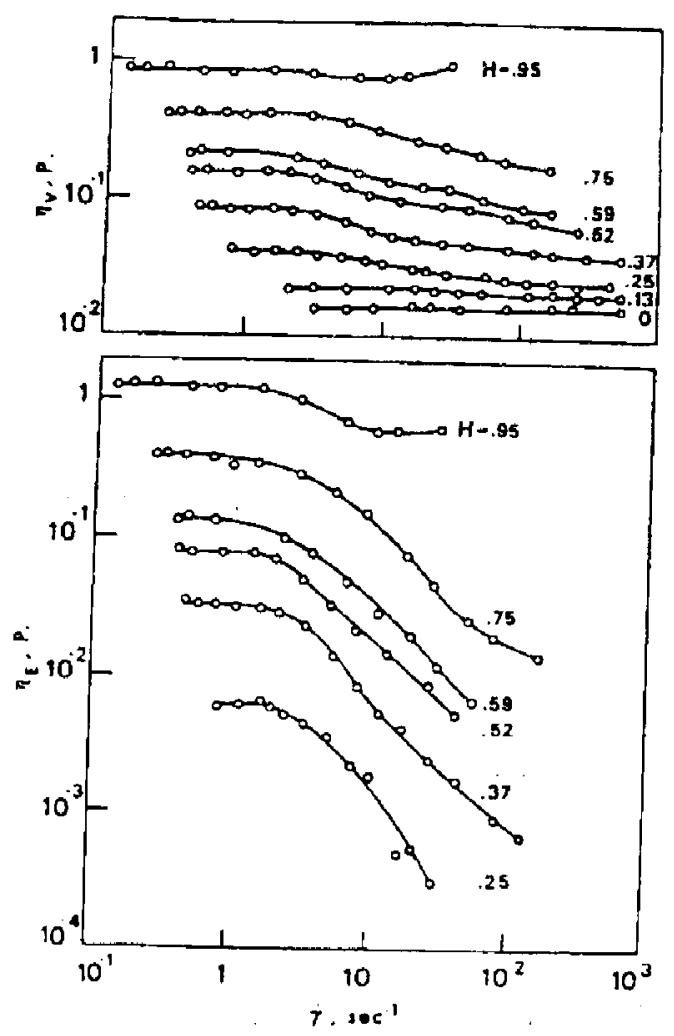

Figure 6. Viscosity $\eta_{\zeta}$ and elasticity $\eta_{E}$, components of the complex coefficient of viscoelasticity, versus shear rate $\gamma$ for adult blood at different hematocrits $H$ and frequency $2 \mathrm{~Hz}$ [Thurston 1989]. 


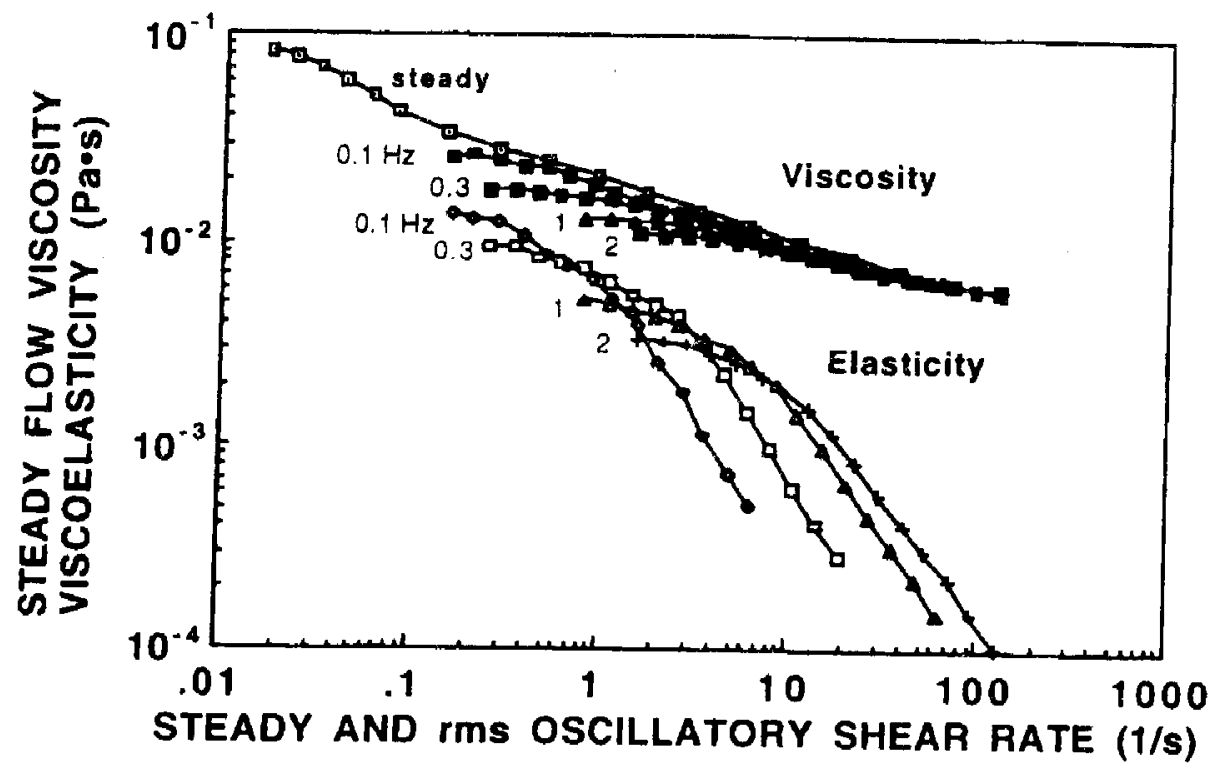

Figure 7. Steady flow viscosity for 0.43 hematocrit blood and oscillatory flow viscoelasticity for 0.46 hematocrit blood measured at frequencies of $0.1,0.3,1$ and $2 \mathrm{~Hz}$.

[Thurston 1989].

Because shear thinning of viscosity is dominated by breakup of rouleaux structure, viscosity asymptotes toward that of steady flow as frequency decreases, and asymptotes toward the constant (Newtonian) value for unattached cells for higher frequency, so long as the yield stress of rouleaux is exceeded. Elasticity, however, exhibits shear thinning for a wide range of frequencies, with the curve shifting downward for increasing frequency as elasticity is associated with the deformation of individual cells rather than rouleaux, and to the right since the time constant for full cell extension occurs at high shear as frequency increases. 
Hematocrit is the strongest determinant of viscoelasticity for normal blood [Thurston 1978]. Women have lower hematocrit and steady state viscosity than men [Mayer 1964]. It has been shown that fresh blood has 10\% lower high shear viscosity and $26 \%$ lower low shear viscosity than suspension of senescent cells [Kameneva, et al. 1995]. Mature red cells, as well as many abnormal cells, have lower flexibility than fresh normal cells [Chien 1977]. It has been shown that a greater number of microvessels become stagnant with increasing hematocrit and aggregability [Driessen, et al. 1988], providing à possible mechanism for organ dysfunction.

Viscosity of blood increases with a reduction in temperature at low shear rates. But the extent and the specific temperatures are debated. One study showed the viscosity increasing approximately $1.2-$ to 3.5 fold as temperature was reduced from $37^{\circ} \mathrm{C}$ to $18^{\circ} \mathrm{C}$. (Figure 8) [Eckmann, et al. 2000]. Another study predicted viscosity to increase by 50 to $300 \%$ as temperature is decreased from $37^{\circ} \mathrm{C}$ to $22^{\circ} \mathrm{C}$ [Rand, et al. 1964] [Reis, et al. 1976]. Both studies used the cone-plate viscometer technique to measure the viscosities. The datasets had 6 and 60 blood samples respectively. Both studies used diluents to adjust the hematocrit value of the samples tested. 


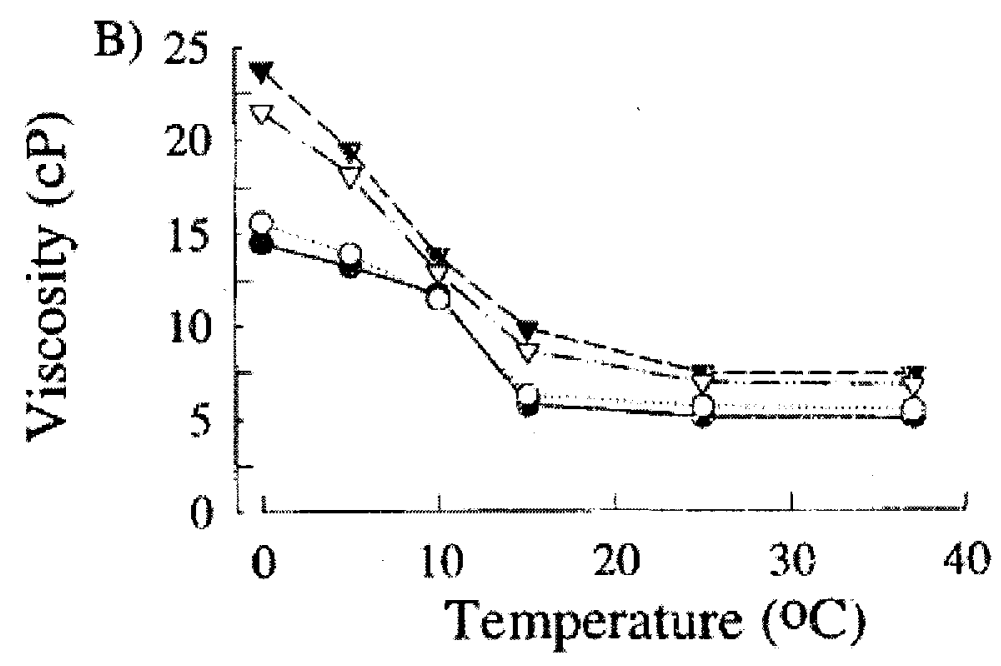

Figure 8. Viscosity vs. temperature at fixed shear rate $\left(45 \mathrm{~s}^{-1}\right)$ and hematocrit $(22.5 \%)$. Hemodilution was with $0.9 \% \mathrm{NaCl}(\bullet), 5 \%$ albumin(o), analogous plasma $(\Delta)$, or $6 \%$ hydroxyethyl starch( $\nabla$ )[Eckmann, et al. 2000]. 


\section{Neonatal Blood Rheology}

Neonatal $^{2}$ blood theology varies significantly depending on the age of the neonate. Extremes in viscosity behavior are observed in neonates [Anwar, et al. 1994] as shown in Figure 9. The viscosity of the neonate increases as it approaches full term [Merchant, et al. 1992].

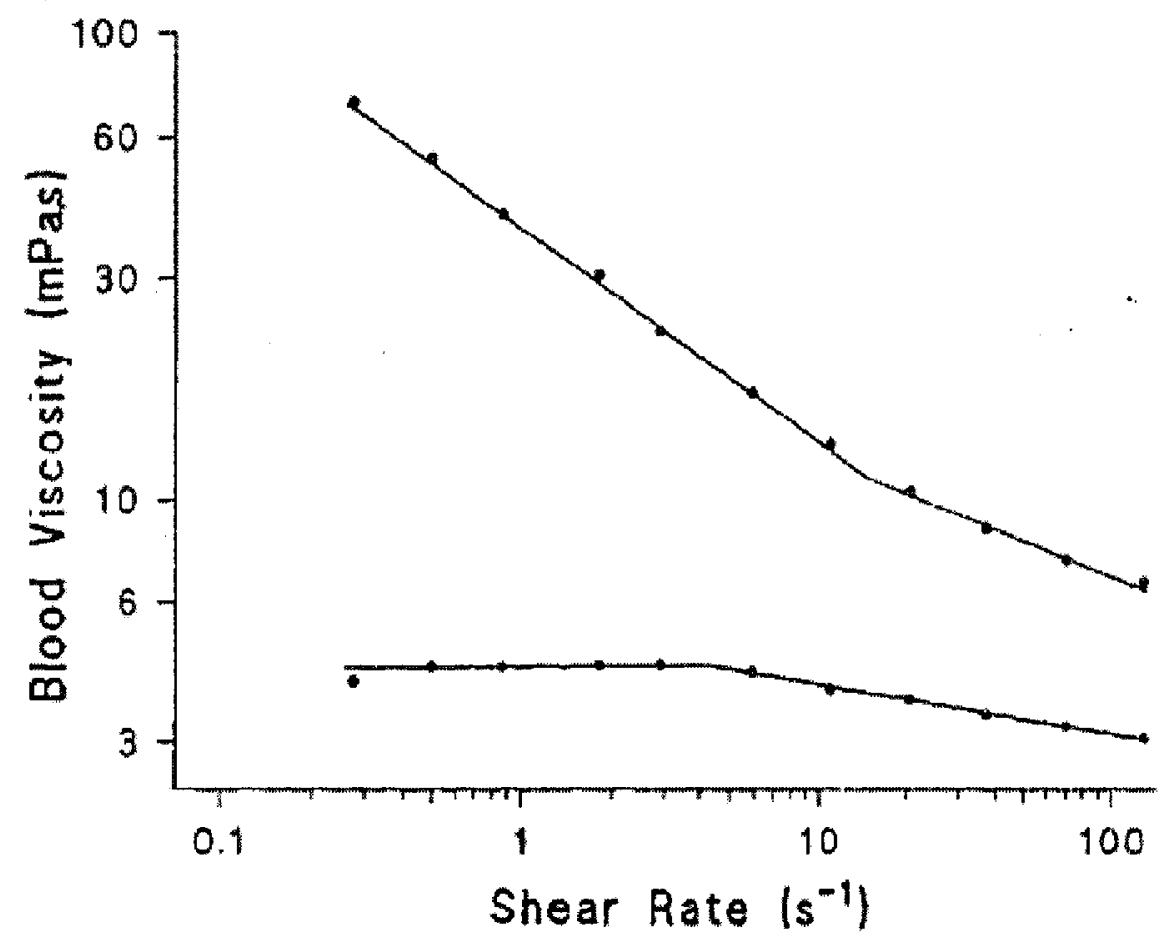

Figure 9. Neonatal whole blood viscosity: shear rate relationships for two neonates illustrating extreme responses. Hematocrits were not reported for these cases [Anwar, et al. 1993].

\footnotetext{
${ }^{2}$ Neonates are defined to be subjects from fetus to approximately one month post birth.
} 
Though the deformability properties of the neonatal RBC vary only slightly from that of the adult RBC [Linderkamp, et al. 1986], the neonatal rheological properties are different from those of adults [Bergvist 1974, Linderkamp, et al. 1984, Rampling, et al. 1989], as shown in Figure 10.

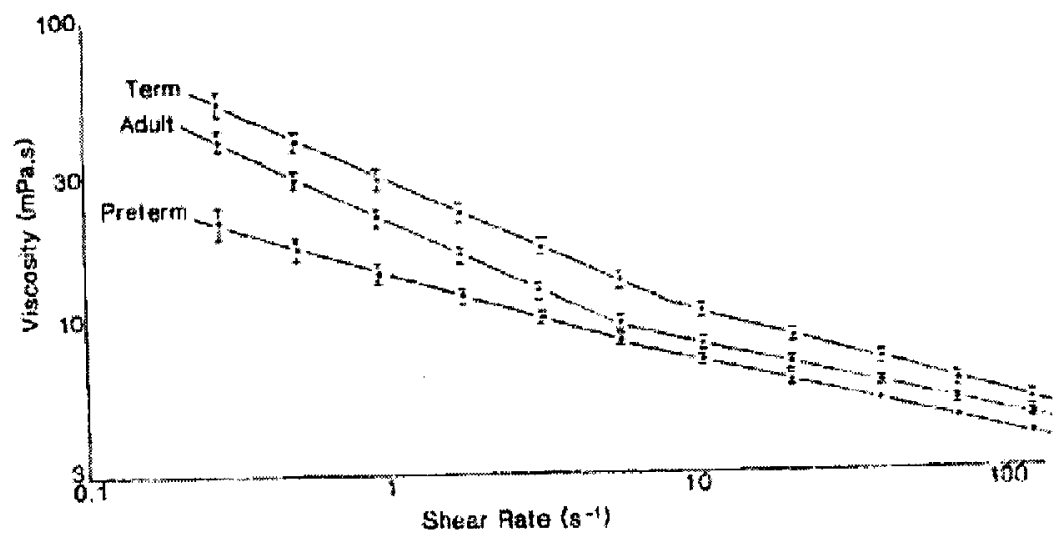

Figure 10. Whole blood viscosity vs. shear rate plotted on log-log axes. The data represent mean \pm SEM for seven preterm, 18 term infants, and nine aulul males. The mean hematocrits $( \pm \mathrm{SD}$ ) for each group were $46.8 \pm 2.1,52.8 \pm 6.1$ and $44.1 \pm 2.5 \%$, respectively [Rampling, et al. 1989].

The difference in viscosity between neonates and adults may be related to the higher average hematocrit of a full term neonate compared to an adult [Bergvist 1974]. In fact a full term neonate has about 59.4\% higher mean hematocrit compared to a pre-term neonate [Merchant, et al. 1992]. There is in fact a high incidence (5-25 out of 1000 births) of hyperviscosity in new-born infants. It is said about $1-5 \%$ of all new born infants have hyperviscosity [Hathaway 1983, Wishwell, et al. 19806]. 
At a given hematocrit, the whole blood viscosity of adult blood is higher than that in neonatal blood [Riopel, et al. 1982], as shown in Figure 11. Plasma viscosity in neonates is lower than that of adults [Linderkamp, et al. 1981, Linderkamp, ex al. 1984], which is considered to contribute to the lower viscosity values in neonates.

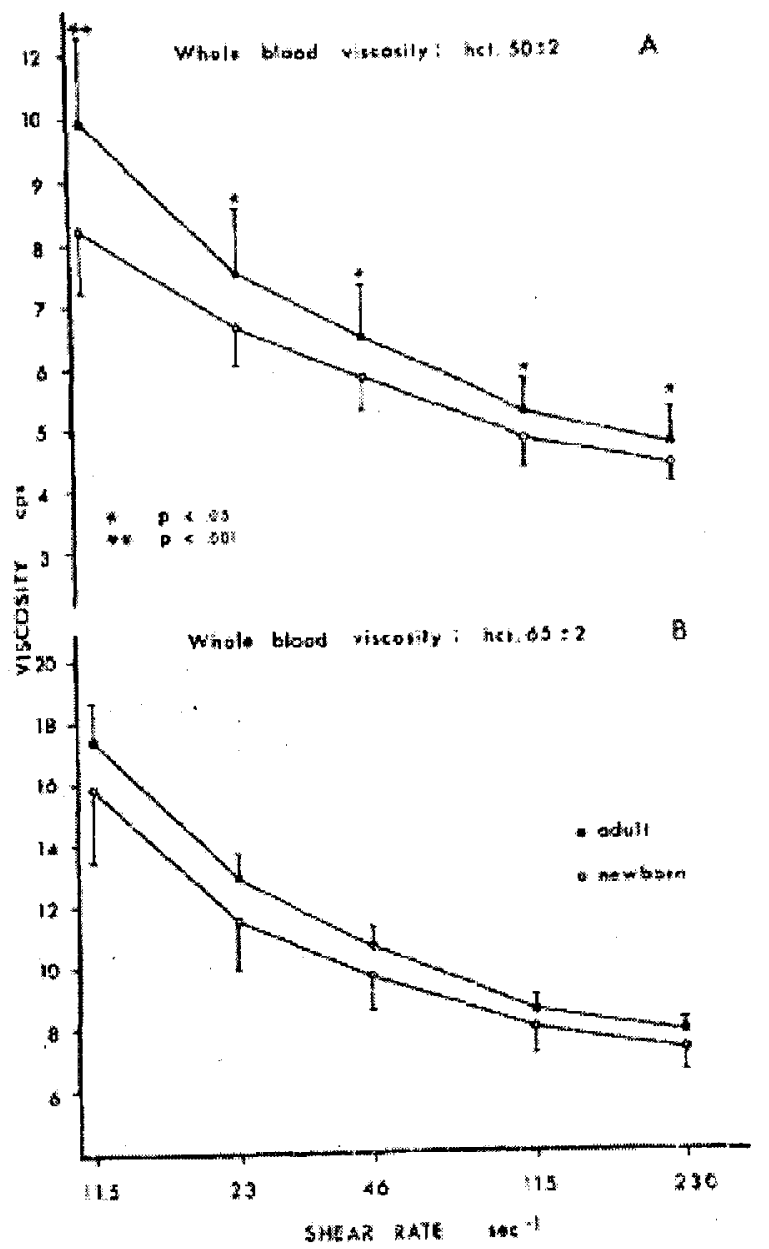

Figure 11 . Comparison of adult and neonatal whole blood viscosity at hematocrit of $A$. $50 \%$ B. $65 \%$ [Riopel, et al. 1982]. 
The lower levels of fibrinogen in neonatal blood [Mabry, et al. 1979, Foley, et al. 1978] may contribute towards the more pronounced difference between adult and neonate viscosity at low shear rates. The effect of fibrinogen levels on adult and neonate viscosity is shown in Figure 12. In part because of lower fibrinogen levels, rouleaux formation is reduced in newborns [Linderkamp, et al. 1984], leading to reduced low shear rate viscosity [Rampling 1986].

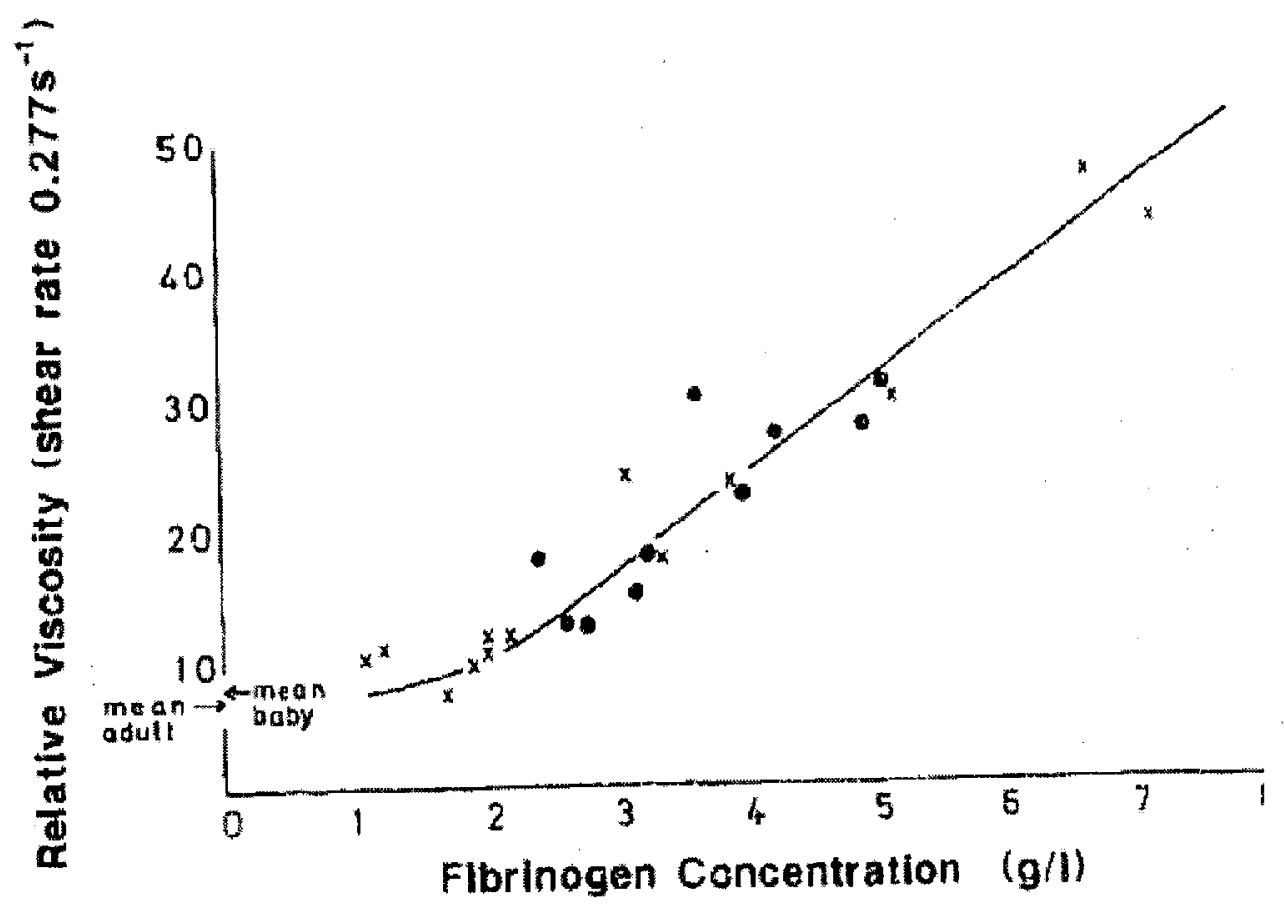

Figure 12. Relative viscosities of suspensions of washed erythrocytes in PBS containing increasing concentrations of fibrinogen. The neonatal data $(\cdot)$ was obtained from five subjects and the adult $(x)$ from four [Rampling, et ai. 1989]. 


\section{Pediatric Blood Rheology}

There is very little pediatric blood viscoelasticity data available. The data used for comparison in this study was obtained from Penn State measurements at $22^{\circ} \mathrm{C}$ in pediatric patients [Long, et al. 2005]. The complete data is plotted in Figures 13 and 14. Long, et al. summarizes pediatric blood viscoelasticity and compares it with adult values at the same hematocrit. The authors conclude that the difference between pediatric and adult blood viscoelasticity is insignificant at the same hematocrit values. All measurements were made at room temperature. This pediatric data measured at $22^{\circ} \mathrm{C}$ was used in the comparison with the pediatric data measured at $37^{\circ} \mathrm{C}$ in the Results section.

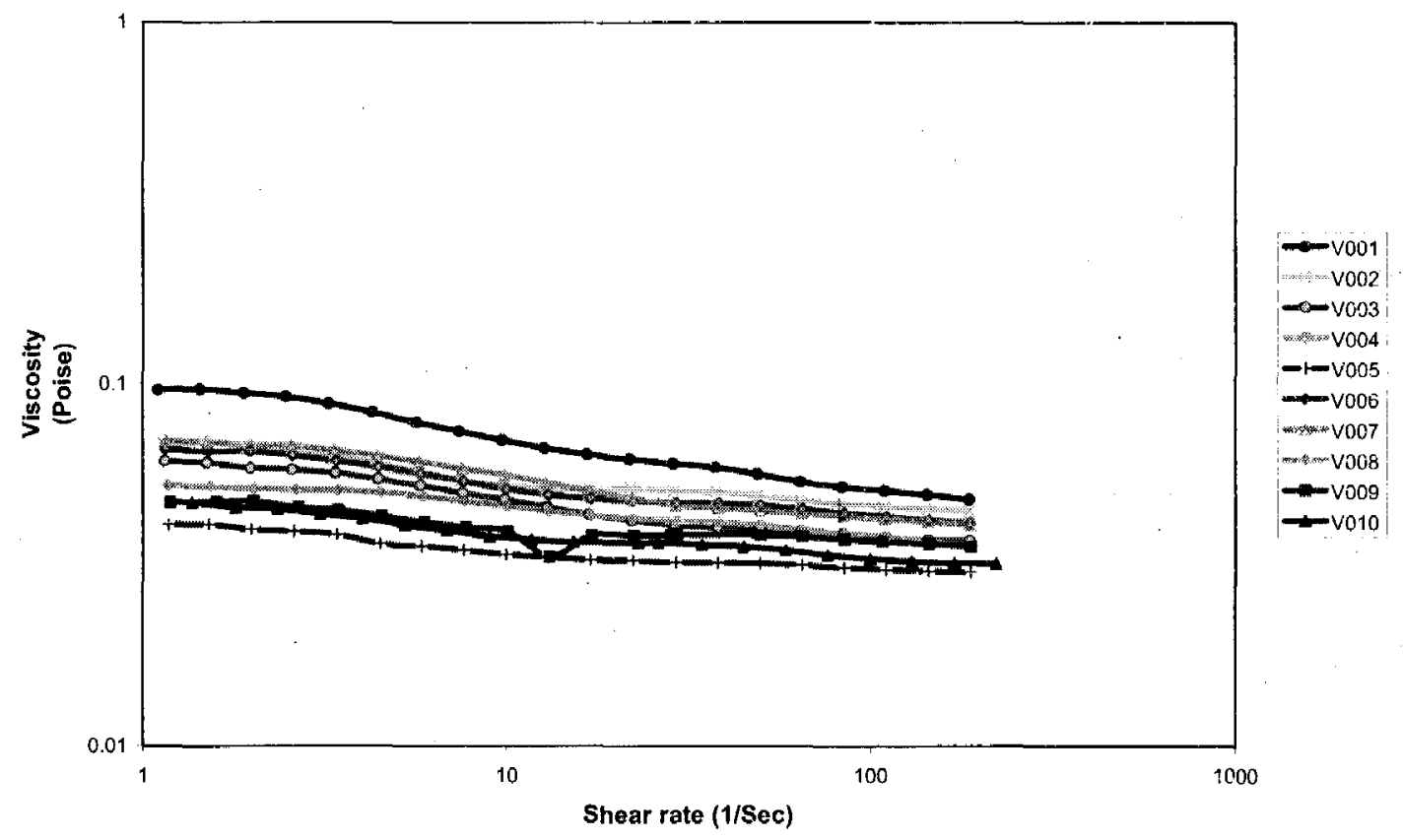

Figure 13 . Viscosity of pediatric blood at $22^{\circ} \mathrm{C}$ [Long, et al. 2005]. 


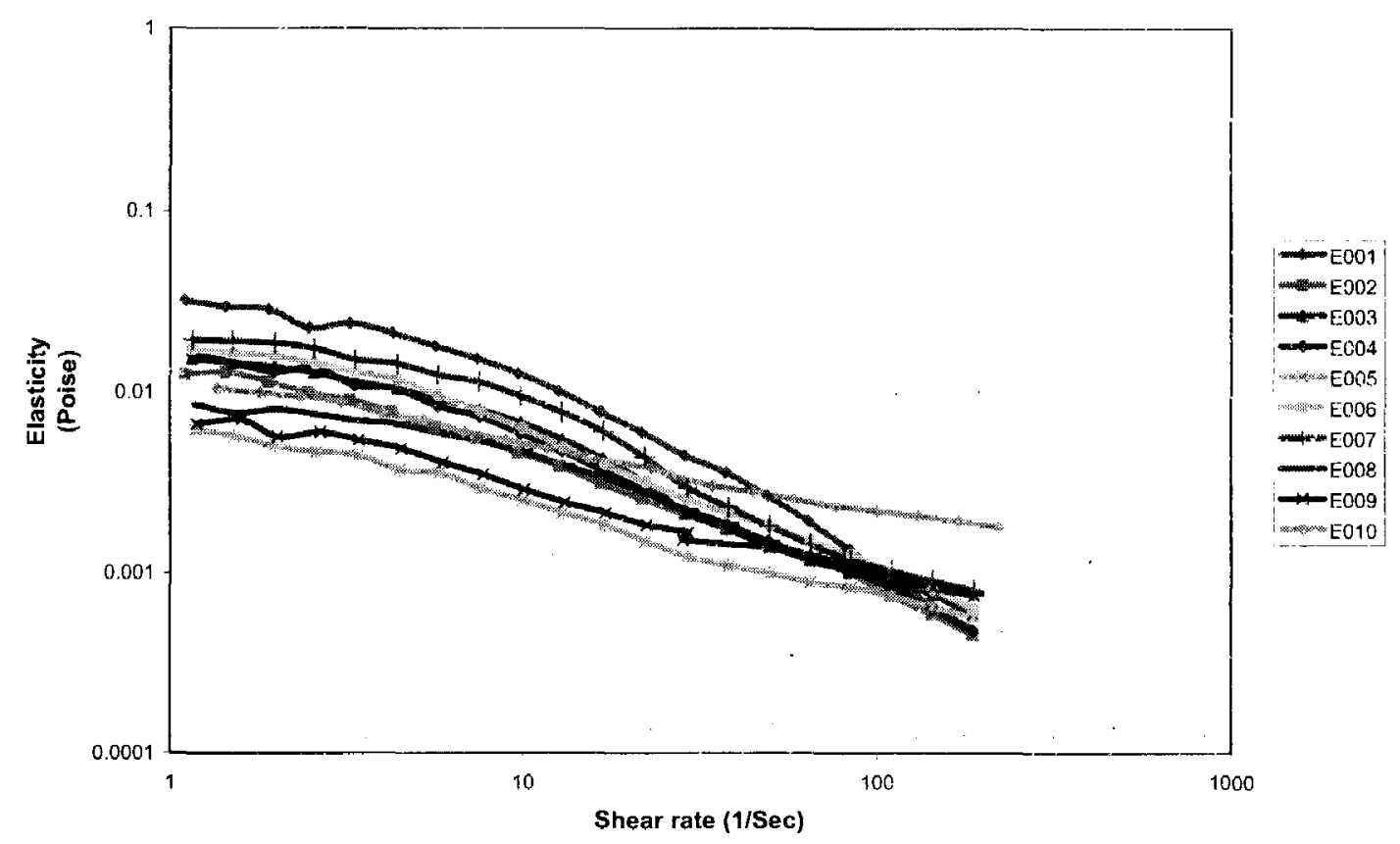

Figure 14. Elasticity of pediatric blood at $22^{\circ} \mathrm{C}$ [Long, et al. 2005].

In summary, it is evident from the data summarized on this section that there is a difference in the viscoelastic behavior of neonatal and aduli blood. The purpose of this study of pediatric blood is to help bridge the gap between the neonatal and adult blood rheological maps at body temperature of $37^{\circ} \mathrm{C}$. 


\section{EXPERIMENTAL METHODS}

In this section, experimental details are presented. This includes the details of the blood samples collected. This section also includes particulars of the experimental set-up and the details of the testing procedure.

\section{Specimen details}

The pediatric blood was obtained from the Kosair Children's Hospital in Louisville, Kentucky between the months of May 2006 and August 2006. The samples were taken in compliance with HIPPA/CITI and the protocol was approved by IRB and Norton Health Care. Informed consent was obtained for all samples. The test-sample size was decided to be $2 \mathrm{ml}$. The samples were tested and recorded over the period of 4 months from 11 different pediatric subjects. The age variation of the research subjects ranged between 2 weeks and 11 years \& 10 months $(2.72 \pm 3.42$ years $)$. The pediatric patients from whom blood was collected, were undergoing surgical procedures. On the morning of the scheduled surgery, $2 \mathrm{ml}$ of the blood was drawn from an in-dwelling catheter in the patients' artery. Subsequently the blood drawn was immediately injected into a $5 \mathrm{ml}$ vacutainer collection tube with EDTA anticoagulant, as shown in Figure 15. After the blood was gently shaken and mixed with the EDTA, the collection tribe was immediately chilled by submersion in crushed ice for transport to the rheometer. Measurements for the viscoelasticity were made using the Vilastic-3 
Viscoelasticity Analyzer (Vilastic Inc., TX) less than two hours from the time of withdrawal of blood from the patients.

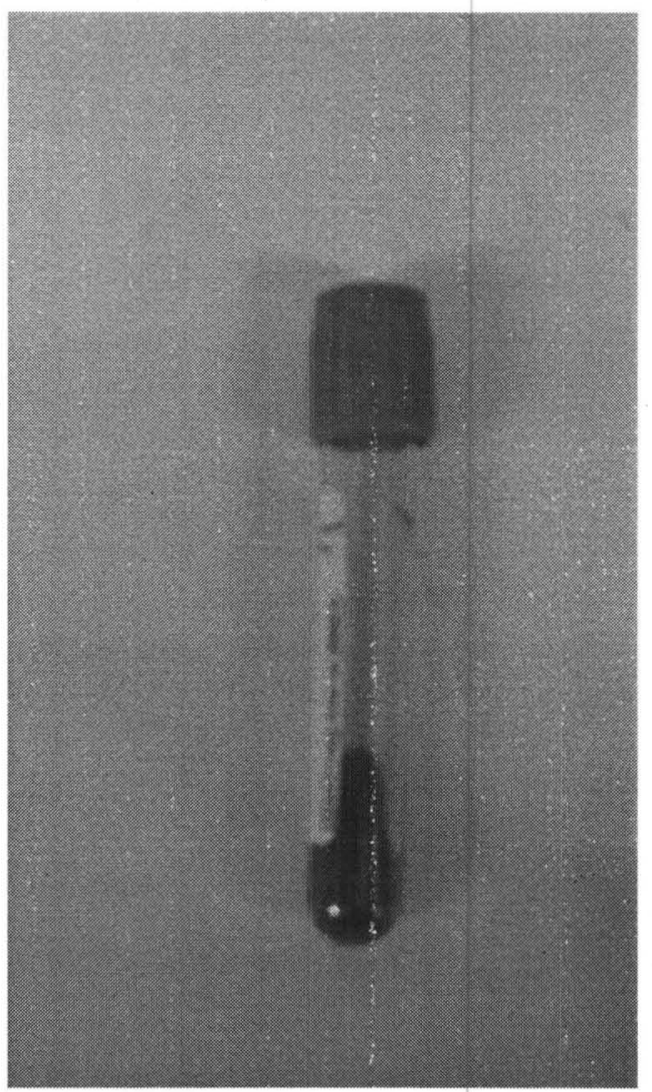

Figure 15. Test tube with purple EDTA top. 


\section{Instrumentation}

\section{Autocrit Ultra-3 Centrifuge}

Before the blood viscoelasticity was measured in the Vilastic-3, a sample was spun in the centrifuge, Autocrit Ultra-3 (Figure 16), to find its hematocrit. The capillary tubes were positioned in the centrifuge as shown in Figure 17. The density of the blood sample was then calculated using ${ }^{3}$ :

$$
\text { Density }=1.0259+0.0006658 * \mathrm{H}
$$

where $\mathrm{H}=$ Hematocrit percentage in the blood.

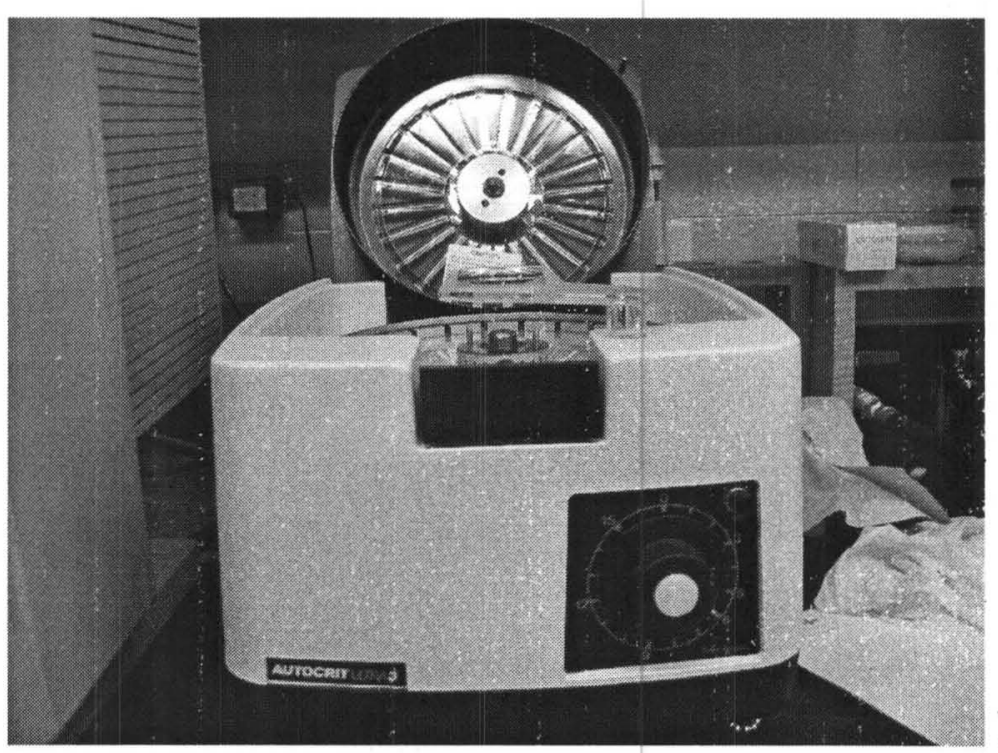

Figure 16. Autocrit Ultra-3 centrifuge.

\footnotetext{
${ }^{3}$ The density equation was provided with the Vilastic-3 operation/testing manual.
} 


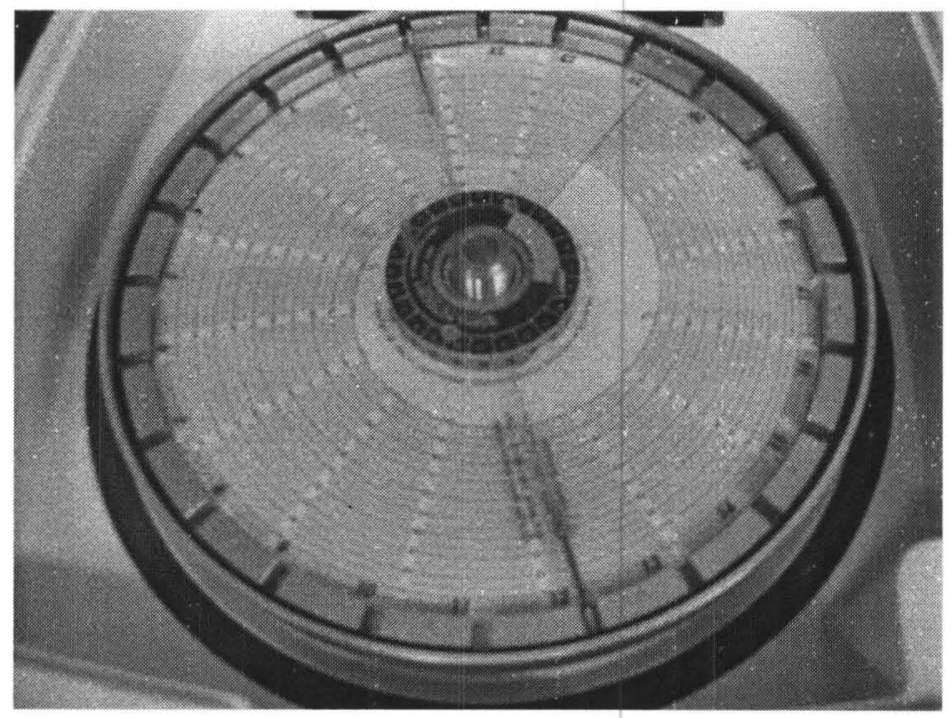

Figure 17. Capillary tubes with blood in place in the centrifuge.

\section{Vilastic-3 Viscoelasticity Analyzer}

The principle of measurement of the Vilastic-3 (Figure 18) is the controlled oscillation of the fluid in a cylindrical tube. Tube dimensions are diameter $2 \mathrm{a}$ of 0.0504 $\mathrm{cm}$ and length $\mathrm{L}$ of $6.333 \mathrm{~cm}$.

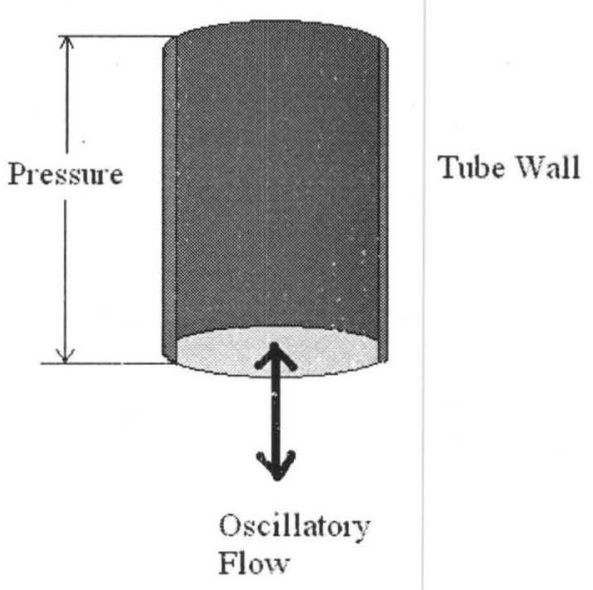

Figure 18. Principle of measurement of Vilastic-3 [www.vilastic.com]. 
The Vilastic-3 was operated at $2 \mathrm{~Hz}$ frequency, which is representative of the frequency range at which the blood flows within the human body and is a standard established by many previous investigations. Variations in viscosity and elasticity with frequency were shown in Figure 7. The complex theory of oscillatory flow in a cylindrical tube that the Vilastic uses was established by G.B. Thurston in 1960 [Thurston 1960, Thurston 1961, Thurston 1976 and Thurston 1981]. The complex impedance of flow in rigid cylindrical tubes is defined by the pressure $\mathrm{P}^{*}$ and the flow $\mathrm{U}^{*}$ as

$$
\mathrm{Z}=\mathrm{P} * / \mathrm{U}^{*}=\mathrm{R}+\mathrm{iX}
$$

where $\mathrm{R}$ is the resistance of the tube and $\mathrm{X}$ is reactance of the tube. The pressure is defined as

$$
\mathrm{P}^{*}=\mathrm{P} \exp \left[\mathrm{i} \theta_{\mathrm{P}}\right]
$$

where $\theta_{\mathrm{P}}$ is the phase of the pressure. The complex volume flow is defined as

$$
\mathrm{U}^{*}=\mathrm{U} \exp \left[\mathrm{i} \theta_{\mathrm{U}}\right]
$$

where $\theta_{\mathrm{U}}$ is the phase of the flow. Then we can calculate the resistance and the reactance as

$$
\mathrm{R}=\frac{\mathrm{P} \cos \theta}{\mathrm{U}} \quad \text { and } \quad \mathrm{X}=\frac{\mathrm{P} \sin \theta}{\mathrm{U}}
$$

where $\theta=\left[\theta_{\mathrm{P}}-\theta_{\mathrm{U}}\right]$ is the phase difference.

The theoretical impedance calculated from the tube geometry and the fluid filling the tube gives

$$
\begin{aligned}
& \text { Ro }=\frac{8 \eta^{\prime} L}{\Pi a^{4}} \\
& X_{0}=\frac{4 \rho \omega L}{3 \Pi a^{2}}-\frac{8 \eta^{\prime \prime} L}{n a^{4}}
\end{aligned}
$$


Also under the same condition the magnitude of shear rate at the tube wall is

$\dot{\gamma}=\left(\frac{4 U}{\pi a^{3}}\right)\left|1+i \frac{\rho \omega a^{2}}{24 \eta^{*}}\right|$

where $U$ is the volume flow, $a$ is the radius of the tube, $\rho$ is the density of the liquid, $\omega$ is the radian frequency of oscillatory flow, and $\eta^{*}=\left[\eta^{\prime}-\right.$ in'] is the complex coefficient of viscosity.

At the wall the shear stress is $\tau_{\mathrm{w}}=\tau^{\prime}-\mathrm{i} \tau^{\prime \prime}=\left[\eta^{\prime}-\mathrm{i} \eta^{\prime \prime}\right] \dot{\gamma}$

where viscous stress is $\tau^{\prime}=\eta^{\prime} \dot{\gamma}$ and elastic stress is $\tau^{\prime \prime}=\eta " \dot{\gamma}$

The Vilastic-3 viscoelastic analyzer (Figure 19) tests viscoelastic properties using the oscillatory principle explained above. The figure shows the chamber with the capillary and the chamber that holds the diaphragm. The pressure across the diaphragm is maintained by silicon oil filling the chamber behind it and the coupling fluid, $0.9 \%$ saline in this case, in the chamber in front of it.

The Vilastic-3 is connected to a HAAKE K10 circulator with HAAKE DC30 heating unit. The HAAKE Circulator has a water bath which can be heated/cooled to the required temperature, either manually using the controls on the $\mathrm{DC} 10$ or via control computer. The Vilastic-3 is also connected to the control computer which can be used to check the filling, for calibrations and for taking and recording measurements. 


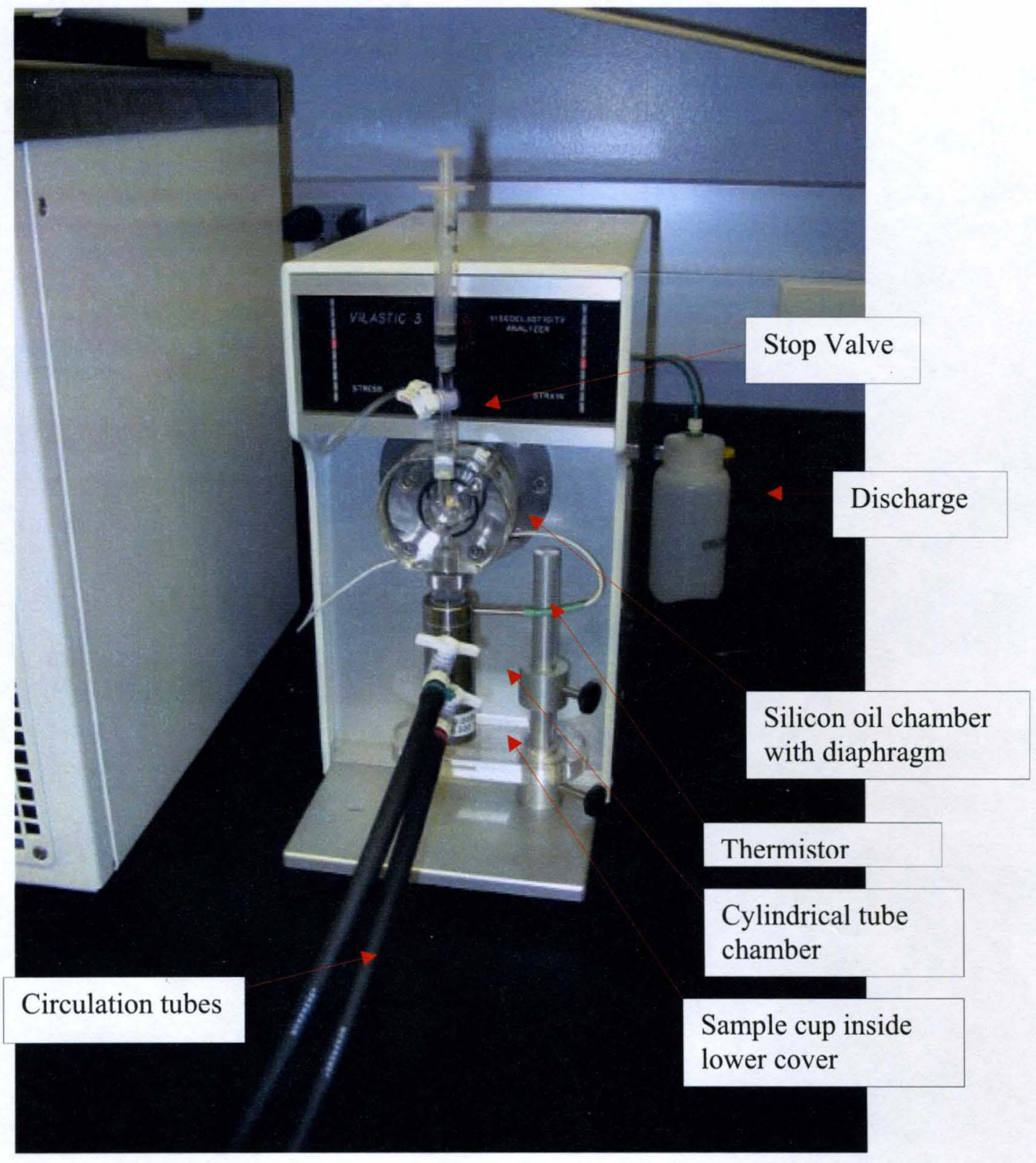

Figure 19. Vilastic-3 viscoelasticity analyzer. 


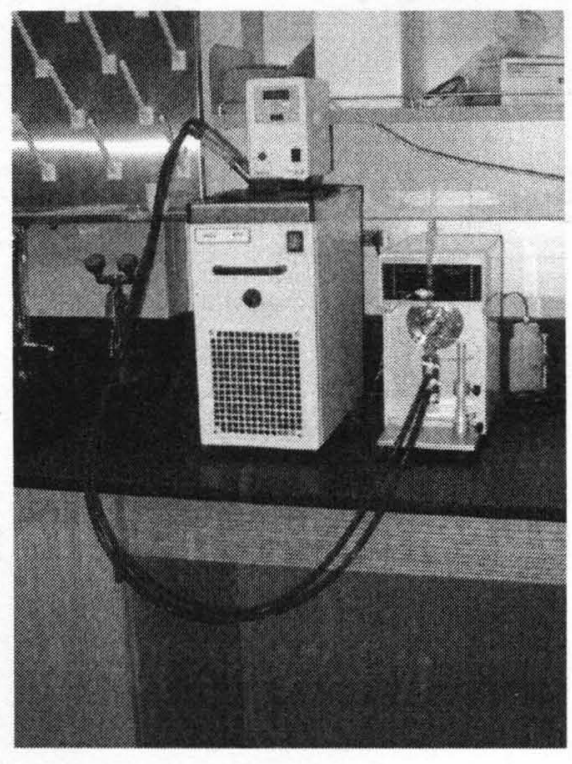

Figure 20. HAAKE circulator connected to the Vilastic-3.

The Vilastic-3 comes with a Vmax software package which is used to control the system through the computer. The entire set-up is shown in Figure 21.

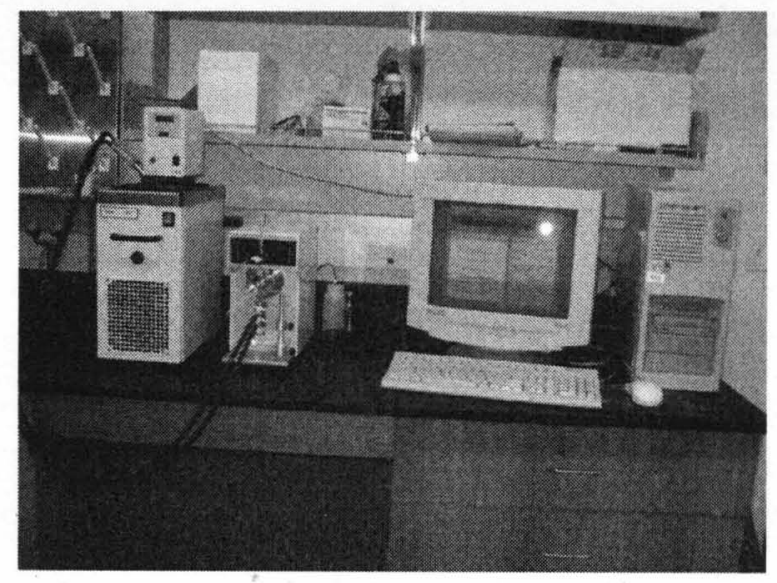

Figure 21. Complete experimental setup showing the circulator, viscoelastic analyzer and control computer. 


\section{Experiment Protocol}

\section{Setup protocol}

The Vmax front screen for setup is as shown in Figure 22. Tube dimensions are diameter of $0.0504 \mathrm{~cm}$ and length of $6.333 \mathrm{~cm}$. The test fluid density is calculated and entered into the Vmax software. The Vilastic is switched $\mathrm{ON}$ and the coupling fluid, $0.9 \%$ saline, is filled in the tube and chamber using a syringe. The pressure sensor and thermistor are checked using the software's Drive and Sensor test options.

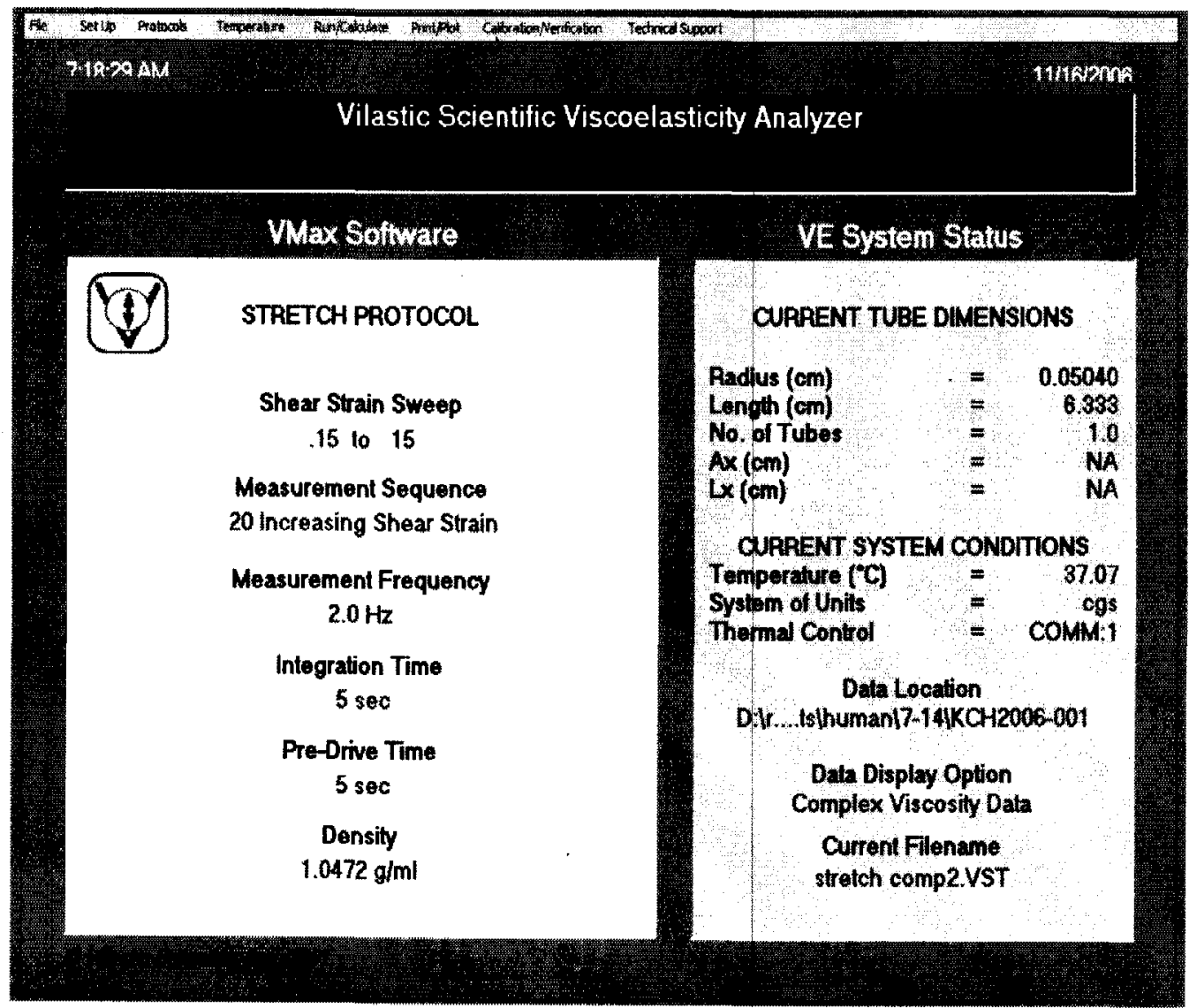

Figure 22. Vmax software main screen. 


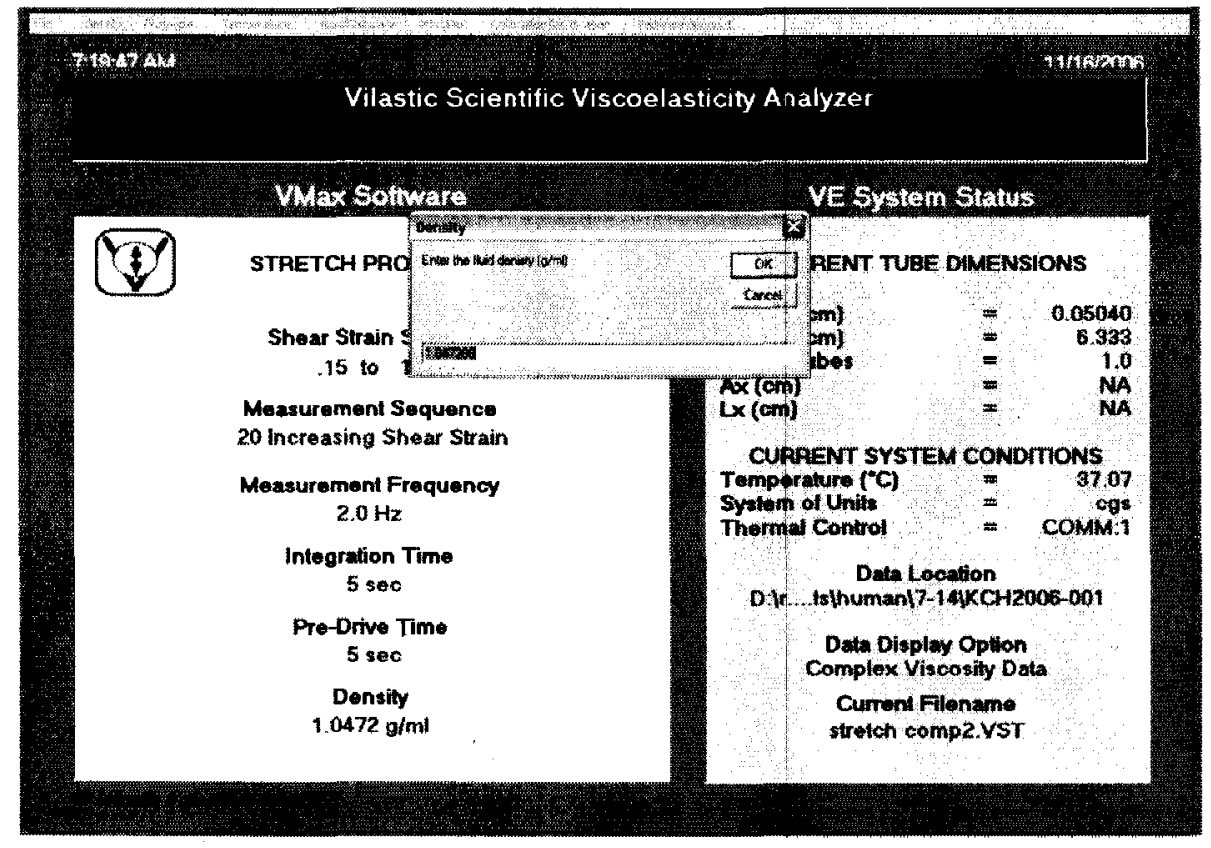

Figure 23. Density entry screen on Vmax.

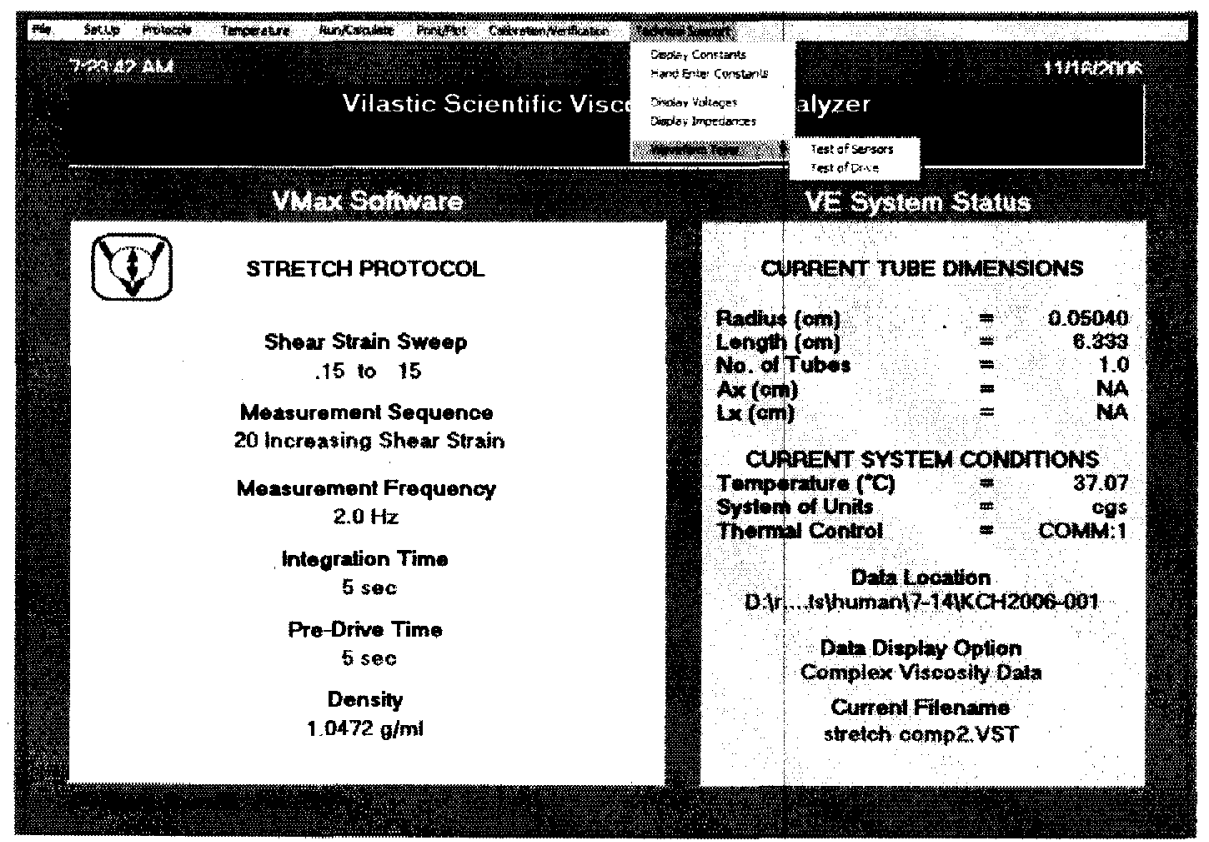

Figure 24. Test of sensors and test of drive tests before filling begins. 
Blood drawn from the pediatric patient is kept submerged in crushed ice from the time it is drawn until testing. The calculated density of blood is entered as per screen shown in Figure 23. The Vilastic 3 is set up as per configuration of measurement and water is circulated using the circulator to maintain temperature close to $37^{\circ} \mathrm{C}$. The sensors are checked by running the test of sensors and drives as shown in Figure 24. The initial temperature of $37^{\circ} \mathrm{C}$ is set via the computer using the Vmax software's set temperature function as shown in Figure 25.

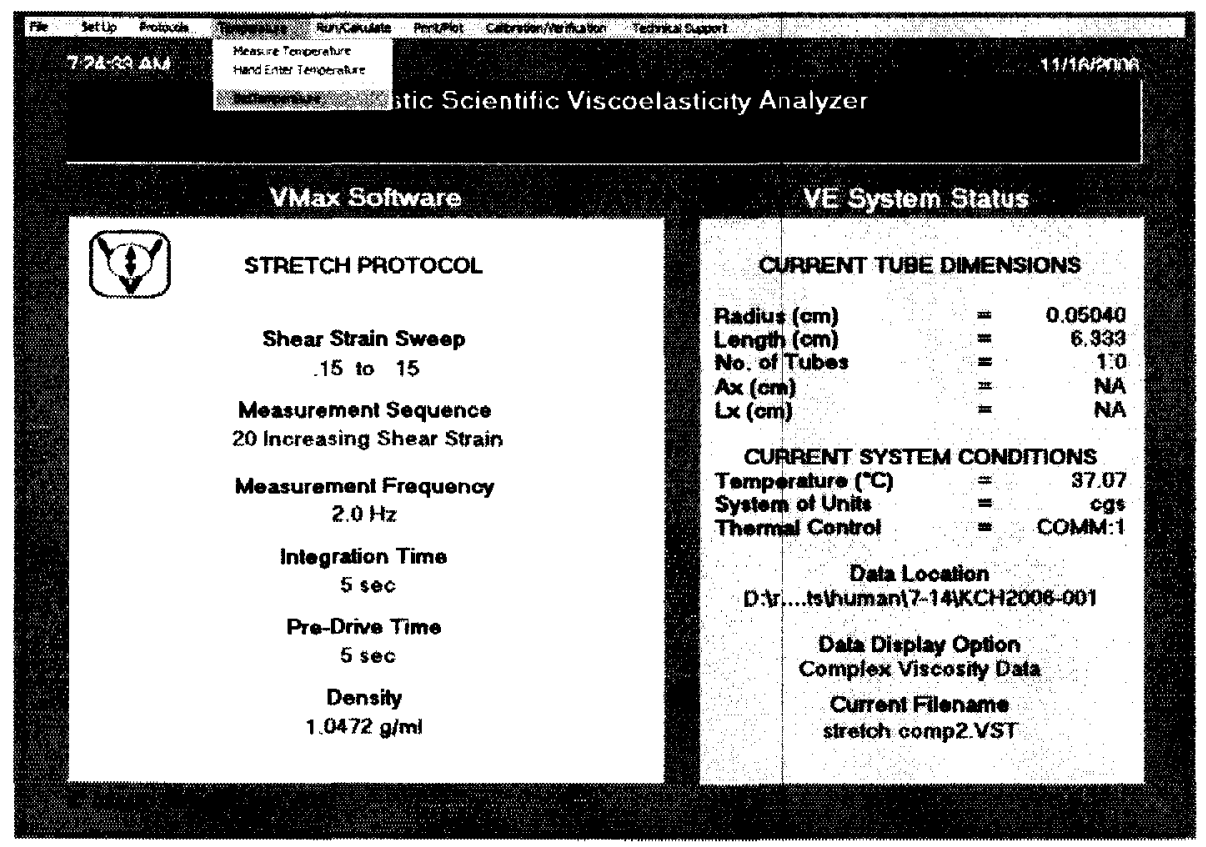

Figure 25. Set temperature function of Vmax.

The thermistor transmits the recorded temperature of circulating water within the Vilastic chamber back to the computer, which is recorded for each measurement in the database. Filling protocol is followed and the blood is filled in the tube from the sample cup using a syringe. The stop valve is closed. 
The tests that can be performed using the Vilastic -3 are the stretch test, time test and shake test. 


\section{$\underline{\text { Test Protocol }}$}

\section{Stretch Test}

The stretch test (Figure 26) is performed to obtain a curve of the viscous and elastic components versus shear rate, which is increased logarithmically at a fixed frequency of $2 \mathrm{~Hz}$. An integration time of $5 \mathrm{sec}$ is used with the drive level sweeping from 10 to 40 (Figure 27).

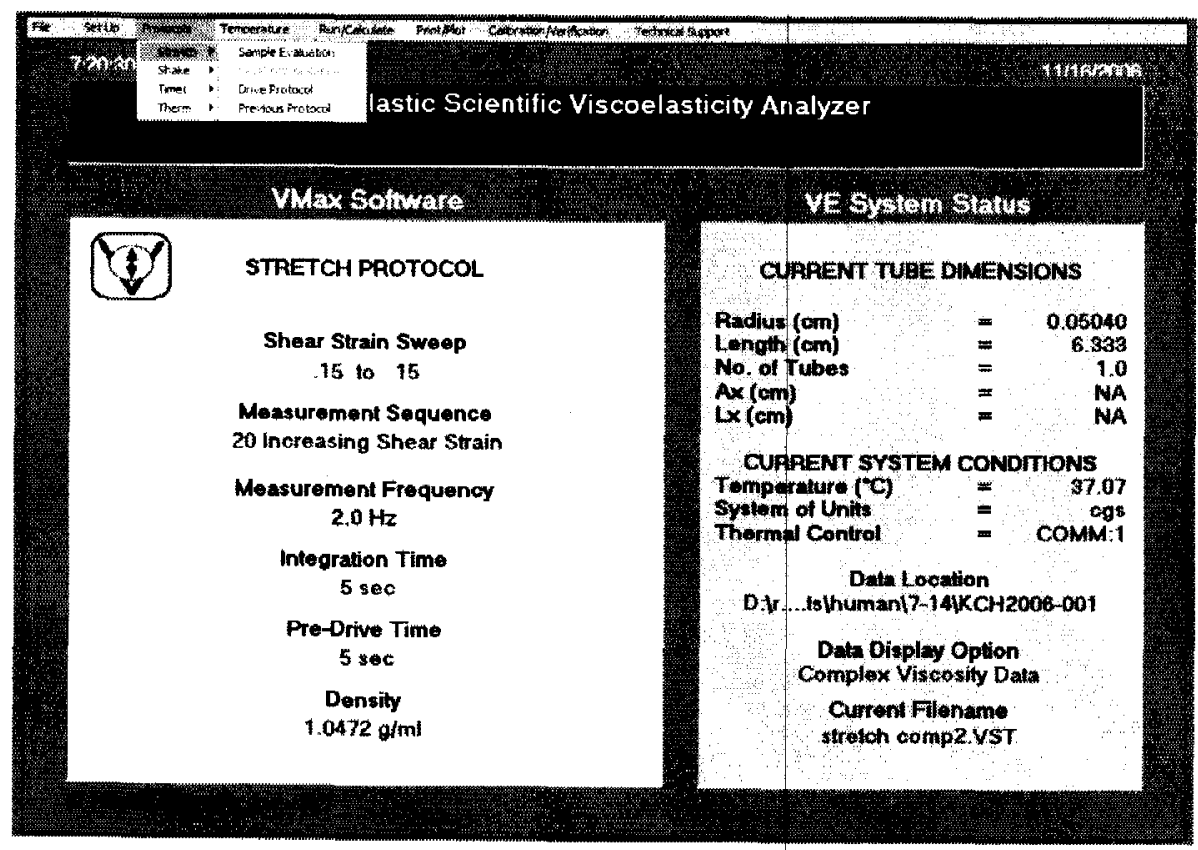

Figure 26. Stretch test options screen. 


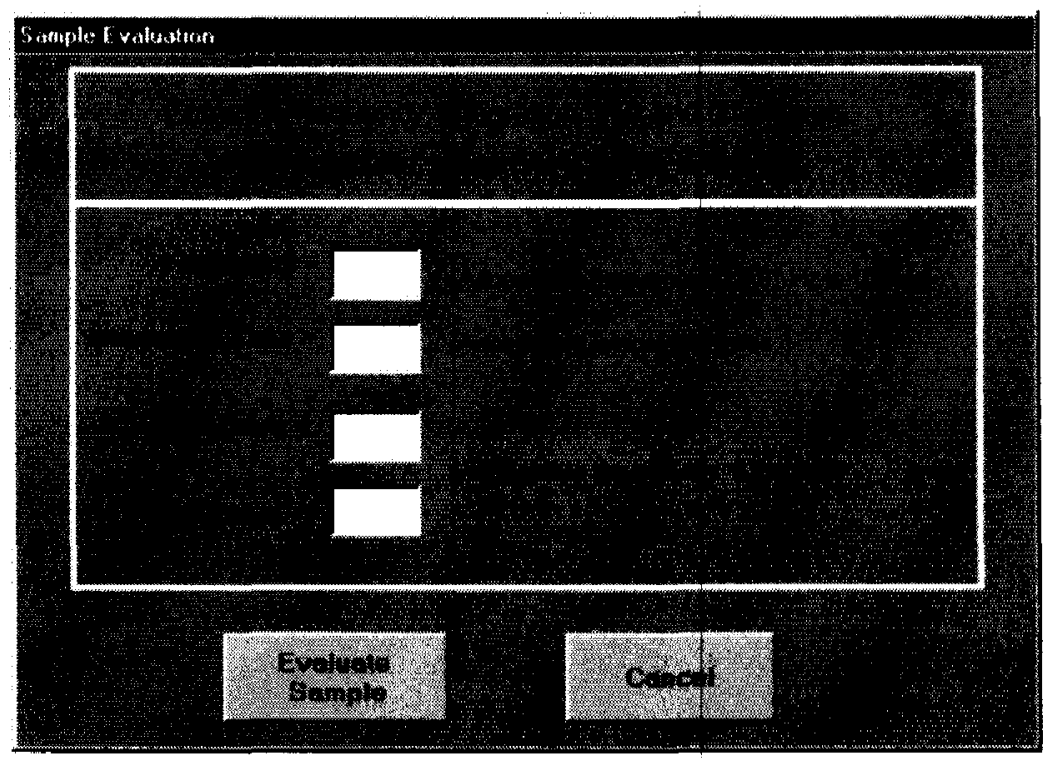

Figure 27. Evaluation test screen for stretch test [Vmax Operation Manual].

For the set protocol we used a strain sweep from 0.15 to 15 through 20 increasing shear strain readings with an integration time of $5 \mathrm{sec}$ and pre-drive of $5 \mathrm{sec}$ (Figure 28).

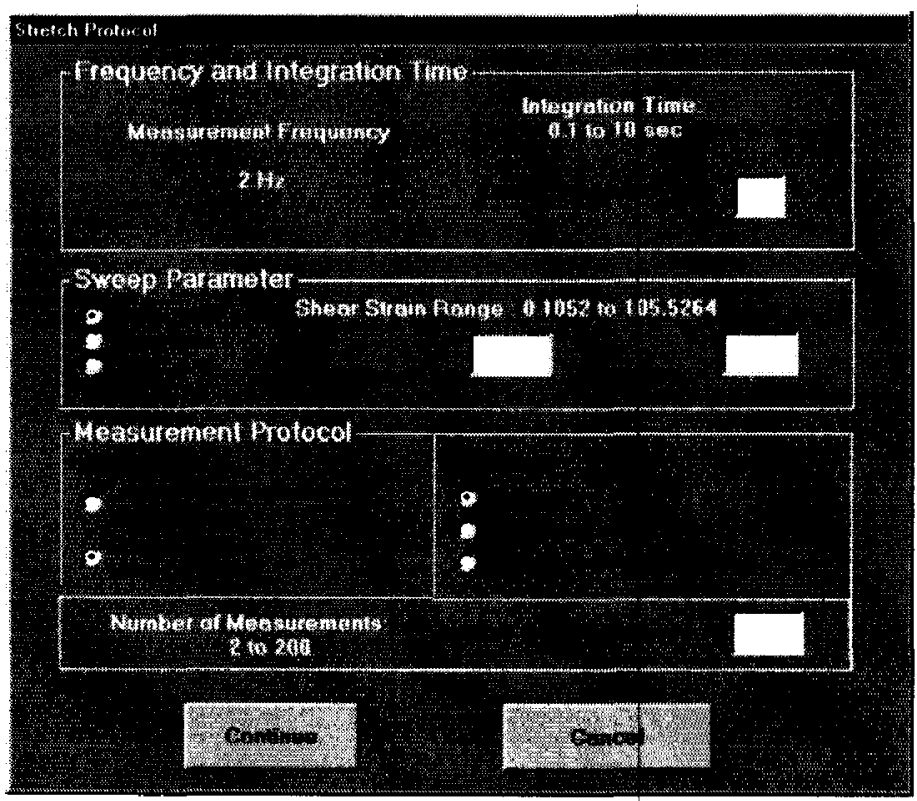

Figure 28. Set up screen for the stretch test [Vmax Operation Manual]. 
This test gives us all the parameters required to study the variation of the viscoelasticity with shear rate and the results obtained can be marked against a strain rate as well. The data obtained in this test is exported to Microsoft Excel and plotted as graphs of viscosity and elasticity versus shear rate and strain. The following tests can also be performed on the blood samples and were performed during preliminary tests to design the procedure for measurement of the main data.

\section{Time Test}

This test can be used for establishing the time dependant properties of viscoelasticity. For this test the evaluation protocol is set at a frequency of $2 \mathrm{~Hz}$, integration time of $5 \mathrm{sec}$ and the drive is set at 40 . For set protocol, measurements are made every $15 \mathrm{sec}$ at a constant strain of 0.5 and frequency $2 \mathrm{~Hz}$, with an integration time of $5 \mathrm{sec}$ and a pre-drive of $5 \mathrm{sec}$. The number of measurements is maintained as 200 . This test was not performed on the main set of blood samples, since the initial tests on other blood samples showed that the variation with respect to time at the same frequency was negligible and thus was not the focus of our final designed study. 


\section{$\underline{\text { Shake Test }}$}

The shake test was performed several initial samples to observe the frequency dependence of viscoelasticity. The protocol was established at $0.1 \mathrm{~Hz}$ to $10 \mathrm{~Hz}$ logarithmically increasing frequencies at a constant strain of 0.5 with an integration time of $5 \mathrm{sec}$ and drive at 40.20 readings were taken. This test was not a focus of the study because no previous pediatric measurements were available for comparison. Erratic results were found for frequency less than $1 \mathrm{~Hz}$. 


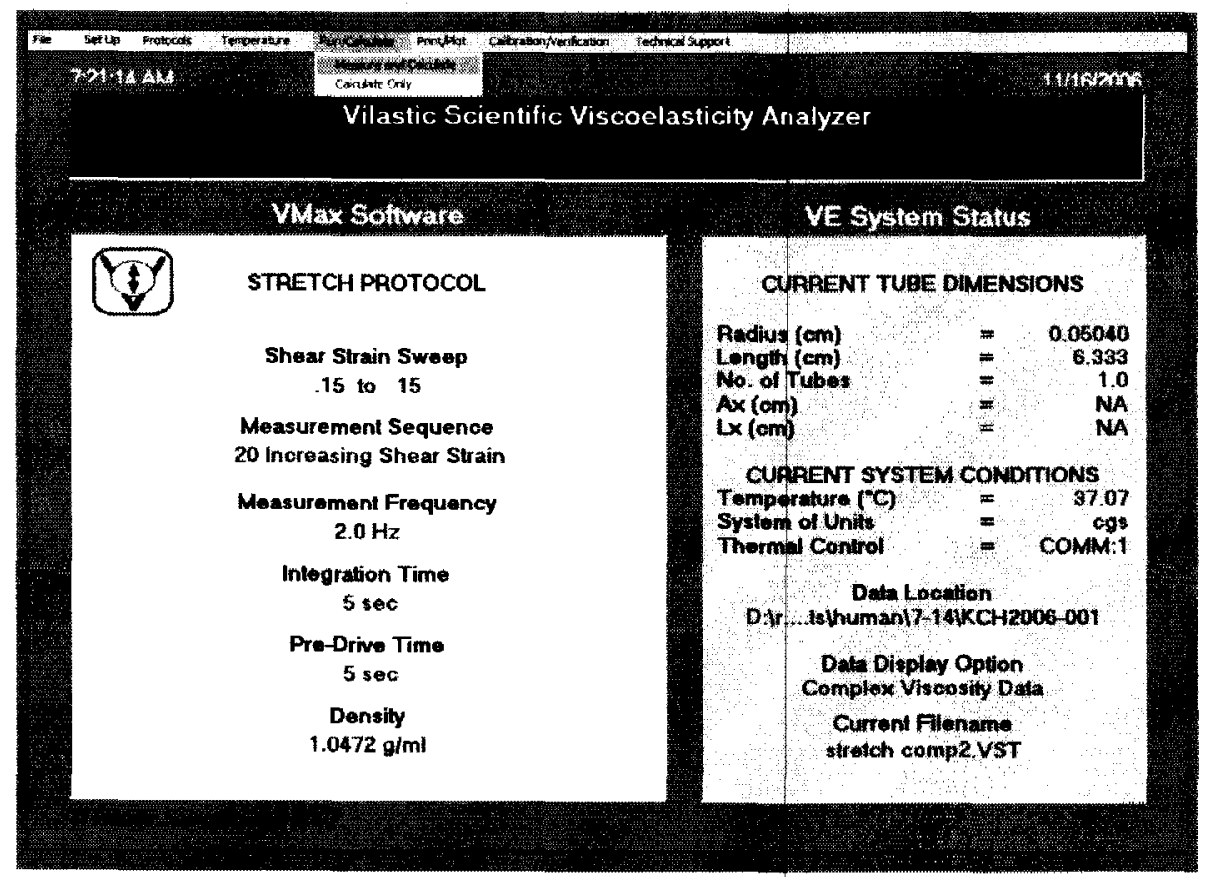

Figure 29. The run/ calculate tab in Vmax.

The only test that was performed on all samples was the stretch test. The sample cup, once loaded, was left untouched until the temperature reached the desired $37^{\circ} \mathrm{C}$. Then the stretch protocol was loaded and the "Measure and Calculate" tab under the Run/Calculate Menu (Figure 29) was selected and the test was performed. When the test was completed, the sample was removed and all blood contacting surfaces cleaned with water, followed by saline. The Vilastic was then ready for another sample to be tested. At the end of all tests the machine was cleaned with a solution of $10 \%$ Clorox and water and then finally cleaned with water. Then the machine was left to air dry. 


\section{DATA ANALYSIS}

The data was extracted and treated to get the required parameters. An Excel sheet was used to plot the required curves and tabulate the parameters.

\section{$\underline{\text { Pediatric Data Analysis }}$}

Once the test was completed, the resulting data was analyzed to get the set of results that can be used for comparison. Also the data was extracted in the desired format for use in any further study of the viscoelasticity. 


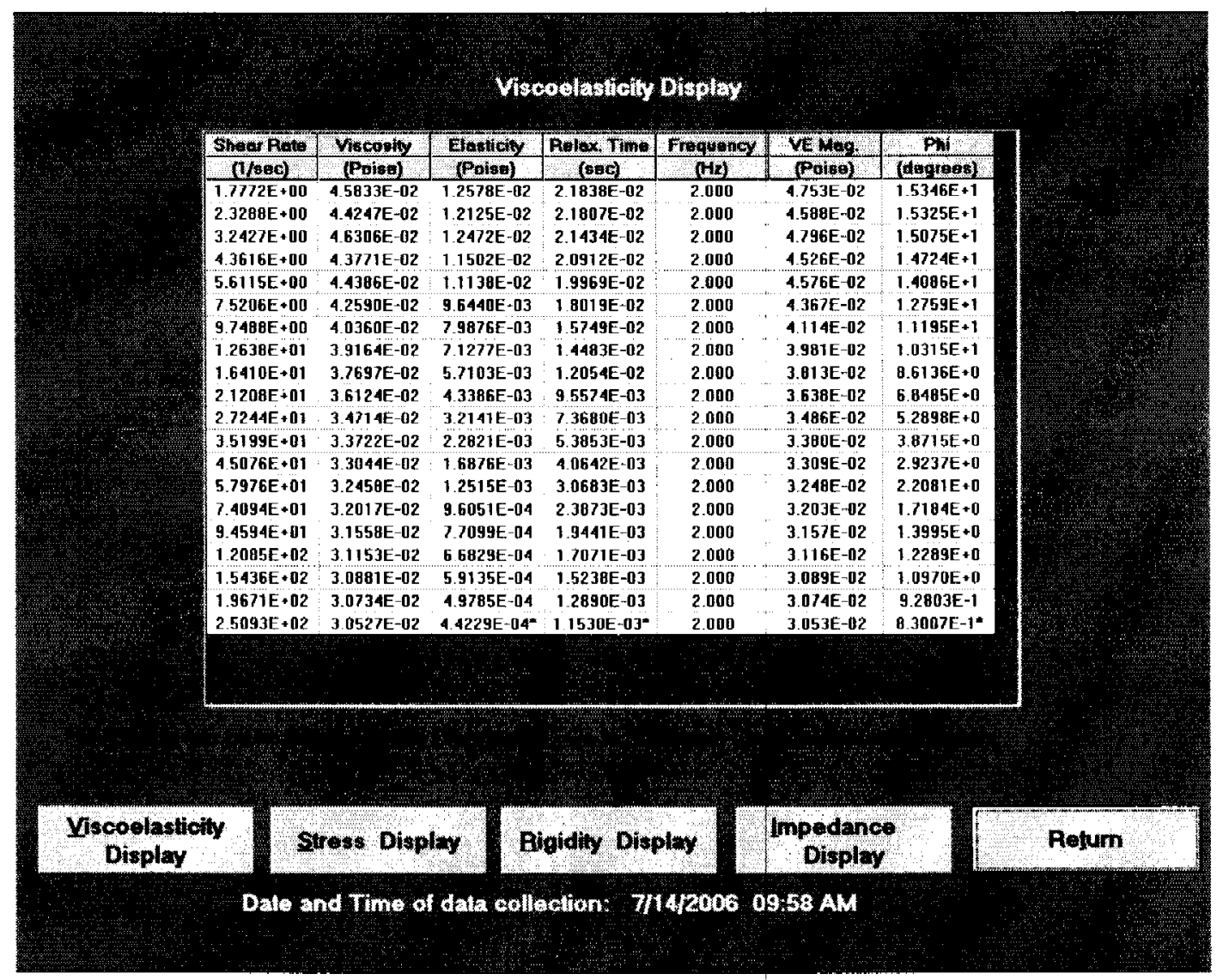

Figure 30. Test data display in table format in Vmax.

The data results appear in a window with all the data for the stretch test (Figure 30). This set gives all the data from all the parameters recorded. Parameters that were needed for result calculations were extracted from this. The data can be plotted using the "plot data" function under the Print/Plot menu in the front screen (Figure 31 and 32). 


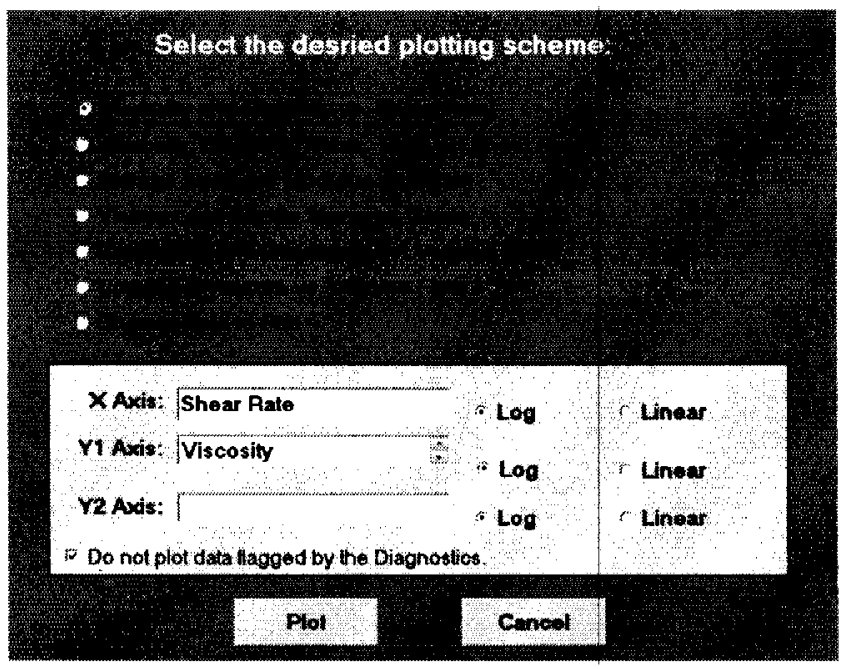

Figure 31. Plot options in Vmax.

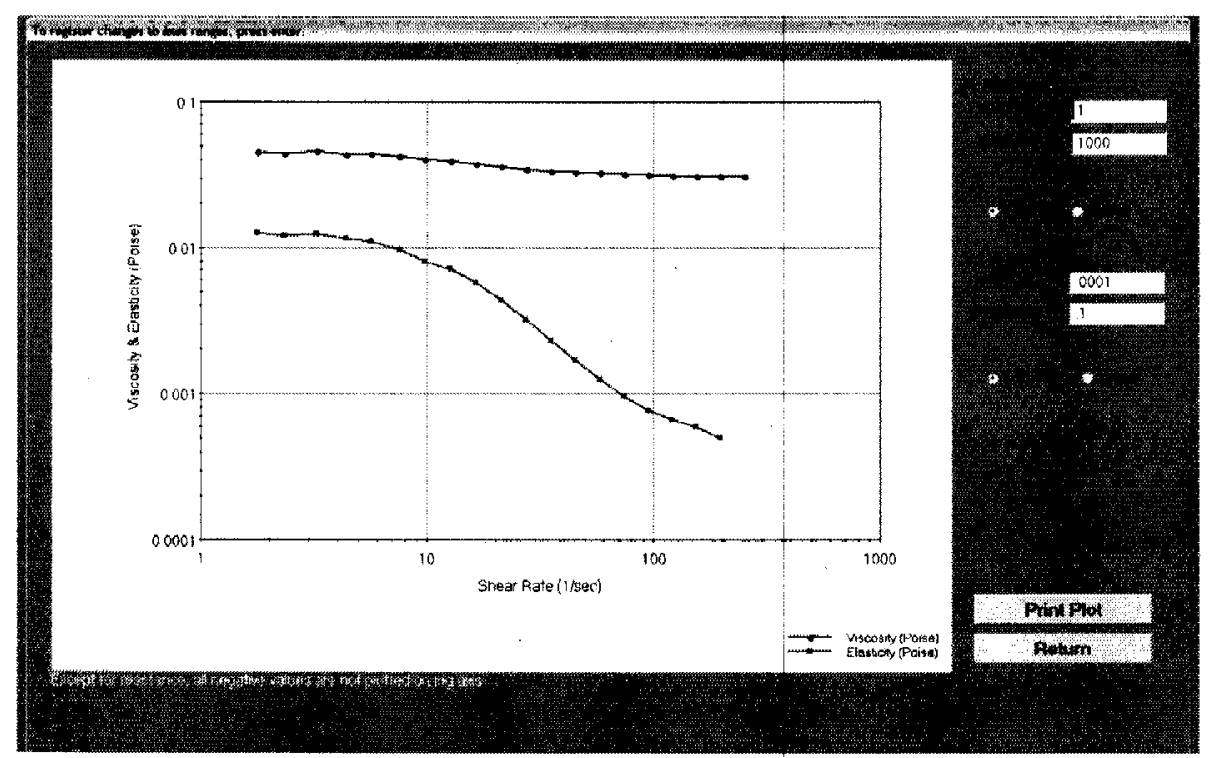

Figure 32. Sample log of viscoelasticity vs. $\log$ of shear rate plot using Vmax,

The data was extracted from the Vmax software. This was done by using the 'save as ASCII' function in the File menu. The menu that opens up is shown in Figure 33. The parameters that need to be exported for the study were selected and then the ASCII file was created. 


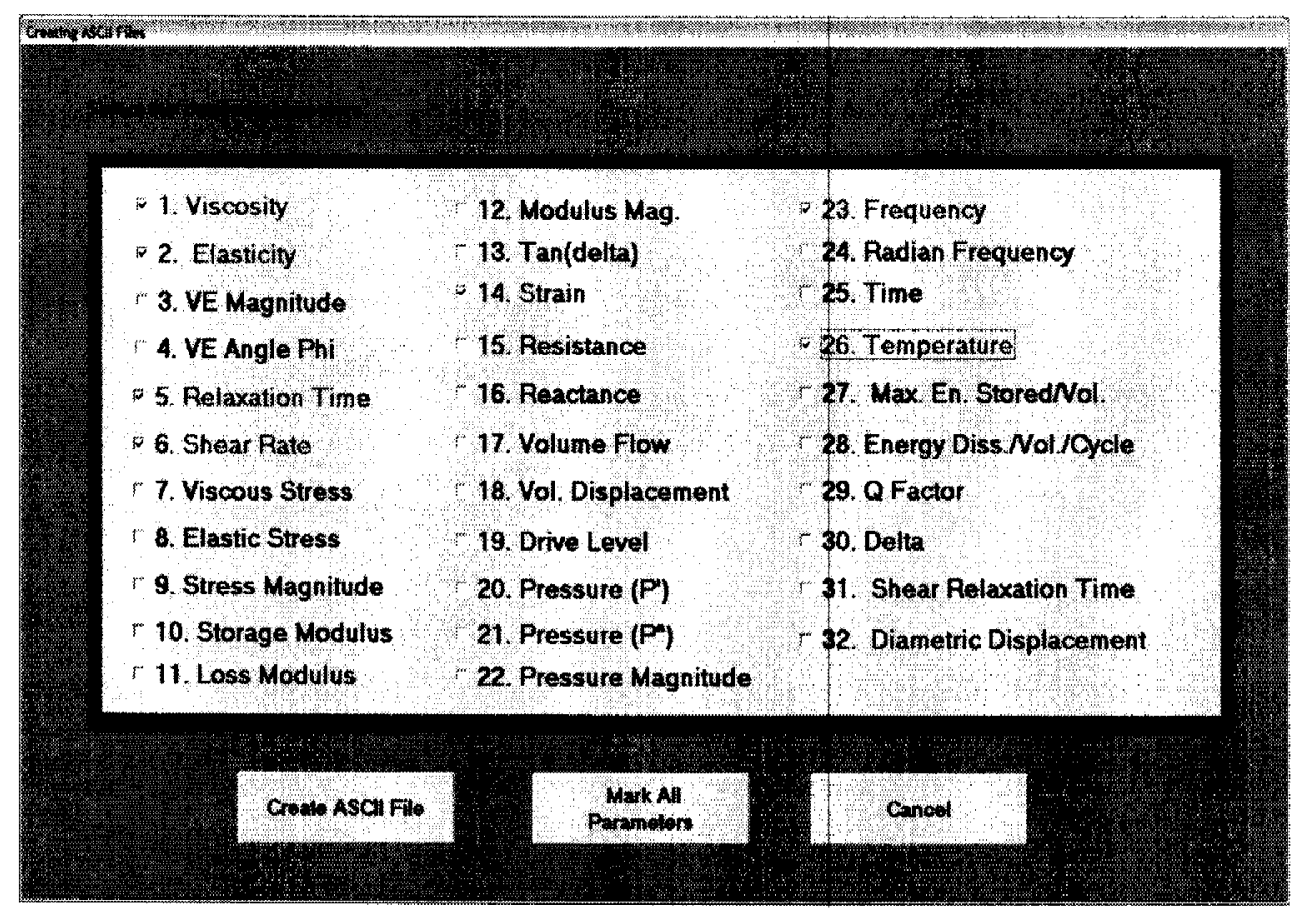

Figure 33. Parameter selection screen for ASCII file. 
The ASCII file was then opened using Excel and stored in the desired format. A sample data table is shown in Table 2.

\begin{tabular}{|c|c|c|c|c|c|c|}
\hline \multicolumn{7}{|c|}{$\begin{array}{l}\text { Source Filename: stretch complete.VS.T [7/14/2006] [09:58 AM] } \\
\text { [cgs units] } \\
\text { Stretch Protocol - Constant Frequency }=2[\mathrm{~Hz}]\end{array}$} \\
\hline $\begin{array}{l}\text { Viscosity } \\
\text { (Poise) }\end{array}$ & $\begin{array}{c}\text { Elasticity } \\
\text { (Poise) }\end{array}$ & $\begin{array}{c}\text { Relax.Time } \\
\text { (s) }\end{array}$ & $\begin{array}{c}\text { ShearRate } \\
(1 / \mathrm{s})\end{array}$ & Strain & $\begin{array}{c}\text { Frequency } \\
(\mathrm{Hz})\end{array}$ & $\begin{array}{c}\text { Temperature } \\
\left({ }^{\circ} \mathrm{C}\right)\end{array}$ \\
\hline 0.0458 & 0.01260 & 0.0218 & 1.777 & 0.1414 & 2 & 36.9 \\
\hline 0.0442 & 0.01210 & 0.0218 & 2.33 & 0.1853 & 2 & 37.0 \\
\hline 0.0463 & 0.01247 & 0.0214 & 3.24 & 0.258 & 2 & 37.0 \\
\hline 0.0438 & 0.01150 & 0.0209 & 4.36 & 0.347 & 2 & 37.0 \\
\hline 0.0444 & 0.01110 & 0.0200 & 5.61 & 0.447 & 2 & 37.0 \\
\hline 0.0426 & 0.00964 & 0.01800 & 7.52 & 0.598 & 2 & 37.0 \\
\hline 0.0404 & 0.00799 & 0.01570 & 9.75 & 0.776 & 2 & 37.0 \\
\hline 0.0392 & 0.00713 & 0.01450 & 12.64 & 1.006 & 2 & 37.1 \\
\hline 0.0377 & 0.00571 & 0.01210 & 16.41 & 1.306 & 2 & 37.1 \\
\hline 0.0361 & 0.00434 & 0.00956 & 21.21 & 1.688 & 2 & 37.1 \\
\hline 0.0347 & 0.00321 & 0.00737 & 27.24 & 2.168 & 2 & 37.1 \\
\hline 0.0337 & 0.00228 & 0.00539 & 35.20 & 2.801 & 2 & 37.0 \\
\hline 0.0330 & 0.001690 & 0.00406 & 45.08 & 3.587 & 2 & 37.0 \\
\hline 0.0325 & 0.001250 & 0.00307 & 57.98 & 4.614 & 2 & 37.0 \\
\hline 0.0320 & 0.000961 & 0.00239 & 74.09 & 5.896 & 2 & 37.0 \\
\hline 0.0316 & 0.000771 & 0.001940 & 94.59 & 7.528 & 2 & 37.0 \\
\hline 0.0312 & 0.000668 & 0.001710 & 120.85 & 9.617 & 2 & 37.0 \\
\hline 0.0309 & 0.000591 & 0.001520 & 154.36 & 12.28 & 2 & 37.0 \\
\hline 0.0307 & 0.000498 & 0.001290 & 196.71 & 15.65 & 2 & 37.1 \\
\hline 0.0305 & 0.000442 & 0.001150 & 250.93 & 19.97 & 2 & 37.1 \\
\hline
\end{tabular}

Table 2. Data from test sample KCH2006-001.

Table 2 shows the viscosity and elasticity in Poise and also the relaxation time in seconds. The table also shows the shear rate and the strain against which the sample was tested for each data point. The frequency as explained in the test procedure was maintained at $2 \mathrm{~Hz}$ and the temperature was maintained close to $37^{\circ} \mathrm{C}$, which is the normal body temperature. 
The data thus extracted into Excel was used to plot the basic viscosity and elasticity curves. The data was plotted as viscosity and elasticity versus shear rate and relaxation time versus shear rate; viscosity and elasticity versus strain and relaxation time versus strain.

Sample plots corresponding to sample KCH2006-001 are shown in Figure 34 and Figure 35 .

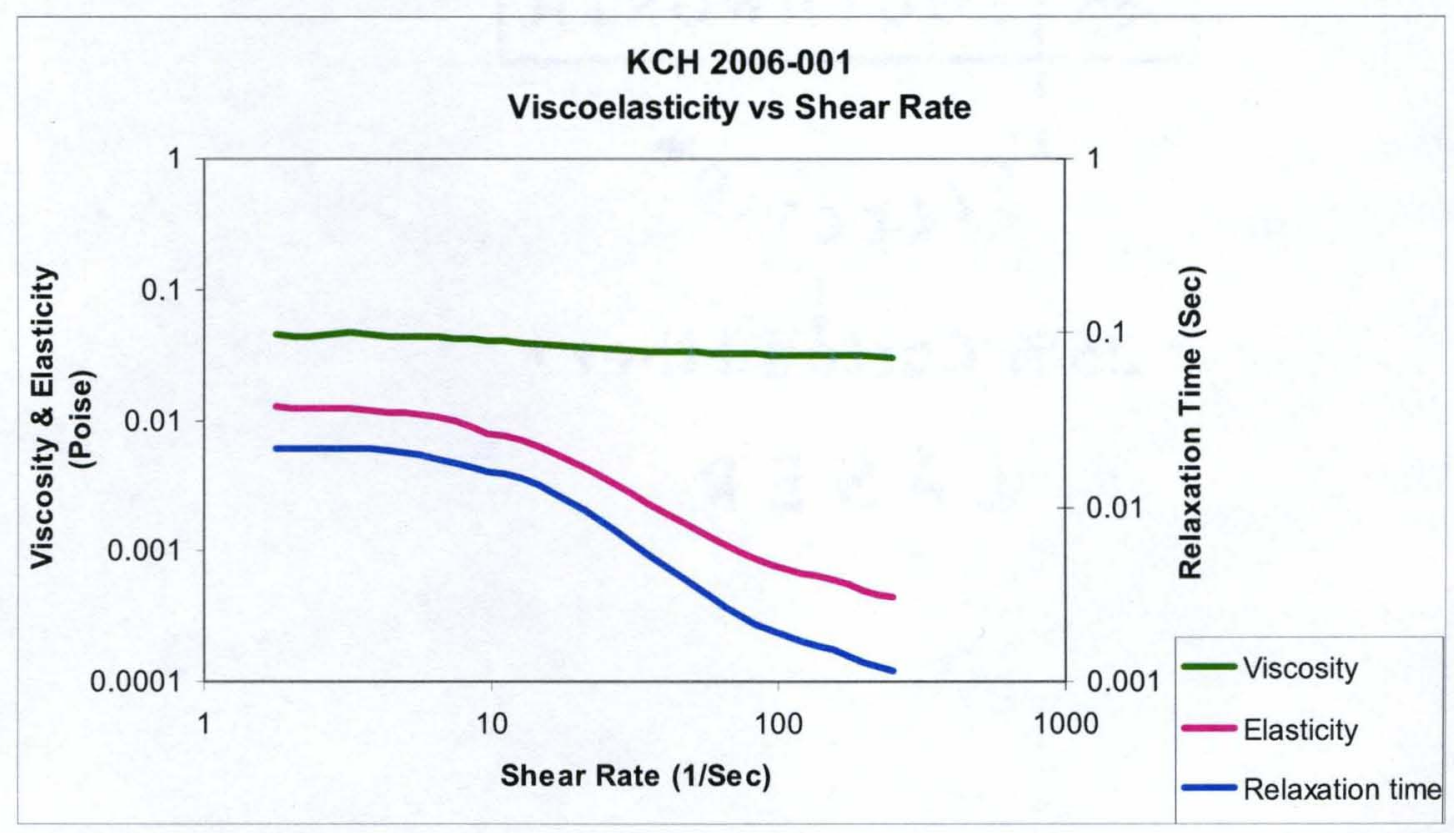

Figure 34. Viscosity, elasticity, relaxation time vs. shear rate. 


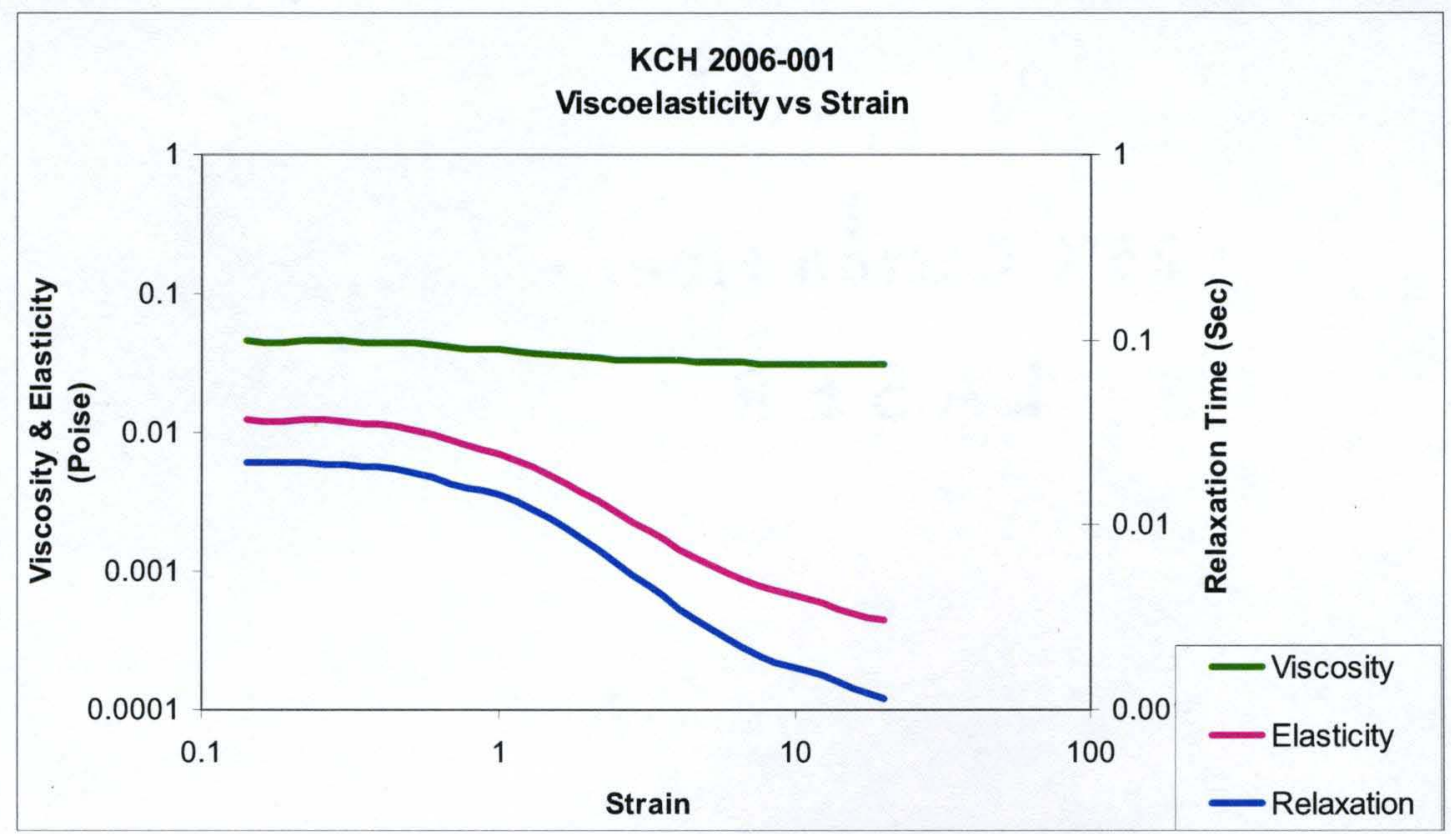

Figure 35. Viscosity, elasticity, relaxation time vs. strain.

The sets of curves are similar, since shear rate and strain are related as

$$
\text { Shear rate }=\text { Strain } x[2 \Pi \times \text { frequency }]
$$

where, the frequency was held constant at $2 \mathrm{~Hz}$.

The viscosity and elasticity curves were fitted with an exponential trend line and the equation of the fitted curve was displayed. Three strain values characterize the different responses of red cells to varying levels of strain [Thurston, 1979]. At 0.2 strain the aggregates are formed and are stable, at 1 strain the aggregates are broken up into single cells and at 5 strain the cells deform and flow in layers. The analysis is done at these three strain values. 
After calculating the values of viscosity and elasticity corresponding to the strain values of $0.2,1$ and 5 , we start the comparison with the adult data and pediatric data obtained at $22^{\circ} \mathrm{C}$.

The adult data used for comparison was obtained from Vilastic [Thurston, 1996] and from another existing study [Kaber, 1988]. The Thurston data is at $37^{\circ} \mathrm{C}$ and with hematocrit of $47 \%$. The data from Thurston was used for graphical comparison, as it is the data closest to the pediatric data measured in procedure of measurement and testing. The dataset from Kaber [1988] was used for its large number of data points.

The pediatric data used for comparison was obtained from Penn State University [Long, et al. 2005]. The data set is from 10 patients tested at $22^{\circ} \mathrm{C}$. This data was used as it is only existing data that has been published with the same procedure of measurement and testing as the measured pediatric data except for it being measured at $22^{\circ} \mathrm{C}$.

The statistical test performed on the data for comparison between the pediatric and adult data was two-way Analysis of Variance, also known as ANOVA. The analysis of variance is a statistical test used to compare the mean of a variable in different sets of data. In this case we compared to see if the mean of the two sets [either adult or pediatric or the two pediatric data sets] was the same. The value of $p$ being less than 0.05 is considered to be statistically significant. 


\section{IV, RESULTS}

A comparison is shown between pediatric and adult rheology, both obtained at $37^{\circ} \mathrm{C}$. This comparison was done using adult data from Thurston [1996] and Kaber, et al. [1988]. There is also shown a comparison between the pediatric viscoelastic data obtained at the University of Louisville at $37^{\circ} \mathrm{C}$ and that obtained at Penn State at $22^{\circ} \mathrm{C}$.

\section{New Pediatric Viscoelasticity Data}

Patient age, body weight, whole blood hematocrit and blood density are documented in Table 3. Viscosity and elasticity versus shear rate for all patients is shown . in Figures 36 and 37. 


\begin{tabular}{|c|c|c|c|c|}
\hline PATIENT & AGE & $\begin{array}{c}\text { HEMATOCRIT } \\
{[\%]}\end{array}$ & $\begin{array}{c}\text { BODY } \\
\text { WEIGHT } \\
{[\mathrm{Kg}]}\end{array}$ & $\begin{array}{c}\text { DENSITY } \\
{[\mathrm{g} / \mathrm{ml}]}\end{array}$ \\
\hline $\mathrm{KCH} 2006-001$ & $\begin{array}{l}4 \text { years } 4 \\
\text { months }\end{array}$ & 32.0 & 20.0 & 1.047 \\
\hline $\mathrm{KCH} 2006-002$ & 2 weeks & 40.1 & 3.6 & 1.053 \\
\hline $\mathrm{KCH} 2006-003$ & $\begin{array}{c}2 \text { years } 10 \\
\text { months }\end{array}$ & 50.0 & 14.0 & 1.059 \\
\hline $\mathrm{KCH} 2006-004$ & 6 months & 51.5 & 6.2 & 1.060 \\
\hline $\mathrm{KCH} 2006-005$ & $\begin{array}{l}2 \text { years } 4 \\
\text { months }\end{array}$ & 33.0 & 12.2 & 1.048 \\
\hline $\mathrm{KCH} 2006-006$ & $\begin{array}{c}11 \text { years } 10 \\
\text { months }\end{array}$ & 38.0 & 34.8 & 1.051 \\
\hline KCH2006-007 & 4 months & 47.0 & 5.0 & 1.057 \\
\hline $\mathrm{KCH} 2006-008$ & $\begin{array}{c}3 \text { years } 1 \\
\text { month }\end{array}$ & 36.0 & 16.0 & 1.050 \\
\hline $\mathrm{KCH} 2006-009$ & 4 years & 34.0 & 20.6 & 1.049 \\
\hline $\mathrm{KCH} 2006-010$ & $\begin{array}{c}7 \text { months } 2 \\
\text { weeks }\end{array}$ & 30.0 & $5: 8$ & 1.046 \\
\hline KCH2006-011 & 11 days & 42.0 & 1.68 & 1.054 \\
\hline
\end{tabular}

Table 3. Patient characteristics for the 11 pediatric samples.

The ranges of viscosity and elasticity exhibited in Figure 36 and 37 could be attributed primarily to variation in hematocrit among the patients. The highest viscosity curve was for sample $\mathrm{KCH} 2006-003$ with a hematocrit of $50 \%$ (for a 2 years old patient) and the lowest curve in the plot was for $\mathrm{KCH} 2006-010$ with hematocrit of $30 \%$ (for a 7 months old patient). The highest and lowest elasticity curves corresponded to the same two samples. Mean hematocrit values are in the range of $52 \%$ for neonates and $44 \%$ for adults [Linderkamp, et al. 1992]. 


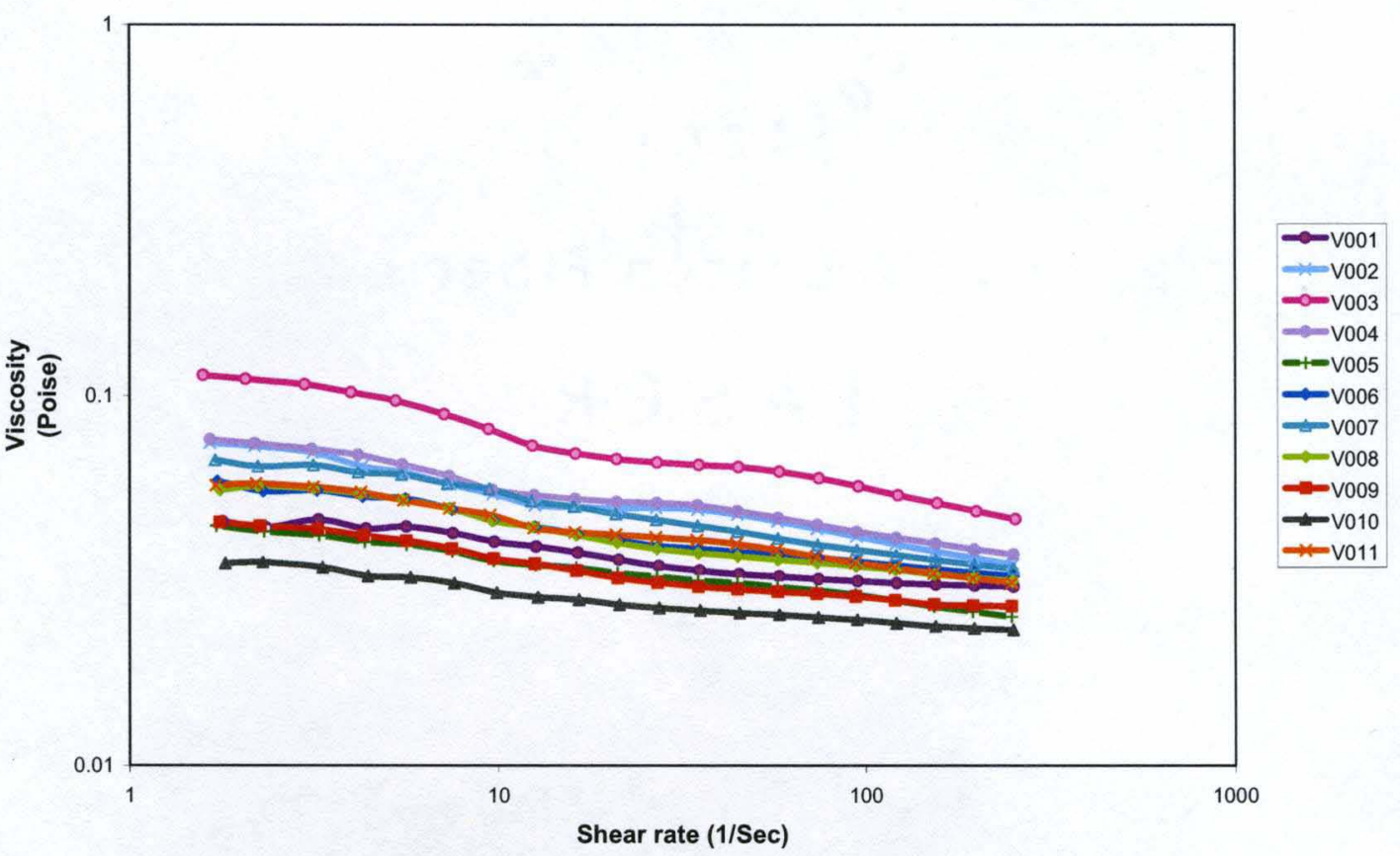

Figure 36. Viscosity vs. shear rate for all samples.

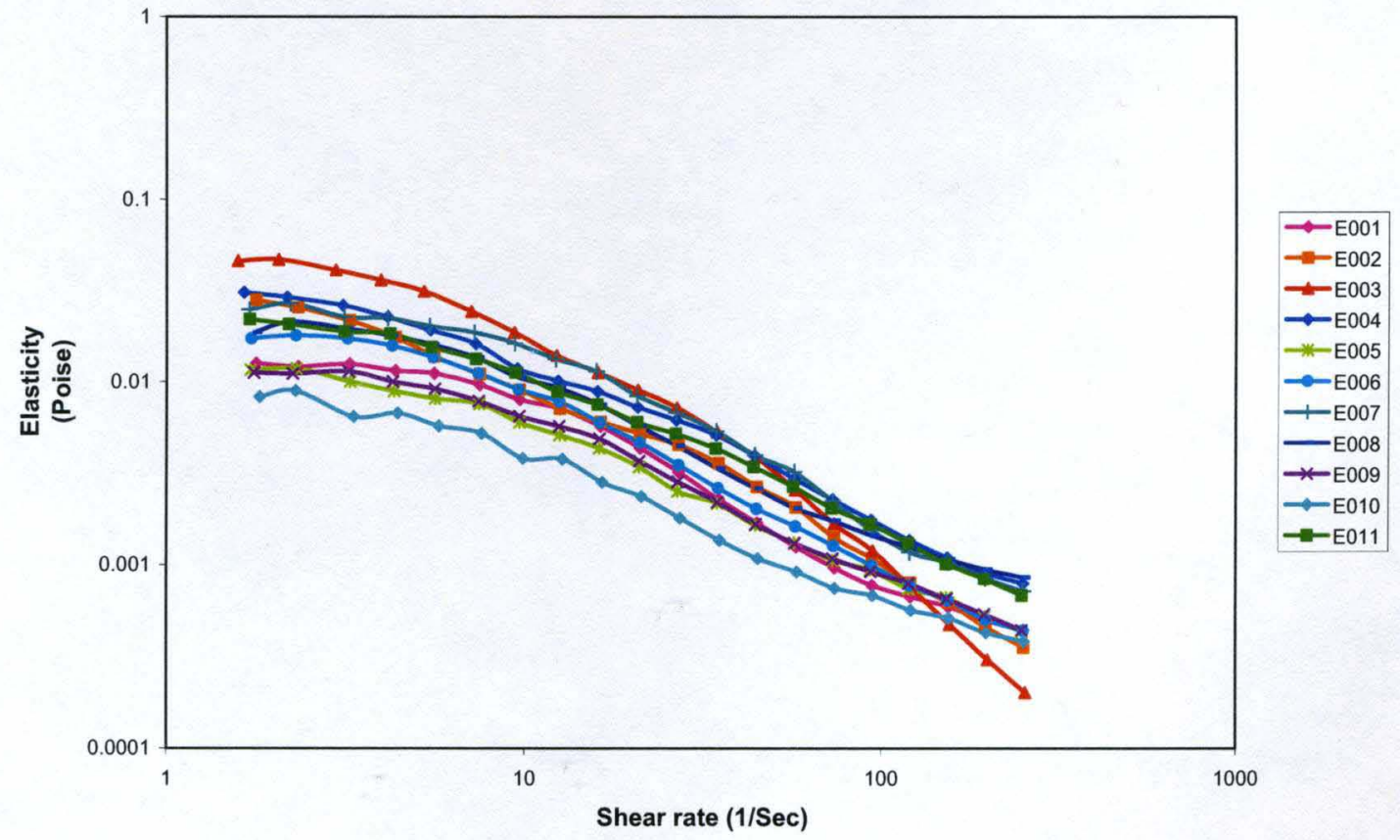

Figure 37. Elasticity vs. shear rate for all samples. 
The next two charts (Figures 38 and 39) show mean viscoelasticity versus shear rate and strain, with the calculated standard deviation at each point being shown in the form of error bars. The variation was larger for lower shear rate and strain and lower for increasing shear rate and increasing strain.

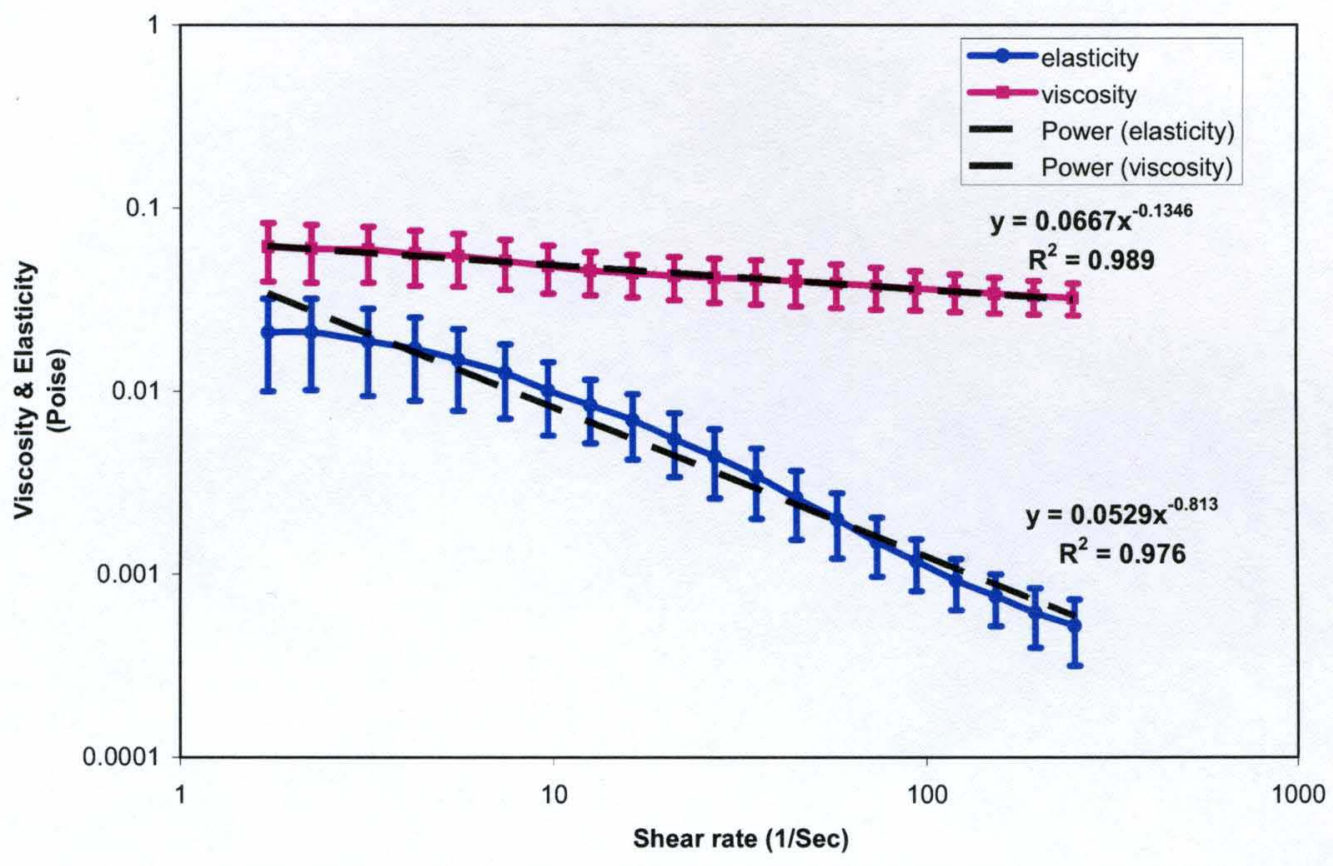

Figure 38 . Viscosity vs. shear rate with standard deviation error bars. 


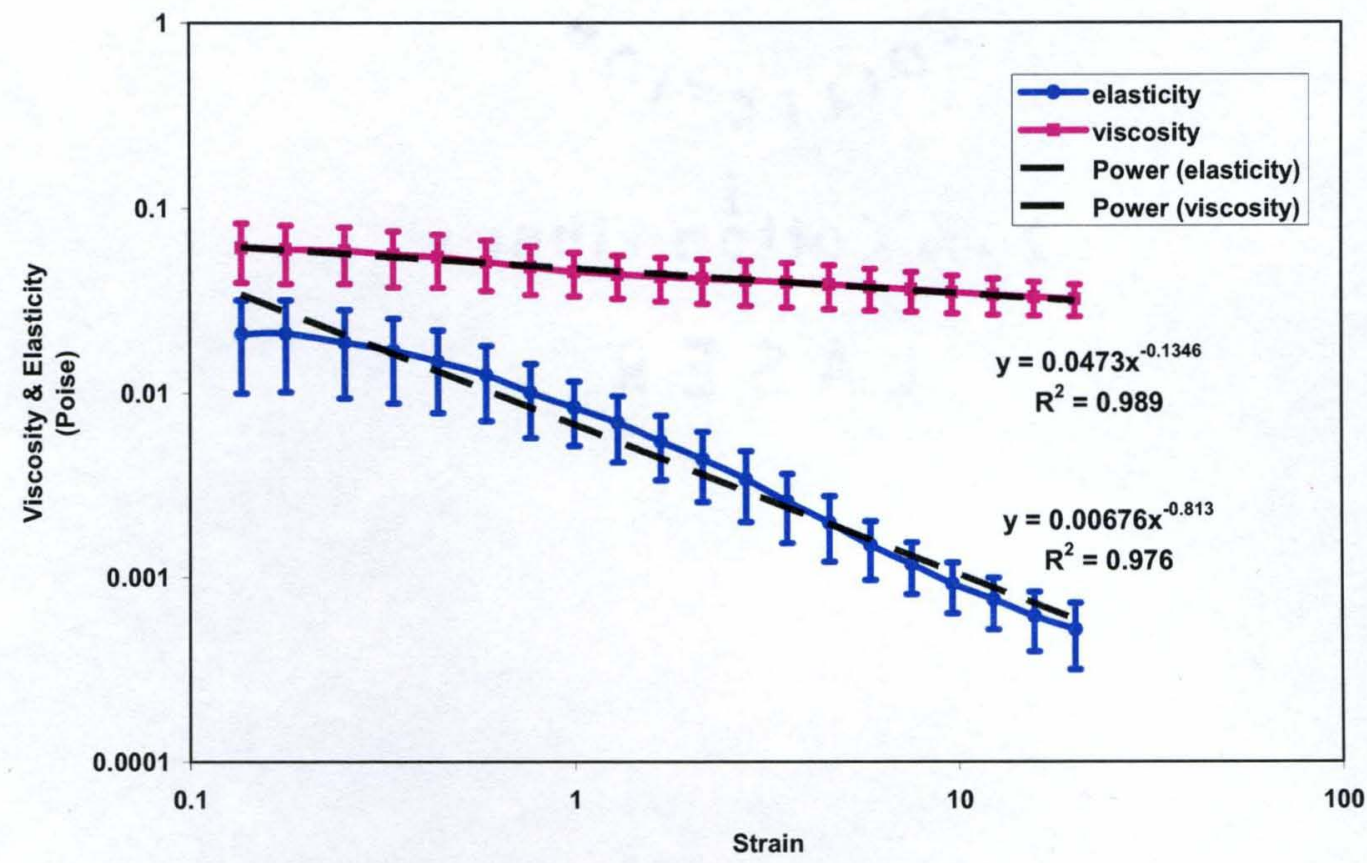

Figure 39. Viscosity vs. strain with standard deviation error bars.

The raw data was used to interpolate the viscosity and elasticity values corresponding to $0.2,1$ and 5 strains, since the data points do not fall exactly on these strain values. The interpolated data is logged in Table 4 . 


\begin{tabular}{|c|c|c|c|c|c|c|}
\hline & \multicolumn{3}{|c|}{ Viscosity (Poise) } & \multicolumn{3}{c|}{ Elasticity (Poise) } \\
\hline Patient & $\mathbf{0 . 2}$ strain & 1 strain & 5 strain & 0.2 strain & 1 strain & 5 strain \\
\hline KCH2006-001 & 0.0446 & 0.0392 & 0.0323 & 0.01218 & 0.00716 & 0.001163 \\
\hline KCH2006-002 & 0.0722 & 0.0508 & 0.0452 & 0.0240 & 0.00713 & 0.001833 \\
\hline KCH2006-003 & 0.1092 & 0.0733 & 0.0617 & 0.0437 & 0.01376 & 0.00229 \\
\hline KCH2006-004 & 0.0735 & 0.0540 & 0.0462 & 0.0279 & 0.01007 & 0.00272 \\
\hline KCH2006-005 & 0.0428 & 0.0349 & 0.0302 & 0.01140 & 0.00511 & 0.001228 \\
\hline KCH2006-006 & 0.0554 & 0.0443 & 0.0370 & 0.01773 & 0.00780 & 0.001509 \\
\hline KCH2006-007 & 0.0647 & 0.0520 & 0.0407 & 0.0254 & 0.01317 & 0.00289 \\
\hline KCH2006-008 & 0.0568 & 0.0442 & 0.0359 & 0.0208 & 0.00923 & 0.001939 \\
\hline KCH2006-009 & 0.0443 & 0.0352 & 0.0294 & 0.01116 & 0.00572 & 0.001231 \\
\hline KCH2006-010 & 0.0353 & 0.0286 & 0.0255 & 0.00839 & 0.00385 & 0.000864 \\
\hline KCH2006-011 & 0.0576 & 0.0440 & 0.0378 & 0.01999 & 0.00875 & 0.00244 \\
\hline
\end{tabular}

Table 4. Interpolated viscosity and elasticity values for the pediatric blood at the strains of $0.2,1$ and 5 . 


\section{Comparison of Pediatric and Adult Blood}

Viscosity and elasticity of the individual pediatric samples are compared to adult values [Thurston 1996] at $37^{\circ} \mathrm{C}$ and with hematocrit of $47 \%$, in Figures 40 and 41. In Figure 40 , the viscosity of the adult falls within the range of the pediatric data. The adult elasticity (Figure 41) is slightly out of the range. The average pediatric viscosity and elasticity (for which the mean hematocrit is $39.6 \%$ ) is compared to the same adult values in Figures 42 and 43 along with the error bars for standard deviation. In these figures, it is evident that both pediatric viscosity and elasticity are lower than the adult values, except for elasticity at high shear, and both exhibit less strain thinning than do the adult curves.

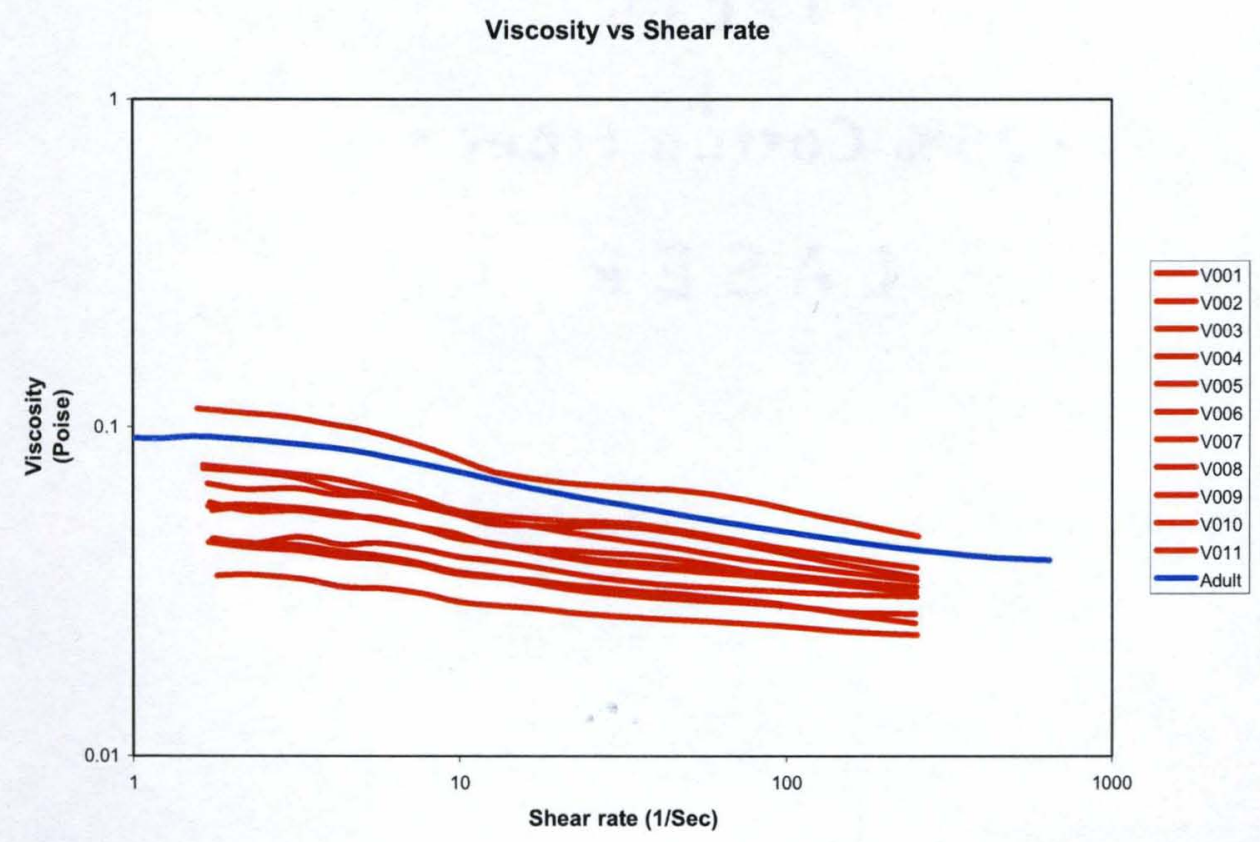

Figure 40. Viscosity versus shear rate of pediatric samples (red) compared to adult (blue). 


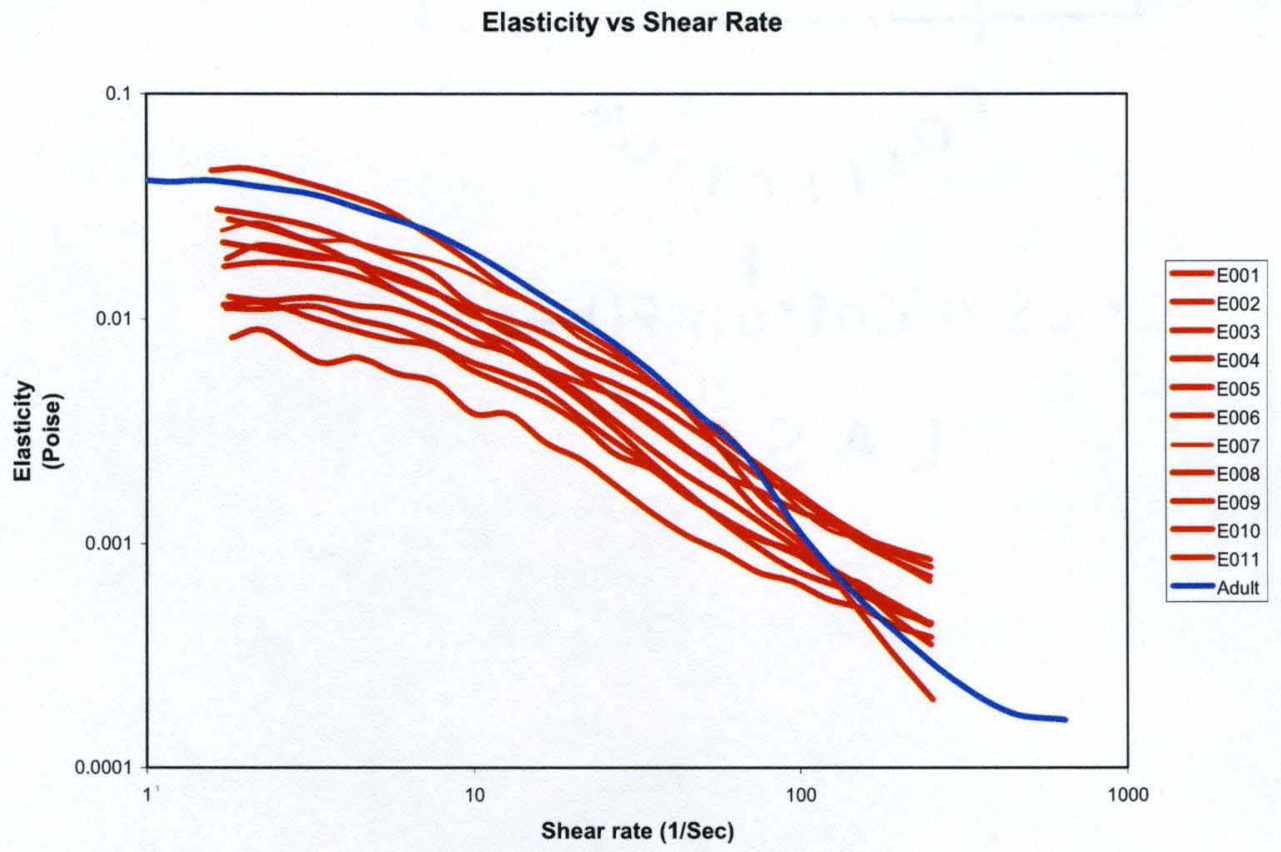

Figure 41. Elasticity versus shear rate of pediatric samples (red) compared to adult (blue).

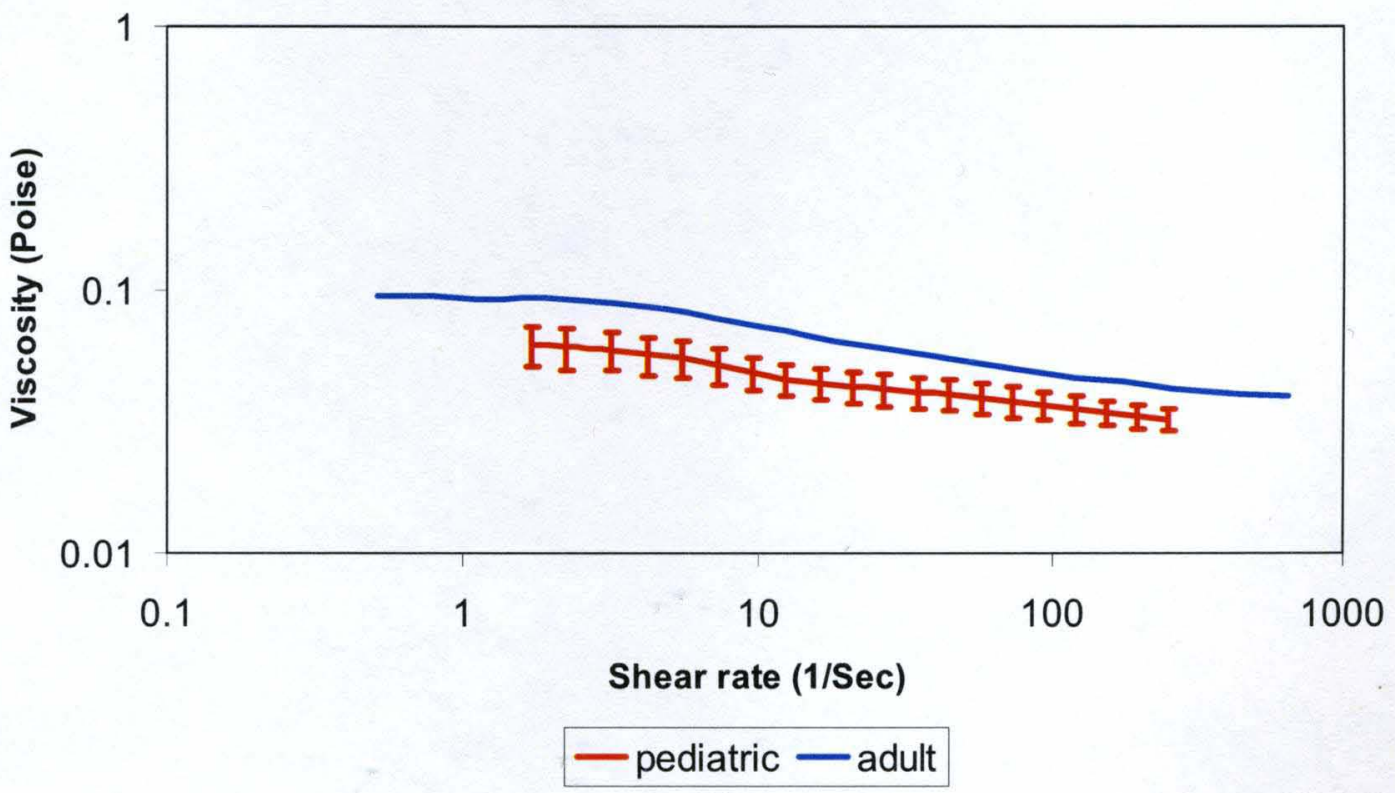

Figure 42. Average pediatric (mean hematocrit $39.6 \%$ ) vs. adult viscosity at $47 \%$ hematocrit. 


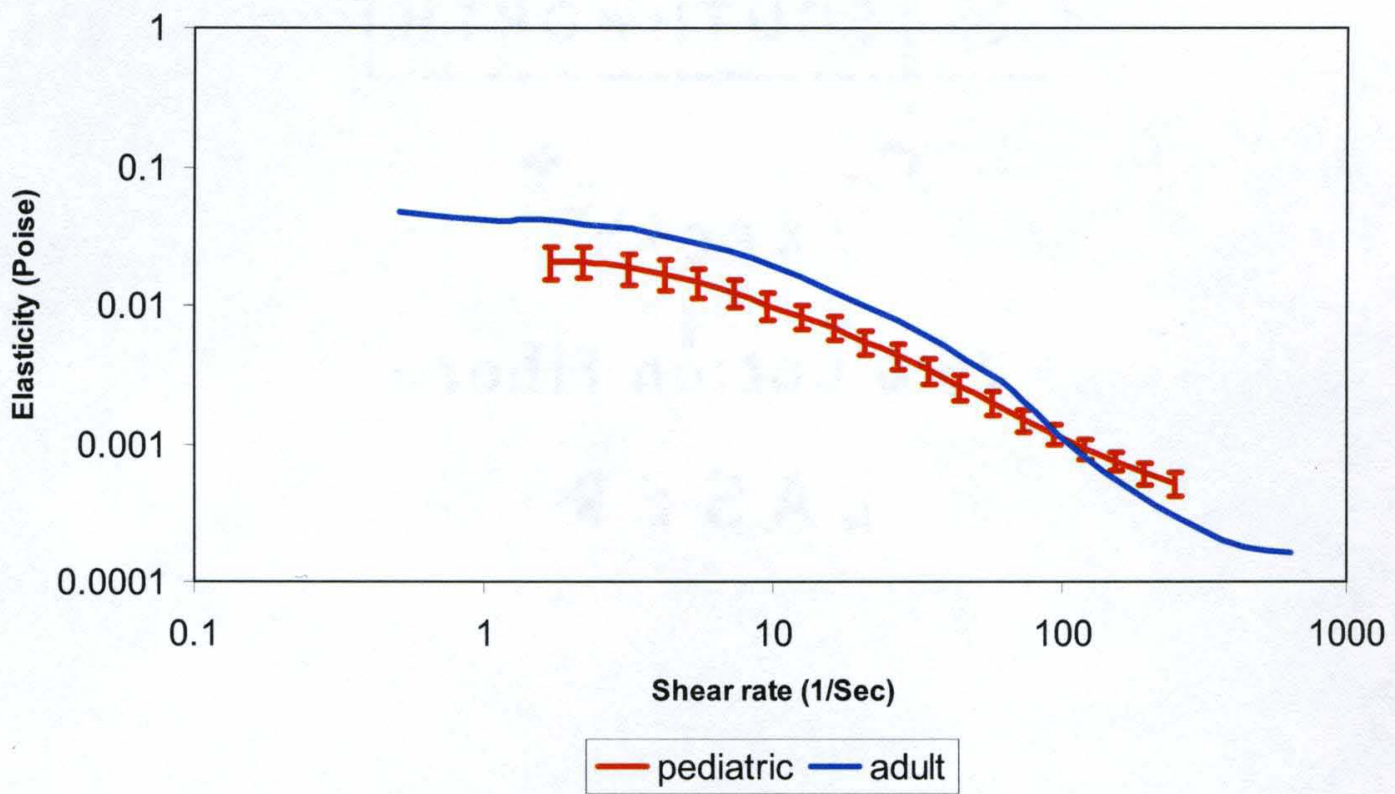

Figure 43. Average pediatric (mean hematocrit $39.6 \%$ ) vs. adult elasticity at $47 \%$ hematocrit.

Curve fits of viscosity and elasticity versus hematocrit at three strain levels, similar to Long, et al. [2005], were calculated for the new pediatric data (Table 5). The values for pediatric viscosity and elasticity at hematocrit of $47 \%$ calculated from these curve fits are compared to adult values [Thurston 1996] at the same hematocrit in Figures 44 and 45 . This comparison tries to neutralize the effect of hematocrit, which affects viscoelasticity. These figures show that both pediatric viscosity and elasticity are lower than adult values at the same hematocrit for all three strain levels. 


\begin{tabular}{|c|c|c|}
\hline STRAIN & VISCOSITY (Poise) & ELASTICITY (Poise) \\
\hline 0.2 & $\eta^{\prime}=0.000215 \mathrm{H}^{1.525}$ & $\eta^{\prime \prime}=0.00000246 \mathrm{H}^{2.44}$ \\
& $\mathrm{R}^{2}=0.797$ & $\mathrm{R}^{2}=0.849$ \\
\hline 1 & $\eta^{\prime}=0.000475 \mathrm{H}^{1.239}$ & $\eta^{\prime \prime}=0.00001040 \mathrm{H}^{1.810}$ \\
& $\mathrm{R}^{2}=0.803$ & $\mathrm{R}^{2}=0.749$ \\
\hline 5 & $\eta^{\prime}=0.000479 \mathrm{H}^{1.190}$ & $\eta^{\prime \prime}=0.000001221 \mathrm{H}^{2.40}$ \\
& $\mathrm{R}^{2}=0.790$ & $\mathrm{R}^{2}=0.853$ \\
\hline
\end{tabular}

Table 5. Power curve fits for viscoelasticity versus hematocrit for all pediatric data, where $\eta$ ' and $\eta$ " represent the viscosity and elasticity, respectively, and $\mathrm{H}$ denotes the hematocrit value.

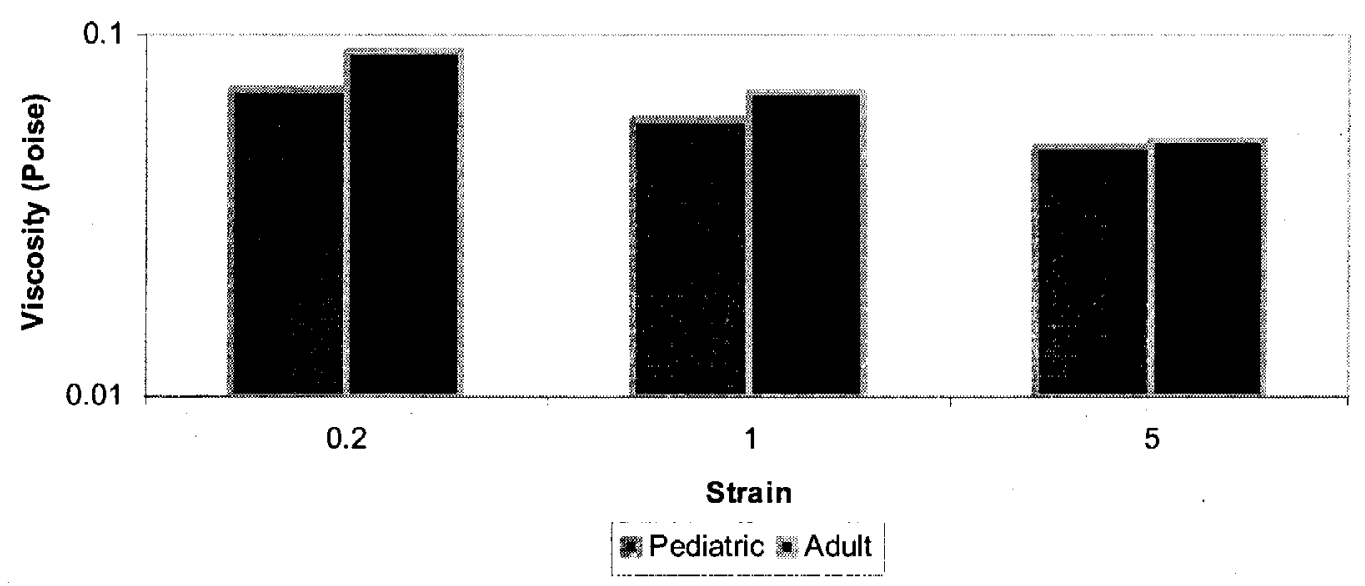

Figure 44 . Viscosity vs. strain at $47 \%$ hematocrit. 


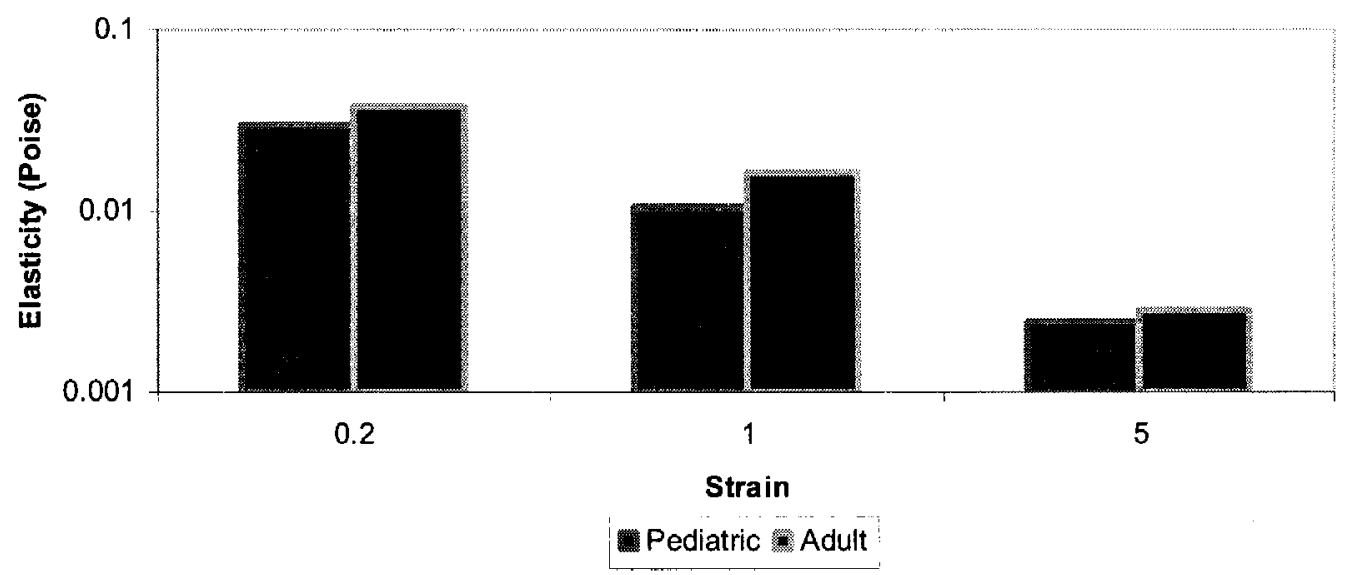

Figure 45 . Elasticity vs. strain at $47 \%$ hematocrit.

The pediatric data was also compared with the adult data from Kaber, et al. [1988]. To reduce variability, 22 data points ${ }^{4}$ were chosen from the paper's large set of 113 patients and plotted in the Figure 46. The data was chosen such that it encompassed as many hematocrit points from the range of our pediatric data as possible. This data was measured at a single shear rate of $10 \mathrm{~s}^{-1}$ and a temperature of $37^{\circ} \mathrm{C}$, and hematocrit ranged from $35 \%$ to $52 \%$.

\footnotetext{
${ }^{4}$ The dataset was established by selecting all data points at selected hematocrit values.
} 


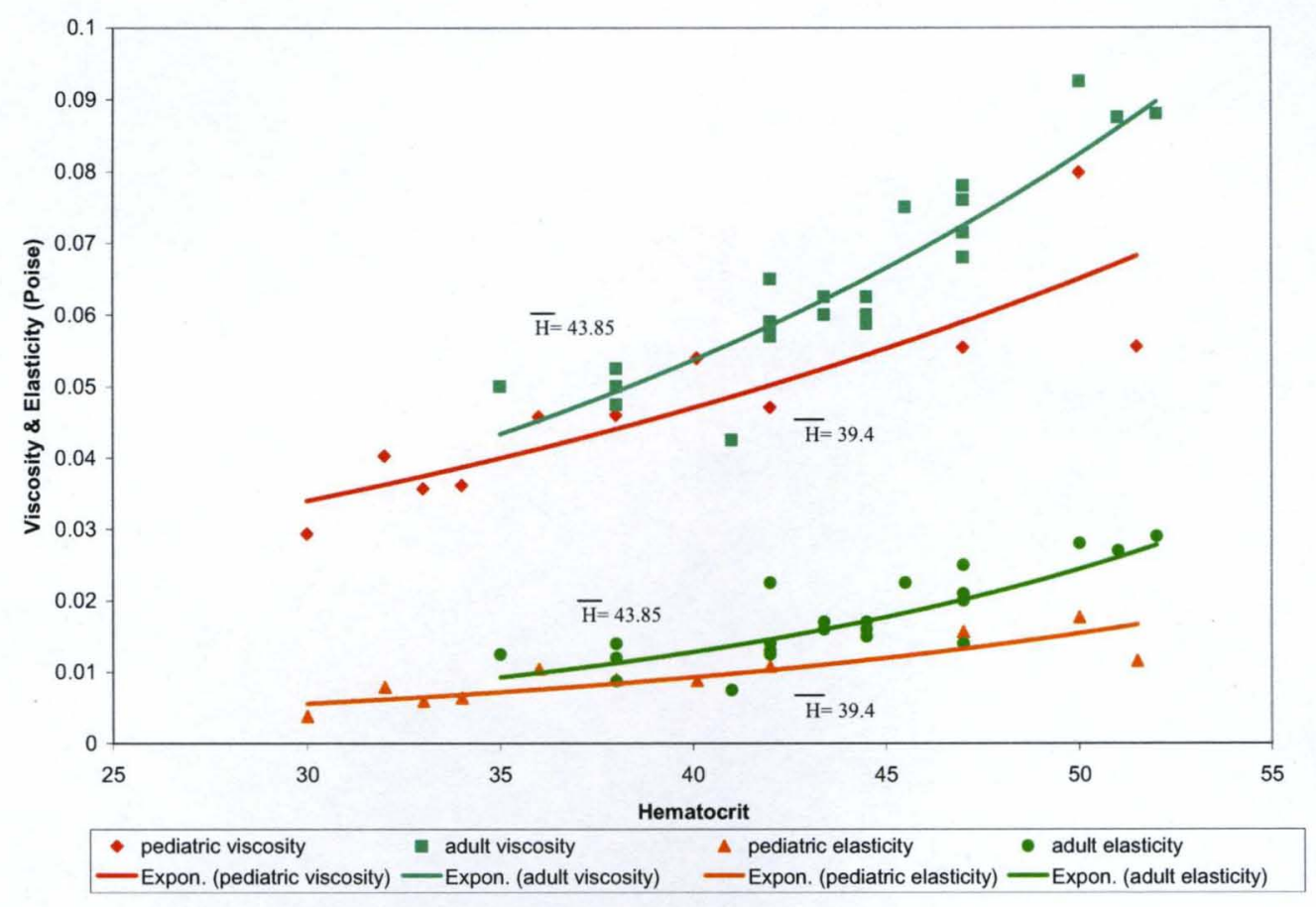

Figure 46. Comparison of pediatric viscoelasticity with adult values [Kaber et al. 1988] at shear rate of $10 \mathrm{~s}^{-1}$.

The visual differences observed in the data were quantified through statistical analysis tools. A two-way ANOVA analysis was performed on the pediatric and adult viscosity and elasticity [Kaber, et al. 1988] at the shear rate of $10 \mathrm{~s}^{-1}$. A subset of the Kaber, et al. data, as shown in Table 6, was taken for the comparison. The data points were narrowed down from the initial 22 points by choosing points with the same hematocrit as the pediatric samples since we already know that hematocrit affects the viscoelasticity of blood [Kaber 1988, Thurston 1989]. Hematocrit values with multiple viscoelasticity readings were averaged. At hematocrits that did not have the raw data 
necessary, we used the regression equations in the Kaber, et al. paper to calculate the values $(H=40.5$ and $H=51.5)$. These regression equations were,

For female, $\quad \eta^{\prime}=1.495^{*} \mathrm{e}^{0.032 \mathrm{PCV}}$

$\eta^{\prime \prime}=0.165^{*} \mathrm{e}^{0.052 \mathrm{PCV}}$

For male, $\quad \begin{array}{ll}\eta^{\prime}=0.924 * \mathrm{e}^{0.044 P C V} \\ \eta^{\prime}=0.068 * \mathrm{e}^{0.073 P C V}\end{array}$

Where, $\eta^{\prime}$ is the viscosity in mPa.s, $\eta$ ' is the elasticity in mPa.s and PCV is the packed cell volume.

The raw data is displayed below in Table 6 . The data is then averaged for each hematocrit value and, with the additional calculated viscoelasticity values at hematocrit of 40.5 and 51.5, presented in Table 7. 


\begin{tabular}{|r|r|r|}
\hline Hematocrit & \multicolumn{1}{l|}{ Viscosity } & \multicolumn{1}{l|}{ llasticity } \\
\hline & \multicolumn{1}{l|}{ Poise } & \multicolumn{1}{l|}{ Poise } \\
\hline 35 & 0.0500 & 0.01250 \\
\hline 38 & 0.0500 & 0.01200 \\
\hline 38 & 0.0525 & 0.01400 \\
\hline 38 & 0.0475 & 0.00880 \\
\hline 41 & 0.0425 & 0.00750 \\
\hline 42 & 0.0570 & 0.0225 \\
\hline 42 & 0.0580 & 0.01400 \\
\hline 42 & 0.0590 & 0.01300 \\
\hline 42 & 0.0650 & 0.01250 \\
\hline 43.4 & 0.0600 & 0.01600 \\
\hline 43.4 & 0.0625 & 0.01700 \\
\hline 44.5 & 0.0625 & 0.01500 \\
\hline 44.5 & 0.0600 & 0.01700 \\
\hline 44.5 & 0.0588 & 0.01600 \\
\hline 45.5 & 0.0750 & 0.0225 \\
\hline 47 & 0.0780 & 0.0250 \\
\hline 47 & 0.0760 & 0.0210 \\
\hline 47 & 0.0715 & 0.0200 \\
\hline 47 & 0.0680 & 0.01400 \\
\hline 50 & 0.0925 & 0.0280 \\
\hline 51 & 0.0875 & 0.0270 \\
\hline 52 & 0.0880 & 0.0290 \\
\hline
\end{tabular}

Table 6. Viscoelastic adult data at shear rate of $10 \mathrm{~s}^{-1}$ [Kaber, et al.1988]. 


\begin{tabular}{|c|c|c|}
\hline $\begin{array}{c}\text { Hematocrit } \\
(\%)\end{array}$ & $\begin{array}{c}\text { Viscosity } \\
\text { (Poise) }\end{array}$ & $\begin{array}{c}\text { Elasticity } \\
\text { (Poise) }\end{array}$ \\
\hline 38 & 0.0500 & 0.01158 \\
\hline 40.1 & 0.0539 & 0.01299 \\
\hline 42 & 0.0598 & 0.01550 \\
\hline 47 & 0.0734 & 0.0200 \\
\hline 50 & 0.0925 & 0.0280 \\
\hline 51.5 & 0.0834 & 0.0266 \\
\hline
\end{tabular}

Table 7. Averaged viscoelastic adult data at shear rate of $10 \mathrm{~s}^{-1}$ for analysis [Kaber, et al.1988].

This way of choosing the points should isolate the effect of age more effectively. The pediatric and adult data were compared using two-way ANOVA analysis with hematocrit and age group (adult or pediatric) being the two factors and the dependent variable being viscosity or elasticity. A p-value of less than 0.05 is considered significant. The results are tabulated below in Table 8 and plotted in Figures 47 and 48 . The p-value is significant for both viscosity and elasticity comparisons for the 'age' factor. For hematocrit the effect is significant for viscosity and insignificant for elasticity values. But the $\mathrm{p}$-value for this insignificance is close to $0.05(\mathrm{p}=0.0652)$.

\begin{tabular}{|c|c|c|}
\hline Factor & VISCOSITY & ELASTICITY \\
\hline Age & $p=0.0273$ & $p=0.01697$ \\
\hline Hematocrit & $p=0.0201$ & $p=0.0652$ \\
\hline
\end{tabular}

Table 8. Two-way ANOVA results for pediatric and adult blood result comparison at shear rate of $10 \mathrm{~s}^{-1}$. 


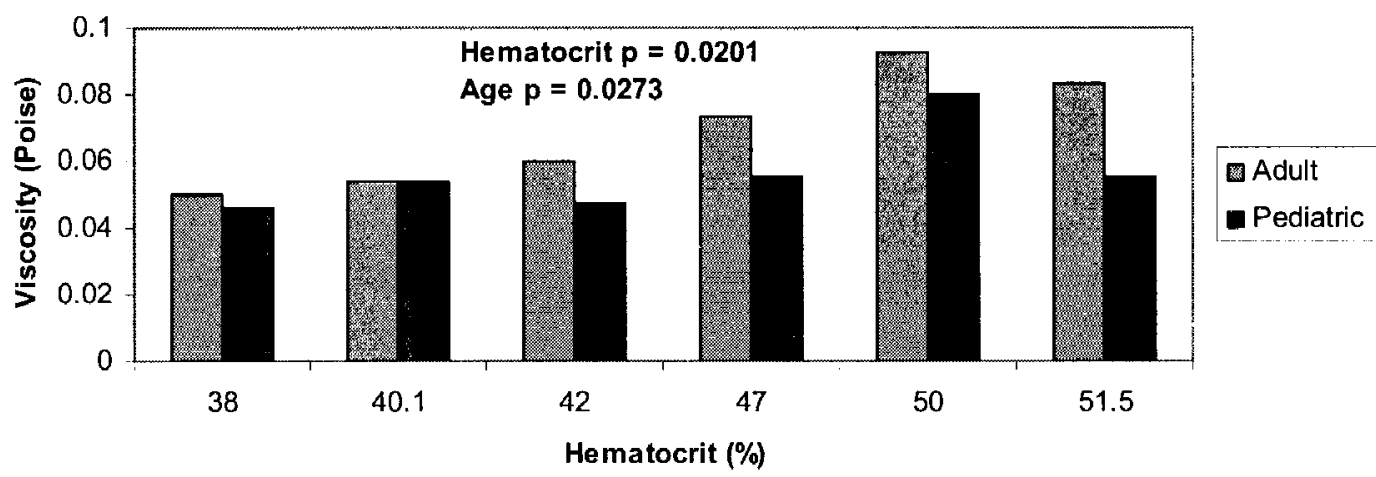

Figure 47. Adult and pediatric viscosity vs. hematocrit showing the p-values from the 2 way ANOVA analysis.

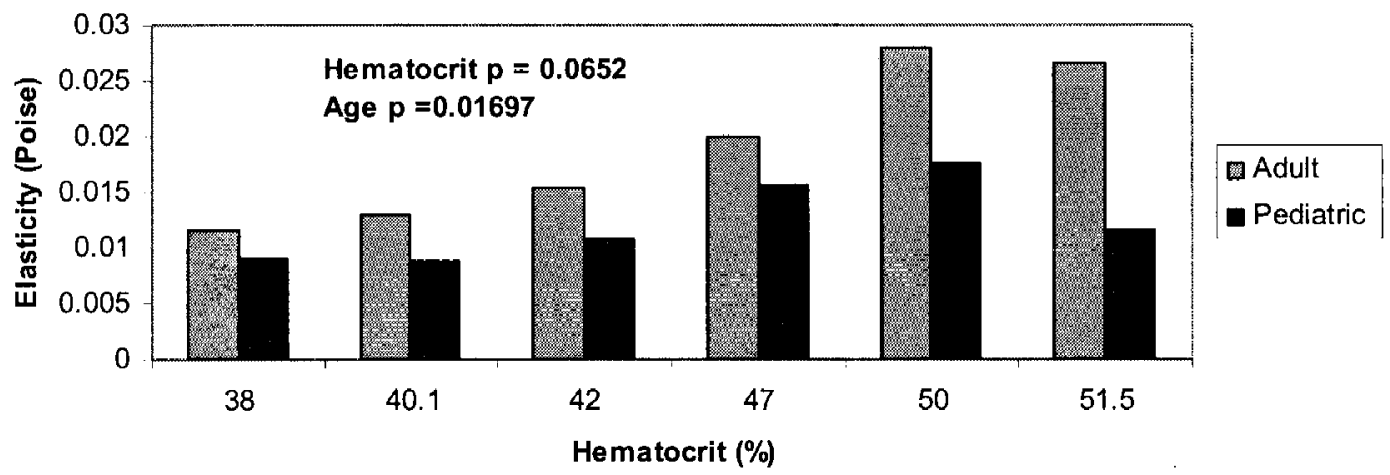

Figure 48. Adult and pediatric elasticity vs. hematocrit showing the p-values from the 2 way ANOVA analysis. 
For comparison, the regression equations over the hematocrit range of the measured pediatric blood are shown in Table 9 along with adult regression equations [Thurston, 2004] over a hematocrit range. The regression equations for the pediatric blood follow the same convention as regression equations for pediatric blood in the Penn State paper [Long, et al. 2005].

\begin{tabular}{|c|c|c|c|c|}
\hline Strain & Pedi: & $\begin{array}{l}\text { Blood } \\
\text { s] } \\
515\end{array}$ & $\begin{array}{l}\text { Adult Blood } \\
\begin{array}{c}{[\mathrm{mPa} . \mathrm{s}]} \\
\mathrm{H}=0.15-0.50\end{array}\end{array}$ & \\
\hline 0.2 & $\begin{aligned} \eta^{\prime} & =25.0 \mathrm{H}^{1.553} \\
\eta^{\prime \prime} & =18.22 \mathrm{H}^{2.44}\end{aligned}$ & $\begin{array}{l}\mathrm{R}^{2}=0.811 \\
\mathrm{R}^{2}=0.849\end{array}$ & $\begin{array}{c}\eta^{\prime}=0.3+25.47 \mathrm{H}^{1.252} \\
\eta^{\prime \prime}=34.84 \mathrm{H}^{2.6013} \\
\eta^{\prime \prime}=15.9 \mathrm{H}^{1.997}\end{array}$ & $\begin{array}{l}H=0.15-0.50 \\
H=0.15-0.28 \\
H=0.29-0.50\end{array}$ \\
\hline 1 & $\begin{array}{l}\eta^{\prime}=14.26 \mathrm{H}^{1.239} \\
\eta^{\prime \prime}=4.33 \mathrm{H}^{1.820}\end{array}$ & $\begin{array}{l}R^{2}=0.803 \\
R^{2}=0.749\end{array}$ & $\begin{array}{c}\eta^{\prime}=1.27+21.3 \mathrm{H}^{1.4796} \\
\eta^{\prime \prime}=14.75 \mathrm{H}^{2.4693} \\
\eta^{\prime \prime}=5.39 \mathrm{H}^{1.579}\end{array}$ & $\begin{array}{l}H=0.15-0.50 \\
H=0.15-0.30 \\
H=0.31-0.50\end{array}$ \\
\hline 5 & $\begin{array}{l}\eta^{\prime}=11.498 \mathrm{H}^{1.190} \\
\eta^{\prime \prime}=1.112 \mathrm{H}^{1.980}\end{array}$ & $\begin{array}{l}\mathrm{R}^{2}=0.790 \\
\mathrm{R}^{2}=0.853\end{array}$ & $\begin{array}{c}\eta^{\prime}=1.73+17.1 \mathrm{H}^{1.709} \\
\eta^{\prime \prime}=0.399 \mathrm{H}^{1.3328} \\
\eta^{\prime \prime}=9.98 \mathrm{H}^{20662}\end{array}$ & $\begin{array}{l}H=0.15-0.50 \\
H=0.15-0.29 \\
H=0.30-0.50\end{array}$ \\
\hline
\end{tabular}

Table 9. Regression equations for pediatric and adult blood across the hematocrit range. 


\section{Comparison of Pediatric Data at $22^{\circ} \mathrm{C}$ and $37^{\circ} \mathrm{C}$}

The new measurements of pediatric viscosity and elasticity at $37^{\circ} \mathrm{C}$ are compared to those at $22^{\circ} \mathrm{C}$ [Long, et al. 2005] in Figures 49 and 50. The viscosity values were similar at $22^{\circ} \mathrm{C}$ and $37^{\circ} \mathrm{C}$ for low shear, but for high shear, the viscosity at $22^{\circ} \mathrm{C}$ was slightly higher than at $37^{\circ} \mathrm{C}$. The elasticity at $37^{\circ} \mathrm{C}$ was higher than at $22^{\circ} \mathrm{C}$ at lower shear, but matches at high shear.

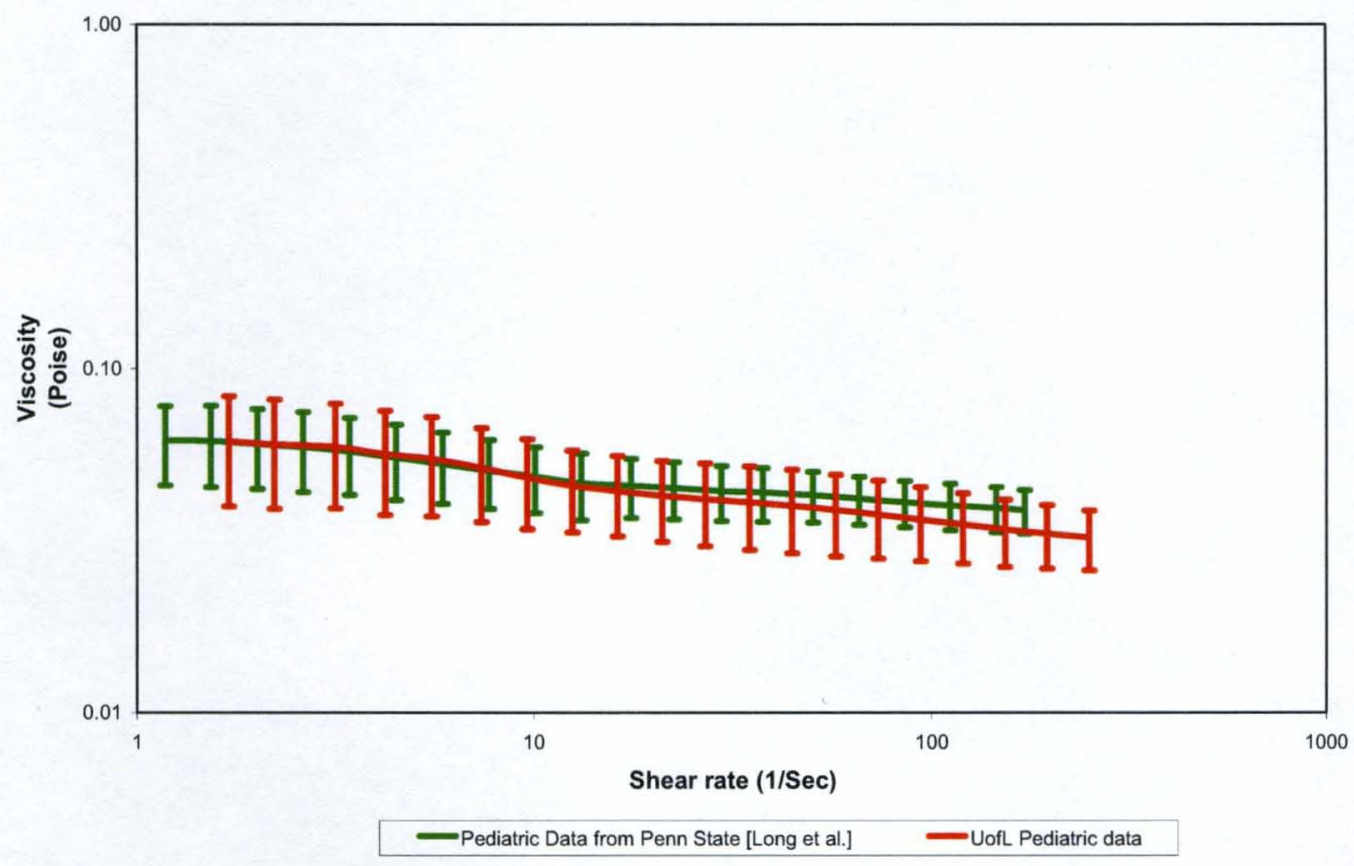

Figure 49. Average viscosity vs. shear rate for pediatric data at $22^{\circ} \mathrm{C}$ and $37^{\circ} \mathrm{C}$ with standard deviation. 


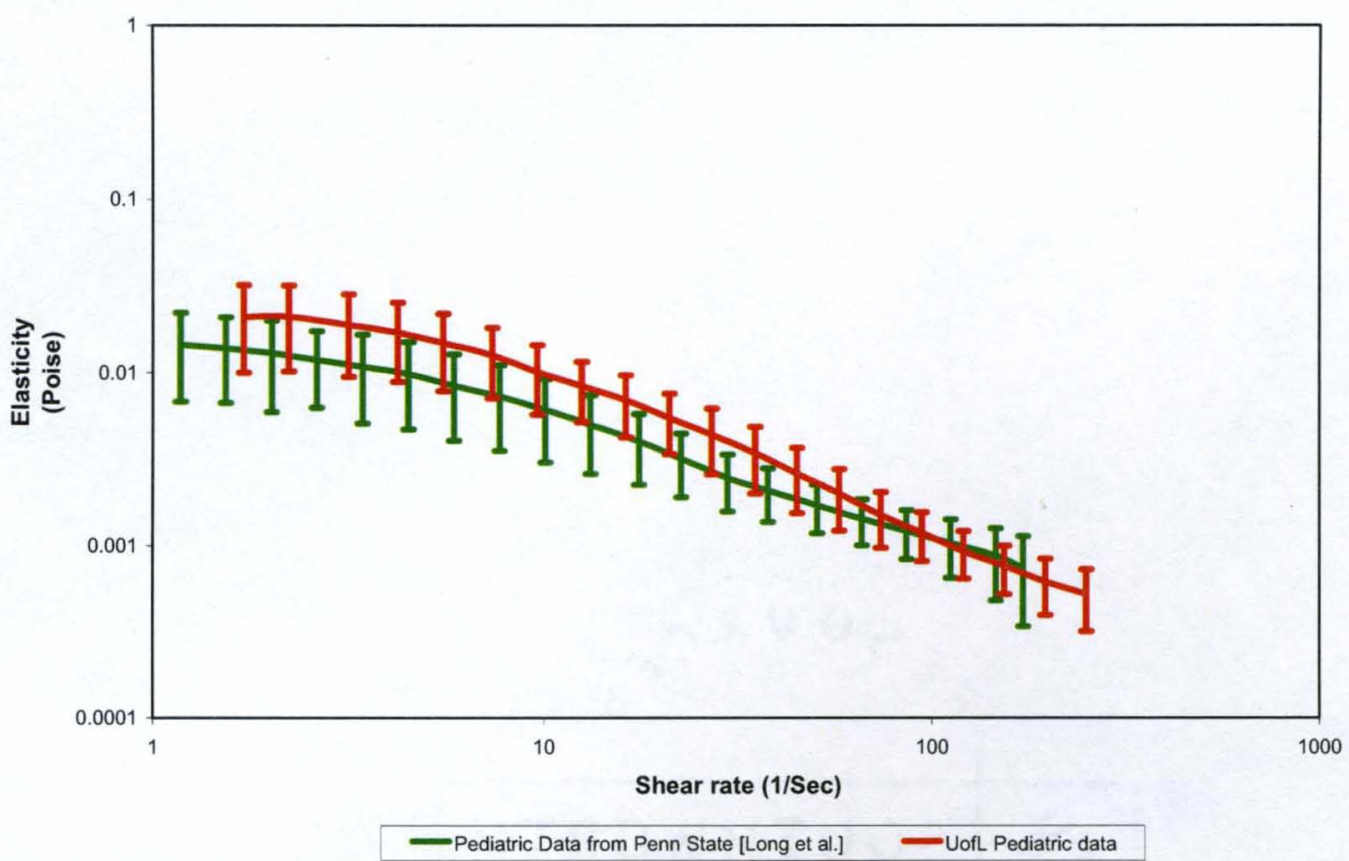

Figure 50. Average elasticity vs. shear rate for pediatric data measured at $22^{\circ} \mathrm{C}$ and $37^{\circ} \mathrm{C}$ with standard deviation.

The comparisons in Figures 49 and 50 are complicated, however, by the fact that the average hematocrit of the samples at $37^{\circ} \mathrm{C}$ is $39.4 \%$ and that of the samples at $22^{\circ} \mathrm{C}$ is $33.3 \%$. Also, the average age of the Penn State data is higher than that of the subjects in the UofL study as shown in Figure 51. Therefore, two-way ANOVA analysis was performed to compare viscosity and elasticity between these two data sets at strains of $0.2,1$ and 5 , where paired samples were chosen with identical hematocrit. This comparison separated the effects of hematocrit and temperature, but still left differences in age between the paired samples (Table 10). P-values are listed in Table 11. Viscosity values are plotted in Figures 52, 53 and 54 for strains of $0.2,1$ and 5, respectively, and elasticity values in Figures 55, 56 and 57. The ANOVA p-values were consistently lower than 0.05 for the temperature factor for viscosity and elasticity. This indicates that the viscoelasticity values are significantly different between the measurements made at $37^{\circ} \mathrm{C}$ 
and those at $22^{\circ} \mathrm{C}$. The p-values for hematocrit comparisons are shown to be insignificant.

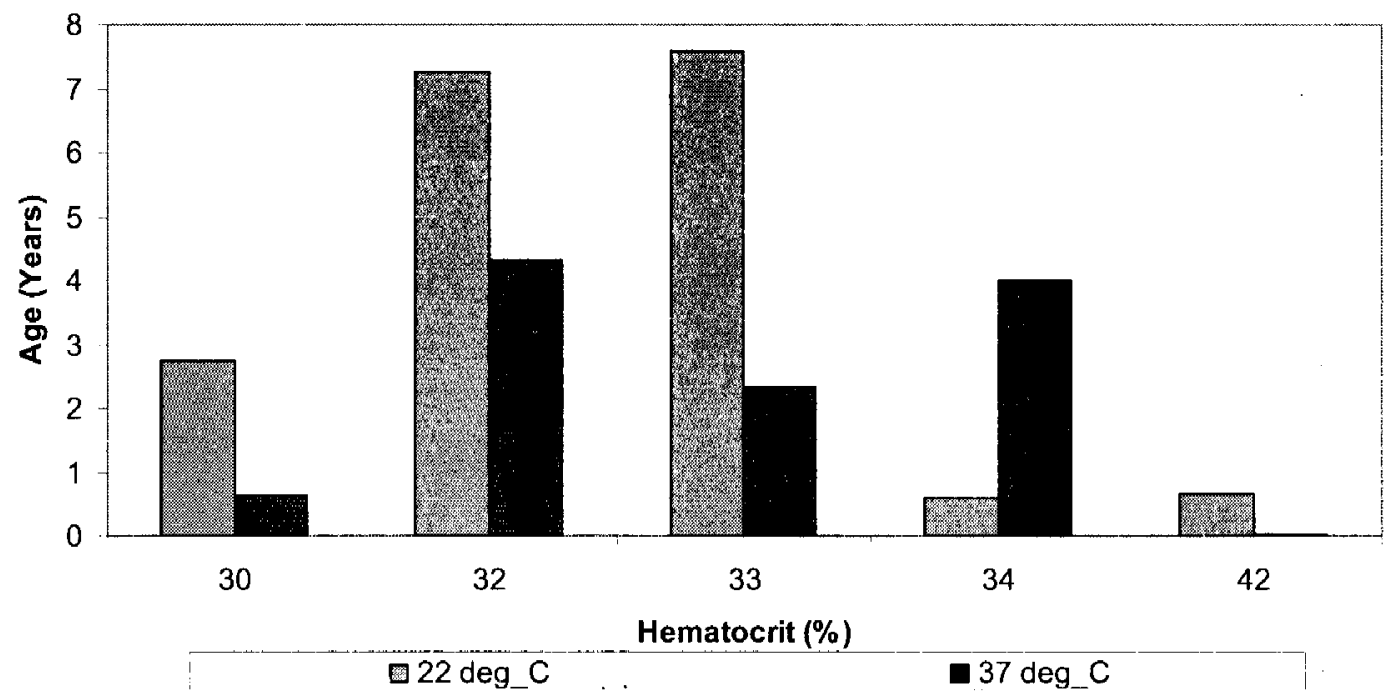

Figure 51. Age vs. hematocrit for the Penn State and UofL patients. (The patient with hematocrit of $42 \%$ measured at $37 \mathrm{C}$ was only 11 days old, so does not show well on this graph.)

\begin{tabular}{|c|c|c|}
\hline Hematocrit (\%) & $\begin{array}{c}\text { Age } \\
\text { (years) } \\
\text { [Penn State] }\end{array}$ & $\begin{array}{c}\text { Age } \\
\text { (years) } \\
\text { [UofL] }\end{array}$ \\
\hline 30 & 2.75 & 0.625 \\
\hline 32 & 7.25 & 4.33 \\
\hline 33 & 7.58 & 2.33 \\
\hline 34 & 0.583 & 4.00 \\
\hline 42 & 0.667 & 0.0301 \\
\hline
\end{tabular}

Table 10. Comparison of age of Penn State vs. UofL paired samples at the same hematocrit. 


\begin{tabular}{|c|c|c|c|c|}
\hline & \multicolumn{2}{|c|}{ VISCOSITY } & \multicolumn{2}{c|}{ ELASTICITY } \\
\hline STRAIN & Hematocrit & Temperature & Hematocrit & Temperature \\
\hline 0.2 & 0.0836 & 0.00667 & 0.237 & 0.0436 \\
\hline 1 & 0.1672 & 0.00438 & 0.355 & 0.0264 \\
\hline 5 & 0.1459 & 0.001970 & 0.375 & 0.00902 \\
\hline
\end{tabular}

Table 11. Two-way ANOVA p-values for pediatric data at $22^{\circ} \mathrm{C}$ [Long et al.] and $37^{\circ} \mathrm{C}$.

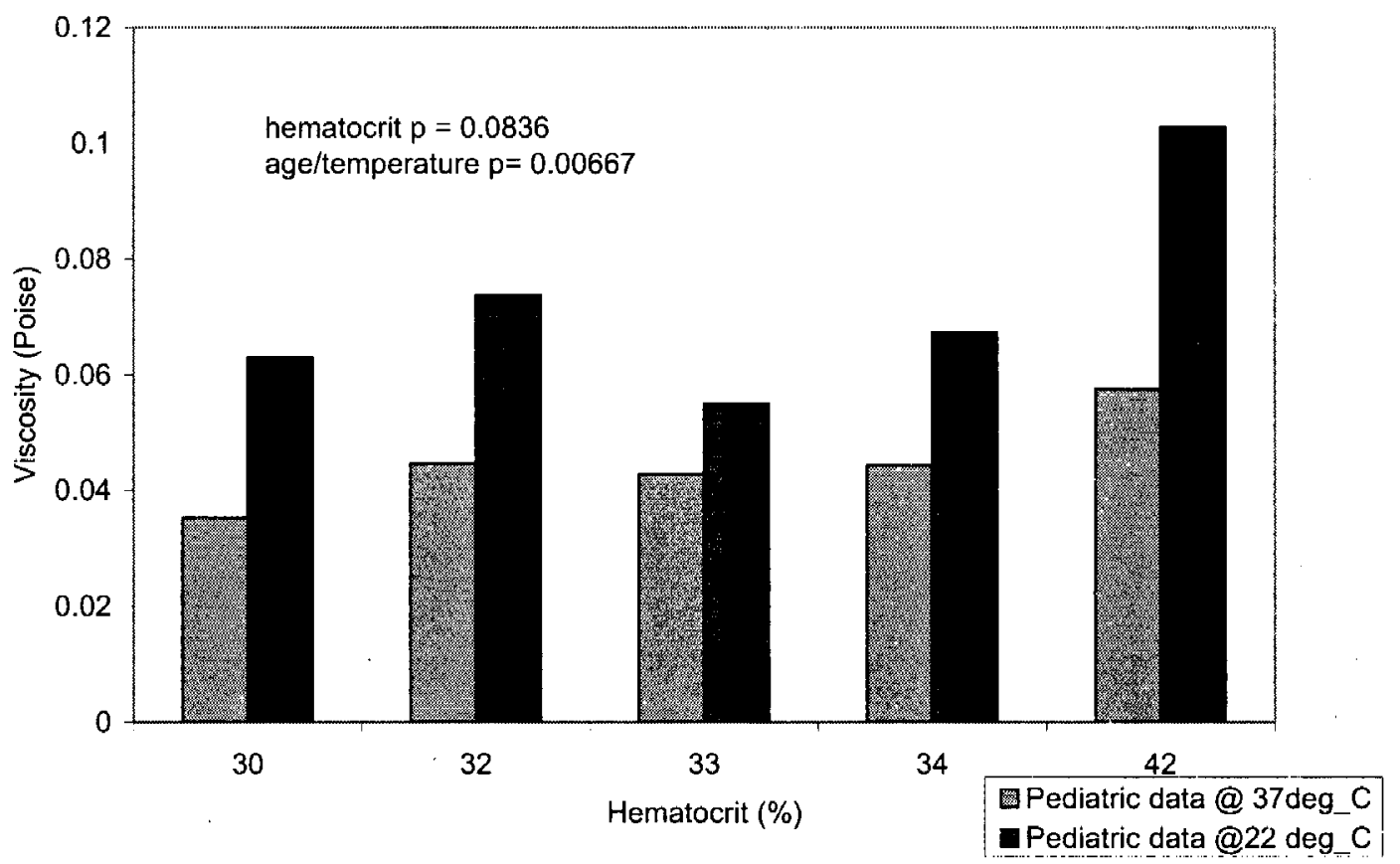

Figure 52. Pediatric viscosity vs. hematocrit (comparison at $22^{\circ} \mathrm{C}$ vs. $37^{\circ} \mathrm{C}$ ) showing the p- values from the 2-way ANOVA analysis at 0.2 strain. 


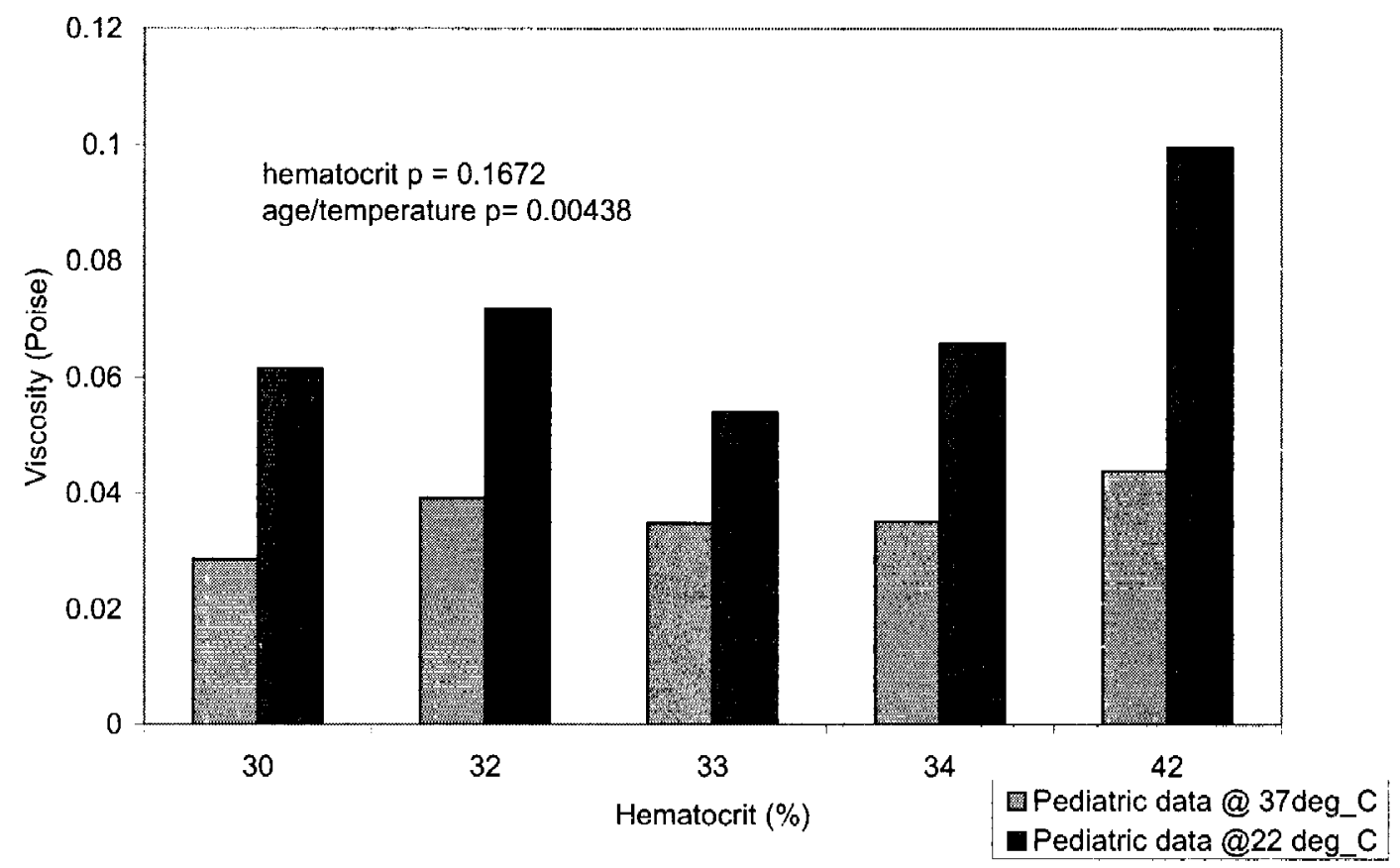

Figure 53. Pediatric viscosity vs. hematocrit (comparison at $22^{\circ} \mathrm{C}$ vs. $37^{\circ} \mathrm{C}$ ) showing the p-values from the 2-way ANOVA analysis at 1 strain.

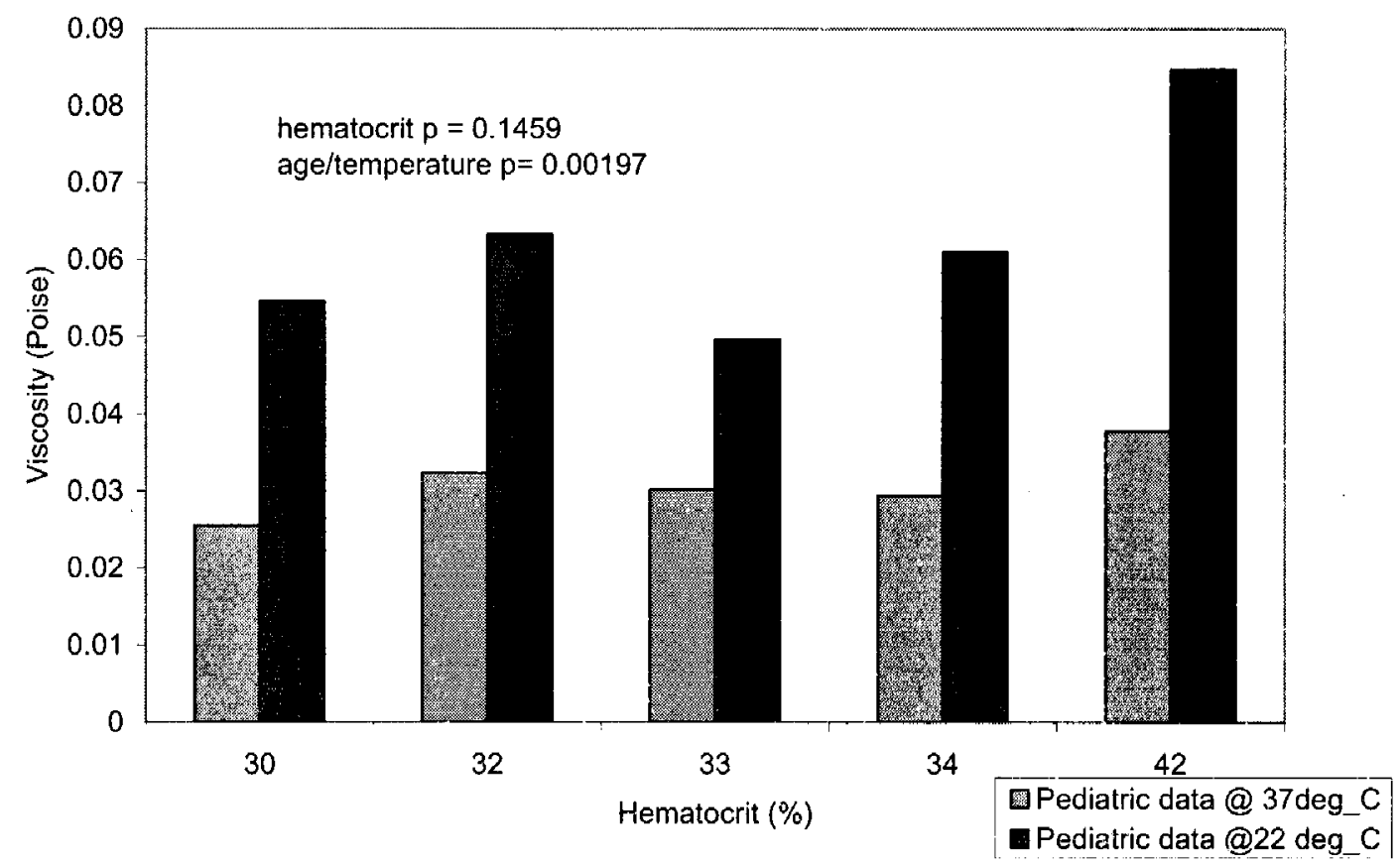

Figure 54. Pediatric viscosity vs. hematocrit (comparison at $22^{\circ} \mathrm{C}$ vs. $37^{\circ} \mathrm{C}$ ) showing the p-values from the 2-way ANOVA analysis at 5 strain. 


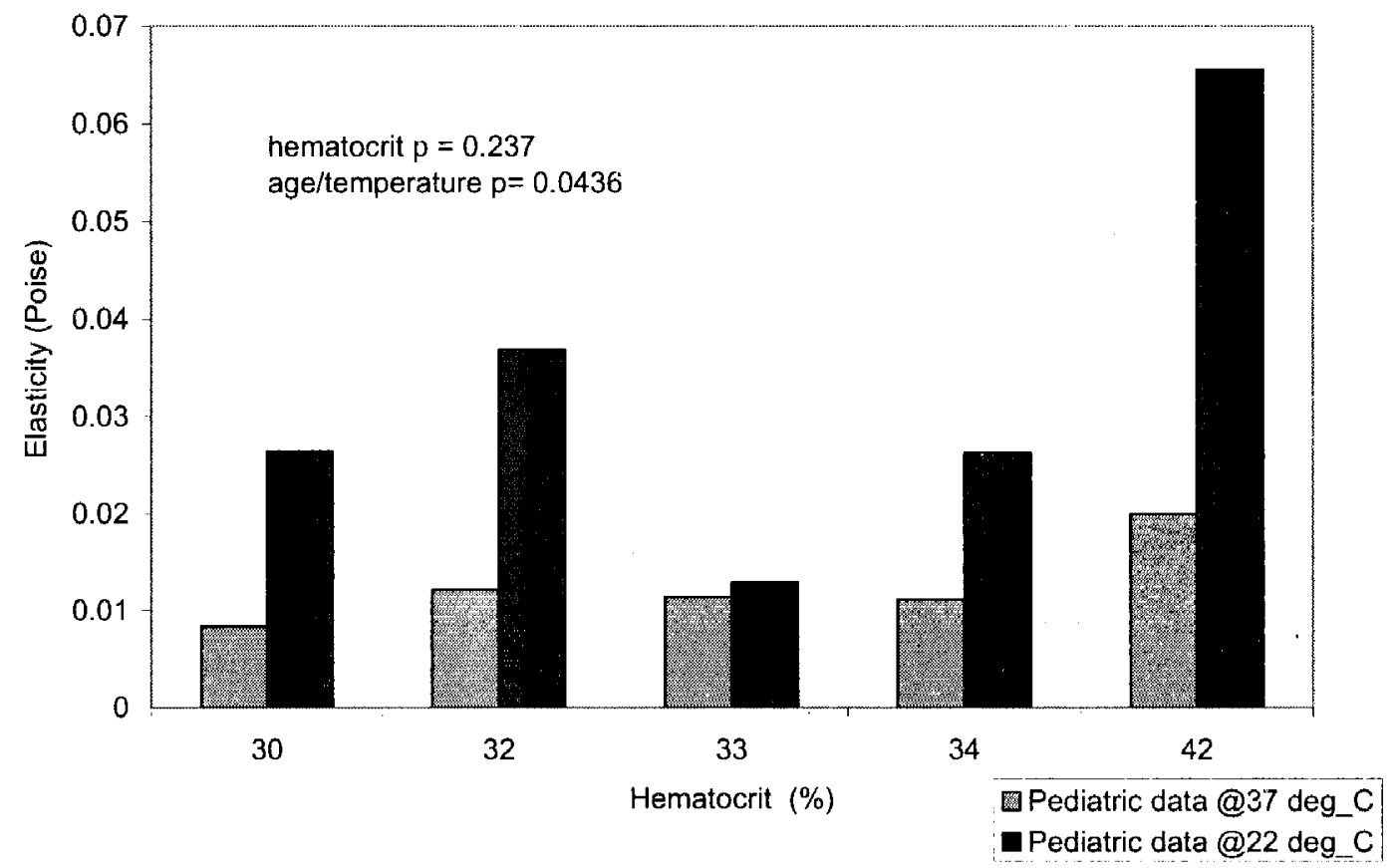

Figure 55. Pediatric elasticity vs. hematocrit (comparison at $22^{\circ} \mathrm{C}$ vs. $37^{\circ} \mathrm{C}$ ) showing the p-values from the 2-way ANOVA analysis at 0.2 strain.

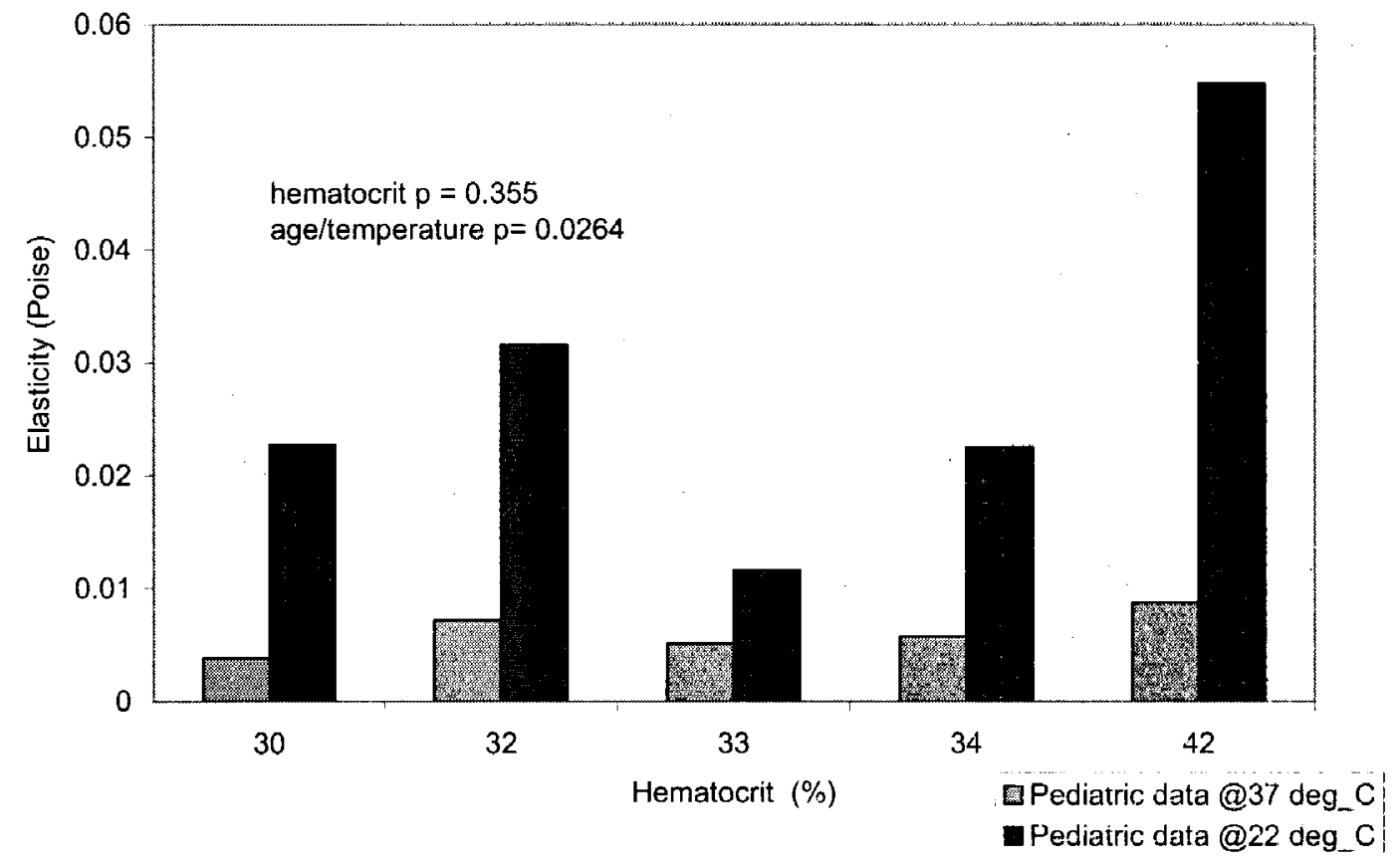

Figure 56. Pediatric elasticity vs. hematocrit (comparison at $22^{\circ} \mathrm{C}$ vs. $37^{\circ} \mathrm{C}$ ) showing the p-values from the 2-way ANOVA analysis at 1 strain. 


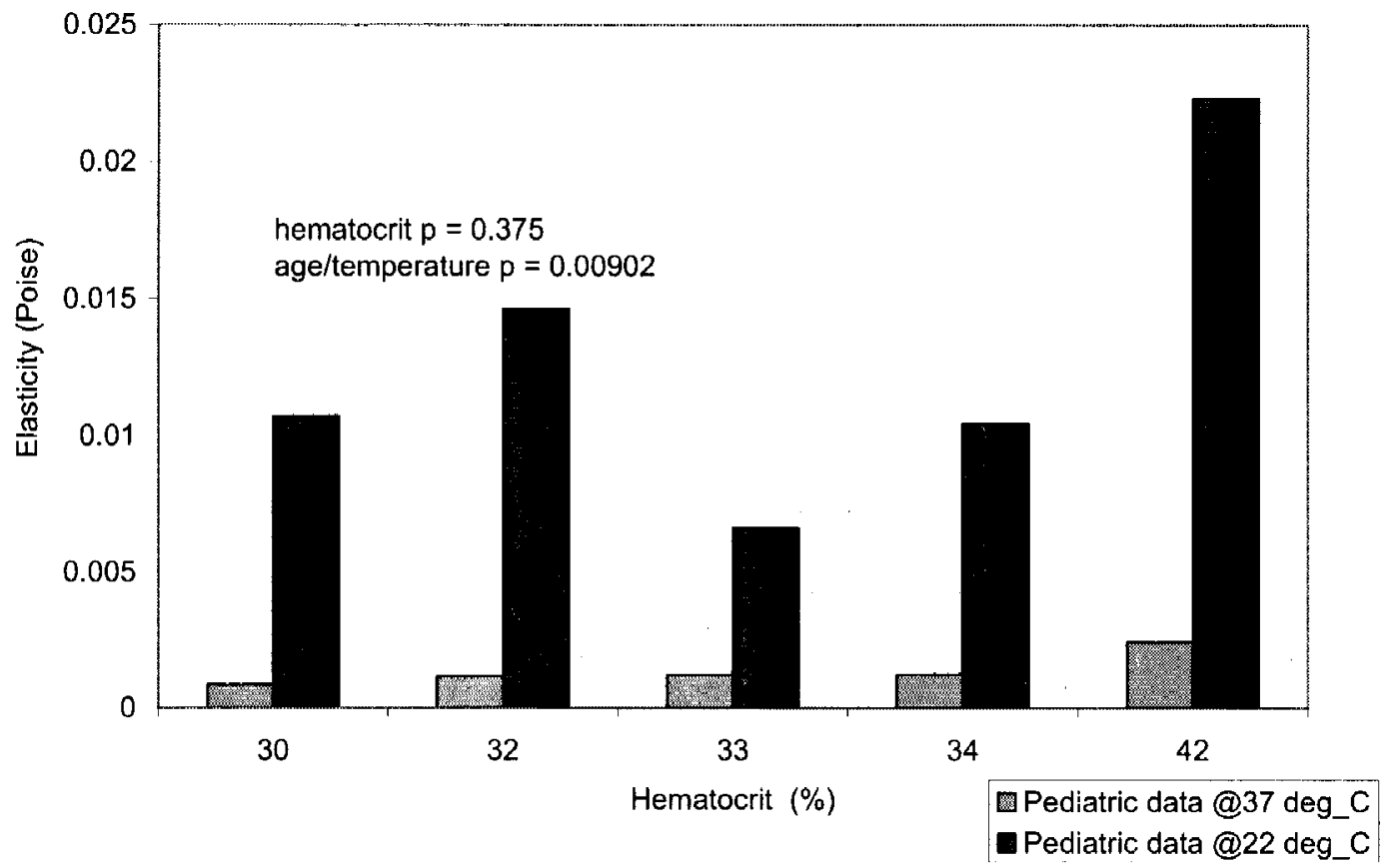

Figure 57. Pediatric elasticity vs. hematocrit (comparison at $22^{\circ} \mathrm{C}$ vs. $37^{\circ} \mathrm{C}$ ) showing the p-values from the 2-way ANOVA analysis at 5 strain.

Regression equations for both sets of pediatric data are compared in Table 12. The regression equations for measured pediatric data follow the same convention of one trend line equation for viscosity and one for elasticity using power equations, as that for the pediatric blood measurements made at $22^{\circ} \mathrm{C}$ [Long, et al. 2005]. 


\begin{tabular}{|c|c|c|c|c|}
\hline \multirow{2}{*}{$\frac{\text { Strain }}{0.2}$} & \multicolumn{2}{|c|}{$\begin{array}{c}\text { Pediatric Blood at } 37^{\circ} \mathrm{C} \\
{[\mathrm{mPa} . \mathrm{s}]} \\
\mathrm{H}=0.3-0.515 \\
\end{array}$} & \multicolumn{2}{|c|}{$\begin{array}{c}\text { Pediatric Blood at } 22^{\circ} \mathrm{C} \\
{[\mathrm{mPa} . \mathrm{s}]} \\
\mathrm{H}=0.27-0.428\end{array}$} \\
\hline & $\begin{aligned} \eta^{\prime} & =25.0 \mathrm{H}^{1.553} \\
\eta^{\prime \prime} & =18.22 \mathrm{H}^{2.44}\end{aligned}$ & $\begin{array}{l}\mathrm{R}^{2}=0.811 \\
\mathrm{R}^{2}=0.849\end{array}$ & $\begin{array}{l}\eta^{\prime}=2.96+64.73 \mathrm{H}^{2.80} \\
\eta^{\prime \prime}=0.15+33.75 \mathrm{H}^{3.17}\end{array}$ & $\begin{array}{l}\mathrm{R}^{2}=0.915 \\
\mathrm{R}^{2}=0.871\end{array}$ \\
\hline 1 & $\begin{array}{l}\eta^{\prime}=14.26 \mathrm{H}^{1.239} \\
\eta^{\prime \prime}=4.33 \mathrm{H}^{1.820}\end{array}$ & $\begin{array}{l}\mathrm{R}^{2}=0.803 \\
\mathrm{R}^{2}=0.749\end{array}$ & $\begin{aligned} \eta^{\prime} & =2.64+38.88 \mathrm{H}^{2.66} \\
\eta^{\prime \prime} & =0.08+11.95 \mathrm{H}^{3.08}\end{aligned}$ & $\begin{array}{l}\mathrm{R}^{2}=0.906 \\
\mathrm{R}^{2}=0.789\end{array}$ \\
\hline 5 & $\begin{array}{l}\eta^{\prime}=11.498 \mathrm{H}^{1.190} \\
\eta^{\prime \prime}=1.112 \mathrm{H}^{1.960}\end{array}$ & $\begin{array}{l}\mathrm{R}^{2}=0.790 \\
\mathrm{R}^{2}=0.853\end{array}$ & $\begin{array}{c}\eta^{\prime}=2.58+22.10 \mathrm{H}^{2.36} \\
\eta^{\prime \prime}=0.73 \mathrm{H}^{1.56}\end{array}$ & $\begin{array}{l}\mathrm{R}^{2}=0.936 \\
\mathrm{R}^{2}=0.787\end{array}$ \\
\hline
\end{tabular}

Table 12. Regression equations for pediatric blood at $37^{\circ} \mathrm{C}$ and $22^{\circ} \mathrm{C}$ [Long, et al. 2005]. 


\section{DISCUSSION}

Comparison of the new pediatric data with other existing data was complicated by the many factors that influence viscoelasticity, including not only age, for which the investigation of the effect was an objective of this project, but also hematocrit and temperature. The first comparison, of pediatric versus adult blood viscoelasticity from Thurston [1996], showed that the pediatric blood viscosity was, for all samples except one, lower than the adult values. Pediatric elasticity was lower than adult values for most of the range of shear rate. For comparison with the adult data of Kaber, et al. [1988], the influences of hematocrit and age were separated by selecting pairs of pediatric and adult samples (Table 7) with nearly identical hematocrit. Two-factor ANOVA found that both viscosity and elasticity of the pediatric blood were significantly lower than adult values at the same hematocrit for a shear rate of $10 \mathrm{~s}^{-1}$ (Figures 47 and 48). This result is different from that of Long, et al. [2005], who found statistically significant differences between their pediatric values and adult values only for elasticity at a strain of 0.2 .

The only other measurements of pediatric viscoelasticity available in the literature [Long, et al. 2005] were performed at $22^{\circ} \mathrm{C}$, thus direct comparison with this data set was not possible, but the influence of temperature could be investigated. Two-way ANOVA found significant differences in viscosity and elasticity due to temperature at all three strains $(0.2,1$ and 5$)$. Figures 51 through 56 show that the viscoelasticity of the pediatric blood at $37^{\circ} \mathrm{C}$ is significantly lower than that at $22^{\circ} \mathrm{C}$. 
The expected statistical significance of hematocrit was not found. On the other hand, all p-values were less than 0.4 , suggesting that another factor may be masking the effect of hematocrit. Indeed, the two youngest subjects in the UofL group also had the largest hematocrit (Figure 51), which would tend to counteract the expected increase in viscoelasticity with hematocrit. These potentially conflicting factors add uncertainty to the comparison of these pediatric groups, and suggest that more data is needed to isolate the influences of hematocrit, age and temperature on pediatric rheological parameters.

Furthermore, the mean ages of the Penn State comparison group (3.77 years $t$ $3.45 \mathrm{SD}$ ) was substantially greater than the UofL group (2.26 years $\pm 1.934 \mathrm{SD}$ ), which would tend to reinforce the expected increase in viscosity with colder sample temperature. Since these factors act in the same direction, it is not possible with this small data set to separate their independent influences.

Viscoelasticity was measured in this project at body temperature, because this temperature best represents the conditions for implanted and extracorporeal blood pumps and, thus, makes the information most useful to pump designers. Since the time response of the temperature control for the rheometer is long, it was impractical to measure each sample at two temperatures. In addition, the samples were too small to be subdivided to allow multiple measurements. Because delay in measurement might cause changes in properties, perhaps the best way of investigating the effect of temperature in future studies would be to have two temperature baths set at different temperatures, so that sample temperature could be quickly changed while it remains in the rheometer by switching connections from one temperature bath to the other. 


\section{CONCLUSION}

This study was undertaken primarily to form a database of the viscoelastic values of pediatric blood. A first step toward accomplishing this goal was made with these eleven samples. Figure 38 shows that all the data can be curve fitted to viscosity $\eta^{\prime}=0.0667 \dot{\gamma}^{-0.1346}$ and $\eta^{\prime \prime}=0.0529 \dot{\gamma}^{-0.813}$ where $\dot{\gamma}$ is the shear rate. But for using this data as input parameter for design of ventricular assist devices, the variation of the viscoelasticity over the entire range of hematocrit, age and body weight of pediatric patients should be considered. The data was also used to investigate the differences between adult and pediatric viscoelasticity and to analyze changes in pediatric viscoelasticity with temperature and hematocrit.

Results showed significantly lower viscosity and elasticity of pediatric blood compared to adult blood at a shear rate of $10 \mathrm{~s}^{-1}$, along with the expected increase in viscosity and elasticity with increasing hematocrit. While statistically significant differences were found between the two groups of pediatric data measured at different temperature, this comparison was not validated by confirmation of the well-known influence of hematocrit on viscoelastic parameters. In addition, since the groups differed not only in temperature, but also in age. conclusions from this comparison must be avoided. 
The results show clearly that there are significant differences in pediatric viscoelastic behavior compared to adult. This dissimilarity justifies the need to use pediatric values of viscoelastic parameters for designing pediatric blood-handling devices. Further study is needed to quantify the influence of temperature on pediatric viscoelasticity, as well as the influence of age within the pediatric age range. Future investigations may also include the viscoelasticity of blood of pediatric patients suffering from genetic blood disorders to understand the evolution of the disorder into full-blown disease in adults. In addition, studies may be pursued to establish viscoelastic markers for the detection of juvenile diabetes and other diseases that affect the viscosity of blood. 


\section{REFERENCES}

- Rheology of Circulation. R. L. Whitmore. Pergamon Press, Oxford, New York. 1968. p17-19

- Principles of Human Physiology. William J. Germann and Cindy L. Stanfield. Benjamin Cummings, San Francisco, California. 2002. p405

- Taber's Cyclopedic Medical Dictionary. $19^{\text {th }}$ Edition. First Indian Edition. Jaypree Brothers Medical Publishers [P] Ltd, New Delhi, India. 2002. Volume I $\&$ II.

- Clinical Blood Rheology. Gordon D. O. Lowe. CRC press, Boca Ration, Florida 1988. Volume I: p1-10.

- Anwar, M. A., M. W. Rampling, S. Bignall and R. P. A. Rivers. 1993. The variation with gestational age of the rheological properties of the blood of the new-born. British J. Haematol. 86:163-168.

- Bergvist G. 1974. Viscosity of the blood in the newborn infant. Aeta Paediatrica Scandinavica, 63:858-864.

- Bishop, J. J., P. R. Nance, A. S. Popel, M. Intaglietta, and P. C. Johnson. 2001. Effect of erythrocyte aggregation on velocity profiles in venules. Am. J. Physiol. Heart Circ. Physiol., 280:H222-H236. 
- Chien, S., A. A. Kaperonis, R. G. King, H. H. Lipowsky, E.A. Schmalzer, L. A. Sung, K. L. Sung and S. Usami. 1987. Rheology of sickle cells and its role in microcirculatory dynamics, Prog. Clin. Biol. Res. 240: 151-165.

- Eckmann D. M., S. Bowers, M. Stecker and A. Cheung. 2000. Hematocrit, Volume Expander, Temperature, and Shear Rate effects on Blood Viscosity. Anesth Analg. 91: 539-545.

- Ernst, E, and A. Matrai. 1986. Altered red and white blood cell rheology in type II diabetes. Diabetes 35 (12): 1412-5.

- Ernst, E., A. Matrai, and M. Marshall. 1988. Blood rheology in patients with transient ischemic attacks. Stroke $19(5): 634-6$.

- Falco, C., A. Vaya, J. Iborra, I. Moreno, S. Palanca and J. Aznar. 2003. Erythrocyte aggregability and disaggregability in thalassemia trait carriers analyzed by a laser backscattering technique, Clin. Hemorheol. 28: 245-249.

- Foley M. E., D. M. Isherwood, G. P. McNicol. 1978. Viscosity, haematocrit, fibrinogen and plasma proteins in maternal and cord blood. Br J Obstet Gynaecol., 85:500-504.

- Hathaway W. E. 1983. Neonatal hyperviscosity. Pediatrics, 72: 567-569.

- Käber, U., H. Kroemer, G. Altrock and P. Heimburg. 1988. Reference ranges of viscoelasticity of human blood. Biorheology, 25: 727-741.

- Kamaneva, M. V., J. F. Antaki, H. S. Borovetz, B. P. Griffith, K. C. Butler, K. K. Yeleswarapu, M. J. Watach and R. L. Kormos. 1995. Mechanisms of red blood cell trauma in assisted circulation. Rheological similarities of red blood cell 
transformations due to natural aging and mechanical stress. ASAIO J. 41(3): M457-460

- Lichtman, M. A., and J. MRowe. 1982. Hyperleukocytic leukemias: xheological, clinical, and therapeutic considerations. Blood 60 (2): 279-83.

- Linderkamp O, Meiselman H. J., Wu P. Y. K., Miller F. C. 1981. Blood and plasma viscosity and optimal hematocrit in the normal newborn infant. Clin. Haematol., 1: 575-584.

- Linderkamp O, Versmold H. T., Riegel K. P., Betke K. 1984. Contributions of red cells and plasma to blood viscosity in preterm and full-term infants and adults. Pediatrics, 74: 45-51.

- Linderkamp O, Ozanne P, Wu P. Y., Meiselman H. J. 1984. Red blood cell aggregation in preterm and term neonates and adults. Pediatr. Res., 18: 13561360.

- Linderkamp O, Nash G. B., Wu P. Y., Meiselman H. J. 1986. Deformability and intrinsic material properties of neonatal red blood cells. Blood, 67: 1244-1250.

- Linderkamp O, A. A. Stadler, E. P. Zilow. 1992. Blood viscosity and optimal hematocrit in preterm and full-term neonates in 50-to 500-micrometer tubes. Pediatr. Res. 32(1): 97-102.

- Long, J. A., A. Undar, K. B. Manning, S. Deutsch 2005. Viscoelasticity of pediatric blood and its implications for the testing of a pulsatile pediatric blood pump. ASAIO Journal, 51: 563-566. 
- Mabry C. C., Tietz N. W. 1979. Tables of normal laboratory values, in Vaugh V. C., Mckay R. J., Behuman R. E. and Nelson W. E., editors: Nelson textbook of pediatrics, Philadelphia, WB saunders Company. p2081.

- Mayer G. A. 1964. Blood viscosity in healthy subjects and patients with coronary heart disease. Can Med Assoc J, 91:951.

- Merchant R. H., Phadke S. D., Sakhalkar V. S., Agashe V. S., Puniyani R. R. 1992. Hematocrit and whole blood viscosity in newborns: analysis of 100 cases. Indian Pediatr., 29: 555-561.

- Mohandas N., W. M. Phillips, and M. Bessis. 1979. Red blood cell deformability and hemolytic anemias. Seminars in hematology, $16.2: 95-114$.

- Rampling M. W., Whittingstall P, Martin G, Bignall S, Rivers R. P., Lissauer T. J., Bailey P. C.. 1989. A comparison of the rheologic properties of neonatal and adult blood. Pediatr. Res., 25: 457-460.

- Rampling M. W. 1986. The fibrinogen: red cell interaction and its influence on blood rheology. In: Lane D. A., Henshen A, Jasani M, editors: Fibrinogen-fibrin formation and Fibrinolysis, vol 4. Walter de Gruyter, Berlin. p219-227.

- Rand P. W., E. Lacombe, H. E. Hunt, W. H. Austin. 1964. Viscosity of normal human blood under normothermic and hypothermic conditions. I Appl Physiol., 19: 117-22.

- Reis A., N. Kirmaier. 1976. The viscosity-temperature function of blood serum and its physio-chemical information content. Biorheology, 13: 143-148.

- Rosenkrantz, Ted S. 2003. Polycythemia and hyperviscosity in the newborn. Seminars in thrombosis and hemostasis $29(5): 515-27$. 
- Somer, T. 1966. The viscosity of blood, plasma and serum in dys- and paraproteinemias. Acta medica Scandinavica. Supplementum 456: 1-97.

- Somer, T. 1977. Hyperviscosity syndrome in plasma cell dyscrasias. Duodecim $93(9):$ 586-603.

- Somer, T. and H. J. Meiselman, Disorders of blood viscosity, Ann. Med. 25[1993] 31-39.

- Thurston, G. B. 1960. Theory of Oscillation of a viscoelastic fluid in a circular tube. J. Acoust. Soc. Amer., 32: 210-213.

- Thurston, G. B. 1976. The effects of frequency of oscillatory flow on the impedance of rigid, blood-filled tubes. Biorheology, 13: 191-199.

- Thurston, G. B. 1961. Measurement of the acoustic impedance of a viscoelastic fluid in a circular tube. J. Acoust. Soc. Amer., 33: 1091-1095.

- Thurston, G. B. and Pope, G. A. 1981. Shear rate dependence of the viscoelasticity of polymer solutions. II Xanthan Gum. J. Non-Newtonian Fluid Mechanics, 9: 69-78.

- Thurston, G. B. 1979. Rheological parameters for the viscosity, viscoelasticity and thixotropy of blood. Biorheology, 16: 149-162.

- Thurston, G. B. 1996. Viscoelastic properties of blood and blood analogs. Advances in Hemodynamics and Hemorheology, T. V. How, ed., JAI Press, 1-30.

- Thurston, G. B., Henderson N. M., Jeng M. 2004. Effects of erythrocytapheresis transfusion on the viscoelasticity of sickle cell blood. Clin. Hemeoreol. 30:83-97.

- Voerman, H J, and A B Groeneveld. 1989. Blood viscosity and circulatory shock. Intensive care medicine 15 (2): 72-8. 
- Walitza, E., I. Anadere, H. Chmiel, and S. Witte. 1988. Evaluation of viscoelasticity measurements of human blood. Biorheology, 25: 209-217.

- Wiswell T. E., Cornish J. D., Northam R. S. 1986. Neonatal polycythemia: frequency of clinical manifestations and other associated findings. Pediatrics, 78 : 26-30.

- Zondervan, H. A. , J. Oosting, M.E. Smorenberg-Schoorl, and P.E. Treffers. 1988. Maternal whole blood viscosity in pregnancy hypertension. Gynecologic and obstetric investigation, 25 (2): 83-8. 


\section{APPENDIX A}

\section{Complete Pediatric Data}

Contained within this appendix is full documentation of each sample test. The data is documented in tables and plots for easy availability.

The raw viscosity and elasticity for each sample is tabulated to aid future research.

\begin{tabular}{|c|c|c|c|c|c|}
\hline Point & $\begin{array}{c}\text { Viscosity } \\
\text { Poise }\end{array}$ & $\begin{array}{c}\text { Elasticity } \\
\text { Poise }\end{array}$ & $\begin{array}{c}\text { Relax.Time } \\
\mathbf{s}\end{array}$ & $\begin{array}{c}\text { ShearRate } \\
\mathbf{1} / \mathbf{s}\end{array}$ & Strain \\
\hline 1 & 0.0458 & 0.01258 & 0.02184 & 1.777 & 0.1414 \\
\hline 2 & 0.0442 & 0.01213 & 0.02181 & 2.33 & 0.1853 \\
\hline 3 & 0.0463 & 0.01247 & 0.02143 & 3.24 & 0.258 \\
\hline 4 & 0.0438 & 0.01150 & 0.02091 & 4.36 & 0.347 \\
\hline 5 & 0.0444 & 0.01114 & 0.01997 & 5.61 & 0.447 \\
\hline 6 & 0.0426 & 0.00964 & 0.01802 & 7.52 & 0.598 \\
\hline 7 & 0.0404 & 0.00799 & 0.01575 & 9.75 & 0.776 \\
\hline 8 & 0.0392 & 0.00713 & 0.01448 & 12.64 & 1.006 \\
\hline 9 & 0.0377 & 0.00571 & 0.01205 & 16.41 & 1.306 \\
\hline 10 & 0.0361 & 0.00434 & 0.00956 & 21.21 & 1.688 \\
\hline 11 & 0.0347 & 0.00321 & 0.00737 & 27.24 & 2.17 \\
\hline 12 & 0.0337 & 0.00228 & 0.00539 & 35.20 & 2.80 \\
\hline 13 & 0.0330 & 0.001688 & 0.00406 & 45.08 & 3.59 \\
\hline 14 & 0.0325 & 0.001252 & 0.00307 & 57.98 & 4.61 \\
\hline 15 & 0.0320 & 0.000961 & 0.00239 & 74.09 & 5.90 \\
\hline 16 & 0.0316 & 0.000771 & 0.001944 & 94.59 & 7.53 \\
\hline 17 & 0.0312 & 0.000668 & 0.001707 & 120.85 & 9.62 \\
\hline 18 & 0.0309 & 0.000591 & 0.001524 & 154.36 & 12.28 \\
\hline 19 & 0.0307 & 0.000498 & 0.001289 & 196.71 & 15.65 \\
\hline 20 & 0.0305 & 0.000442 & 0.001153 & 250.93 & 19.97 \\
\hline
\end{tabular}

Table 13. Data for case KCH2006-001. 


\begin{tabular}{|c|c|c|c|c|c|}
\hline Point & $\begin{array}{c}\text { Viscosity } \\
\text { Poise }\end{array}$ & $\begin{array}{c}\text { Elasticity } \\
\text { Poise }\end{array}$ & $\begin{array}{c}\text { Relax.Time } \\
\text { s }\end{array}$ & $\begin{array}{c}\text { ShearRate } \\
\text { 1 is }\end{array}$ & Strain \\
\hline 1 & 0.0692 & 0.02754 & 0.0317 & 1.698 & 0.1351 \\
\hline 2 & 0.0696 & 0.02499 & 0.0286 & 2.21 & 0.1757 \\
\hline 3 & 0.0680 & 0.02074 & 0.0243 & 3.15 & 0.251 \\
\hline 4 & 0.0637 & 0.01759 & 0.0220 & 4.23 & 0.337 \\
\hline 5 & 0.0616 & 0.01446 & 0.01868 & 5.54 & 0.441 \\
\hline 6 & 0.0572 & 0.01127 & 0.01569 & 7.43 & 0.591 \\
\hline 7 & 0.0536 & 0.00940 & 0.01396 & 9.67 & 0.769 \\
\hline 8 & 0.0507 & 0.00730 & 0.01146 & 12.58 & 1.001 \\
\hline 9 & 0.0504 & 0.00648 & 0.01024 & 16.28 & 1.295 \\
\hline 10 & 0.0498 & 0.00537 & 0.00859 & 21.07 & 1.677 \\
\hline 11 & 0.0499 & 0.00432 & 0.00689 & 27.02 & 2.15 \\
\hline 12 & 0.0495 & 0.00342 & 0.00549 & 34.87 & 2.77 \\
\hline 13 & 0.0481 & 0.00262 & 0.00434 & 44.71 & 3.56 \\
\hline 14 & 0.0462 & 0.001874 & 0.00323 & 57.55 & 4.58 \\
\hline 15 & 0.0440 & 0.001262 & 0.00228 & 73.73 & 5.87 \\
\hline 16 & 0.0420 & 0.000936 & 0.001775 & 94.25 & 7.50 \\
\hline 17 & 0.0400 & 0.000682 & 0.001356 & 120.60 & 9.60 \\
\hline 18 & 0.0383 & 0.000510 & 0.001060 & 154.18 & 12.27 \\
\hline 19 & 0.0368 & 0.000325 & 0.000702 & 196.68 & 15.65 \\
\hline 20 & 0.0355 & 0.000256 & 0.000575 & 251.01 & 19.97 \\
\hline
\end{tabular}

Table 14. Data for case KCH2006-002.

\begin{tabular}{|c|c|c|c|c|c|}
\hline Point & $\begin{array}{c}\text { Viscosity } \\
\text { Poise }\end{array}$ & $\begin{array}{c}\text { Elasticity } \\
\text { Poise }\end{array}$ & $\begin{array}{c}\text { Relax.Time } \\
\mathbf{5}\end{array}$ & $\begin{array}{c}\text { ShearRate } \\
1 / \mathrm{s}\end{array}$ & Strain \\
\hline 1 & 0.1137 & 0.04576 & 0.0320 & 1.576 & 0.1254 \\
\hline 2 & 0.1111 & 0.04658 & 0.0334 & 2.05 & 0.1632 \\
\hline 3 & 0.1073 & 0.04084 & 0.0303 & 2.97 & 0.236 \\
\hline 4 & 0.1022 & 0.03601 & 0.0280 & 3.97 & 0.316 \\
\hline 5 & 0.0971 & 0.03119 & 0.0256 & 5.25 & 0.418 \\
\hline 6 & 0.0892 & 0.02416 & 0.0215 & 7.13 & 0.568 \\
\hline 7 & 0.0814 & 0.01857 & 0.01815 & 9.42 & 0.750 \\
\hline 8 & 0.0735 & 0.01391 & 0.01506 & 12.37 & 0.985 \\
\hline 9 & 0.0700 & 0.01115 & 0.01268 & 16.17 & 1.287 \\
\hline 10 & 0.0676 & 0.00902 & 0.01063 & 20.95 & 1.667 \\
\hline 11 & 0.0662 & 0.00721 & 0.00867 & 26.96 & 2.15 \\
\hline 12 & 0.0652 & 0.00529 & 0.00647 & 34.97 & 2.78 \\
\hline 13 & 0.0643 & 0.00389 & 0.00482 & 44.85 & 3.57 \\
\hline 14 & 0.0625 & 0.002563 & 0.00326 & 57.83 & 4.60 \\
\hline 15 & 0.0600 & 0.001671 & 0.60221 & 74.17 & 5.90 \\
\hline 16 & 0.0571 & 0.001190 & 0.001657 & 94.96 & 7.56 \\
\hline 17 & 0.0540 & 0.000746 & 0.001090 & 121.72 & 9.69 \\
\hline 18 & 0.0514 & 0.000472 & 0.060731 & 155.67 & 12.39 \\
\hline 19 & 0.0489 & 0.000304 & 0.000495 & 198.78 & 15.82 \\
\hline 20 & 0.0466 & 0.000202 & 0.000345 & 253.82 & 20.2 .9 \\
\hline
\end{tabular}

Table 15. Data for case $\mathrm{KCH} 2006-003$. 


\begin{tabular}{|c|c|c|c|c|c|}
\hline Point & $\begin{array}{c}\text { Viscosity } \\
\text { Poise }\end{array}$ & $\begin{array}{c}\text { Elasticity } \\
\text { Poise }\end{array}$ & $\begin{array}{c}\text { Relax.Time } \\
\mathbf{\$}\end{array}$ & $\begin{array}{c}\text { ShearRate } \\
\mathbf{1 / \mathbf { s }}\end{array}$ & Sírain \\
\hline 1 & 0.0763 & 0.0308 & 0.0321 & 1.642 & 0.1307 \\
\hline 2 & 0.0744 & 0.0290 & 0.0310 & 2.17 & 0.1727 \\
\hline 3 & 0.0719 & 0.0261 & 0.0289 & 3.10 & 0.247 \\
\hline 4 & 0.0693 & 0.0226 & 0.0259 & 4.15 & 0.330 \\
\hline 5 & 0.0653 & 0.01907 & 0.0232 & 5.47 & 0.436 \\
\hline 6 & 0.0608 & 0.01614 & 0.0211 & 7.35 & 0.584 \\
\hline 7 & 0.0558 & 0.01176 & 0.01678 & 9.61 & 0.765 \\
\hline 8 & 0.0540 & 0.01013 & 0.01493 & 12.48 & 0.993 \\
\hline 9 & 0.0527 & 0.00883 & 0.01335 & 16.14 & 1.284 \\
\hline 10 & 0.0518 & 0.00726 & 0.01116 & 20.91 & 1.664 \\
\hline 11 & 0.0515 & 0.00618 & 0.00956 & 26.84 & 2.14 \\
\hline 12 & 0.0507 & 0.00511 & 0.00803 & 34.72 & 2.76 \\
\hline 13 & 0.0489 & 0.00395 & 0.00643 & 44.51 & 3.54 \\
\hline 14 & 0.0469 & 0.00295 & 0.00501 & 57.36 & 4.56 \\
\hline 15 & 0.0449 & 0.00227 & 0.00403 & 73.48 & 5.85 \\
\hline 16 & 0.0430 & 0.001757 & 0.003252 & 94.02 & 7.48 \\
\hline 17 & 0.0414 & 0.001363 & 0.002620 & 120.28 & 9.57 \\
\hline 18 & 0.0399 & 0.001085 & 0.002166 & 153.80 & 12.24 \\
\hline 19 & 0.0385 & 0.000901 & 0.001863 & 196.30 & 15.62 \\
\hline 20 & 0.0373 & 0.000789 & 0.001683 & 250.43 & 19.93 \\
\hline
\end{tabular}

Table 16. Data for case KCH2006-004.

\begin{tabular}{|c|c|c|c|c|c|}
\hline Point & $\begin{array}{c}\text { Viscosity } \\
\text { Poise }\end{array}$ & $\begin{array}{c}\text { Elasticity } \\
\text { Poise }\end{array}$ & $\begin{array}{c}\text { Relax.Time } \\
\mathbf{s}\end{array}$ & $\begin{array}{c}\text { ShearRate } \\
1 / \mathbf{s}\end{array}$ & Strain \\
\hline 1 & 0.0446 & 0.01161 & 0.0207 & 1.708 & 0.1360 \\
\hline 2 & 0.0430 & 0.01178 & 0.0218 & 2.30 & 0.1832 \\
\hline 3 & 0.0420 & 0.01003 & 0.01897 & 3.25 & 0.259 \\
\hline 4 & 0.0403 & 0.00889 & 0.01754 & 4.32 & 0.344 \\
\hline 5 & 0.0397 & 0.00809 & 0.01622 & 5.63 & 0.448 \\
\hline 6 & 0.0380 & 0.00757 & 0.01587 & 7.50 & 0.597 \\
\hline 7 & 0.0358 & 0.00600 & 0.01331 & 9.71 & 0.773 \\
\hline 8 & 0.0349 & 0.00511 & 0.01164 & 12.58 & 1.001 \\
\hline 9 & 0.0343 & 0.00433 & 0.01004 & 16.27 & 1.295 \\
\hline 10 & 0.0332 & 0.00343 & 0.00822 & 21.04 & 1.674 \\
\hline 11 & 0.0325 & 0.00252 & 0.00617 & 26.95 & 2.14 \\
\hline 12 & 0.0317 & 0.00216 & 0.00542 & 34.81 & 2.77 \\
\hline 13 & 0.0312 & 0.001643 & 0.00419 & 44.49 & 3.54 \\
\hline 14 & 0.0305 & 0.001318 & 0.00344 & 57.23 & 4.55 \\
\hline 15 & 0.0298 & 0.001058 & 0.00283 & 73.13 & 5.32 \\
\hline 16 & 0.0290 & 0.000936 & 0.00257 & 93.33 & 7.43 \\
\hline 17 & 0.0280 & 0.000739 & 0.00210 & 119.36 & 9.50 \\
\hline 18 & 0.0270 & 0.000654 & 0.001957 & 152.57 & 12.14 \\
\hline 19 & 0.0261 & 0.000521 & 0.001586 & 194.68 & 15.49 \\
\hline 20 & 0.0253 & 0.000434 & 0.001364 & 248.39 & 19.77 \\
\hline
\end{tabular}

Table 17. Data for case KCH2006-005. 


\begin{tabular}{|c|c|c|c|c|c|}
\hline Point & $\begin{array}{c}\text { Viscosity } \\
\text { Poise }\end{array}$ & $\begin{array}{c}\text { Elasticity } \\
\text { Poise }\end{array}$ & $\begin{array}{c}\text { Relax.Time } \\
\mathbf{s}\end{array}$ & $\begin{array}{c}\text { ShearRate } \\
1 / \mathbf{s}\end{array}$ & Strain \\
\hline 1 & 0.0589 & 0.01719 & 0.0232 & 1.720 & 0.1369 \\
\hline 2 & 0.0554 & 0.01788 & 0.0257 & 2.30 & 0.1827 \\
\hline 3 & 0.0556 & 0.01723 & 0.0246 & 3.21 & 0.255 \\
\hline 4 & 0.0536 & 0.01571 & 0.0233 & 4.27 & 0.340 \\
\hline 5 & 0.0528 & 0.01357 & 0.0205 & 5.58 & 0.444 \\
\hline 6 & 0.0495 & 0.01111 & 0.01785 & 7.48 & 0.595 \\
\hline 7 & 0.0462 & 0.00908 & 0.01563 & 9.68 & 0.771 \\
\hline 8 & 0.0443 & 0.00779 & 0.01398 & 12.59 & 1.002 \\
\hline 9 & 0.0423 & 0.00599 & 0.01127 & 16.37 & 1.302 \\
\hline 10 & 0.0406 & 0.00467 & 0.00917 & 21.17 & 1.685 \\
\hline 11 & 0.0393 & 0.00351 & 0.00711 & 27.17 & 2.16 \\
\hline 12 & 0.0386 & 0.00263 & 0.00542 & 35.03 & 2.79 \\
\hline 13 & 0.0379 & 0.00202 & 0.00423 & 44.89 & 3.57 \\
\hline 14 & 0.0372 & 0.001616 & 0.00345 & 57.74 & 4.59 \\
\hline 15 & 0.0366 & 0.001270 & 0.00276 & 73.79 & 5.87 \\
\hline 16 & 0.0357 & 0.000991 & 0.00221 & 94.24 & 7.50 \\
\hline 17 & 0.0348 & 0.000773 & 0.001769 & 120.50 & 9.59 \\
\hline 18 & 0.0340 & 0.000639 & 0.001495 & 154.05 & 12.26 \\
\hline 19 & 0.0333 & 0.000505 & 0.001205 & 196.32 & 15.62 \\
\hline 20 & 0.0326 & 0.000438 & 0.001071 & 250.57 & 19.94 \\
\hline
\end{tabular}

Table 18. Data for case KCH2006-006.

\begin{tabular}{|c|c|c|c|c|c|}
\hline Point & $\begin{array}{c}\text { Viscosity } \\
\text { Poise }\end{array}$ & $\begin{array}{c}\text { Elasticity } \\
\text { Poise }\end{array}$ & $\begin{array}{c}\text { Relax.Time } \\
\mathbf{s}\end{array}$ & $\begin{array}{c}\text { ShearRate } \\
1 / \mathrm{s}\end{array}$ & Strain \\
\hline 1 & 0.0671 & 0.0248 & 0.0294 & 1.698 & 0.1351 \\
\hline 2 & 0.0645 & 0.0268 & 0.0330 & 2.22 & 0.1764 \\
\hline 3 & 0.0651 & 0.0226 & 0.0277 & 3.14 & 0.250 \\
\hline 4 & 0.0622 & 0.0223 & 0.0286 & 4.15 & 0.331 \\
\hline 5 & 0.0614 & 0.0202 & 0.0262 & 5.45 & 0.433 \\
\hline 6 & 0.0581 & 0.01861 & 0.0255 & 7.27 & 0.579 \\
\hline 7 & 0.0562 & 0.01622 & 0.0230 & 9.45 & 0.752 \\
\hline 8 & 0.0521 & 0.01333 & 0.0203 & 12.31 & 0.980 \\
\hline 9 & 0.0503 & 0.01140 & 0.01802 & 16.00 & 1.273 \\
\hline 10 & 0.0480 & 0.00839 & 0.01391 & 20.80 & 1.655 \\
\hline 11 & 0.0463 & 0.00680 & 0.01169 & 26.80 & 2.13 \\
\hline 12 & 0.0446 & 0.00539 & 0.00961 & 34.74 & 2.76 \\
\hline 13 & 0.0431 & 0.00397 & 0.00732 & 44.54 & 3.54 \\
\hline 14 & 0.0412 & 0.00322 & 0.00622 & 57.41 & 4.57 \\
\hline 15 & 0.0396 & 0.00223 & 0.00447 & 73.54 & 5.85 \\
\hline 16 & 0.0384 & 0.001555 & 0.00322 & 94.10 & 7.49 \\
\hline 17 & 0.0372 & 0.001173 & 0.00251 & 120.43 & 9.58 \\
\hline 18 & 0.0360 & 0.001027 & 0.00227 & 153.96 & 12.25 \\
\hline 19 & 0.0350 & 0.000844 & 0.001919 & 196.46 & 15.63 \\
\hline 20 & 0.0341 & 0.000717 & 0.001675 & 250.69 & 19.95 \\
\hline
\end{tabular}

Table 19. Data for case KCH2006-007. 


\begin{tabular}{|c|c|c|c|c|c|}
\hline Point & $\begin{array}{c}\text { Viscosity } \\
\text { Poise }\end{array}$ & $\begin{array}{c}\text { Elasticity } \\
\text { Poise }\end{array}$ & $\begin{array}{c}\text { Relax.Time } \\
\text { s }\end{array}$ & $\begin{array}{c}\text { ShearRate } \\
1 / \mathbf{s}\end{array}$ & Strain \\
\hline 1 & 0.0557 & 0.01856 & 0.0265 & 1.751 & 0.1394 \\
\hline 2 & 0.0571 & 0.0213 & 0.0297 & 2.22 & 0.1767 \\
\hline 3 & 0.0563 & 0.01956 & 0.0277 & 3.15 & 0.251 \\
\hline 4 & 0.0545 & 0.01794 & 0.0262 & 4.21 & 0.335 \\
\hline 5 & 0.0524 & 0.01603 & 0.0244 & 5.50 & 0.437 \\
\hline 6 & 0.0498 & 0.01357 & 0.0217 & 7.35 & 0.585 \\
\hline 7 & 0.0460 & 0.01063 & 0.01841 & 9.63 & 0.767 \\
\hline 8 & 0.0443 & 0.00929 & 0.01668 & 12.43 & 0.989 \\
\hline 9 & 0.0421 & 0.00751 & 0.01420 & 16.23 & 1.291 \\
\hline 10 & 0.0401 & 0.00576 & 0.01144 & 20.99 & 1.670 \\
\hline 11 & 0.0386 & 0.00446 & 0.00918 & 26.94 & 2.14 \\
\hline 12 & 0.0376 & 0.00337 & 0.00712 & 34.86 & 2.77 \\
\hline 13 & 0.0369 & 0.00262 & 0.00566 & 44.61 & 3.55 \\
\hline 14 & 0.0361 & 0.00204 & 0.00449 & 57.43 & 4.57 \\
\hline 15 & 0.0354 & 0.001740 & 0.00391 & 73.42 & 5.84 \\
\hline 16 & 0.0347 & 0.001454 & 0.00334 & 93.70 & 7.46 \\
\hline 17 & 0.0339 & 0.001251 & 0.00294 & 119.88 & 9.54 \\
\hline 18 & 0.0330 & 0.001073 & 0.00259 & 153.17 & 12.19 \\
\hline 19 & 0.0323 & 0.000943 & 0.00233 & 195.31 & 15.54 \\
\hline 20 & 0.0316 & 0.000853 & 0.00215 & 249.24 & 19.83 \\
\hline
\end{tabular}

Table 20. Data for case $\mathrm{KCH} 2006-008$.

\begin{tabular}{|c|c|c|c|c|c|}
\hline Point & $\begin{array}{c}\text { Viscosity } \\
\text { Poise }\end{array}$ & $\begin{array}{c}\text { Elasticity } \\
\text { Poise }\end{array}$ & $\begin{array}{c}\text { Relax.Time } \\
\mathbf{s}\end{array}$ & $\begin{array}{c}\text { ShearRate } \\
1 / \mathbf{s}\end{array}$ & Strain \\
\hline 1 & 0.0456 & 0.01122 & 0.01959 & 1.750 & 0.1392 \\
\hline 2 & 0.0445 & 0.01107 & 0.01978 & 2.25 & 0.1788 \\
\hline 3 & 0.0437 & 0.01136 & 0.0207 & 3.22 & 0.257 \\
\hline 4 & 0.0419 & 0.01005 & 0.01909 & 4.29 & 0.341 \\
\hline 5 & 0.0406 & 0.00914 & 0.01791 & 5.63 & 0.448 \\
\hline 6 & 0.0386 & 0.00784 & 0.01618 & 7.48 & 0.595 \\
\hline 7 & 0.0363 & 0.00649 & 0.01423 & 9.71 & 0.773 \\
\hline 8 & 0.0352 & 0.00572 & 0.01293 & 12.55 & 0.999 \\
\hline 9 & 0.0337 & 0.00488 & 0.01154 & 16.28 & 1.296 \\
\hline 10 & 0.0322 & 0.00369 & 0.00911 & 21.08 & 1.677 \\
\hline 11 & 0.0313 & 0.00284 & 0.00721 & 27.01 & 2.15 \\
\hline 12 & 0.0305 & 0.00220 & 0.00574 & 34.90 & 2.78 \\
\hline 13 & 0.0300 & 0.001659 & 0.00439 & 44.63 & 3.55 \\
\hline 14 & 0.0295 & 0.001305 & 0.00352 & 57.39 & 4.57 \\
\hline 15 & 0.0292 & 0.001083 & 0.00295 & 73.30 & 5.83 \\
\hline 16 & 0.0287 & 0.0009 & 0.00254 & 93.60 & 7.45 \\
\hline 17 & 0.0280 & 0.000790 & 0.00225 & 119.59 & 9.52 \\
\hline 18 & 0.0273 & 0.000651 & 0.001899 & 152.80 & 12.16 \\
\hline 19 & 0.0271 & 0.000538 & 0.001579 & 194.84 & 15.50 \\
\hline 20 & 0.0270 & 0.000441 & 0.001301 & 248.56 & 19.78 \\
\hline
\end{tabular}

Table 21. Data for case KCH2006-009. 


\begin{tabular}{|c|c|c|c|c|c|}
\hline Point & $\begin{array}{c}\text { Viscosity } \\
\text { Poise }\end{array}$ & $\begin{array}{c}\text { Elasticity } \\
\text { Poise }\end{array}$ & $\begin{array}{c}\text { Relax.Time } \\
\text { s }\end{array}$ & $\begin{array}{c}\text { ShearRate } \\
1 / \mathbf{s}\end{array}$ & Strain \\
\hline 1 & 0.0353 & 0.00827 & 0.01862 & 1.813 & 0.1443 \\
\hline 2 & 0.0355 & 0.00892 & 0.0200 & 2.29 & 0.1822 \\
\hline 3 & 0.0344 & 0.00644 & 0.01491 & 3.33 & 0.265 \\
\hline 4 & 0.0326 & 0.00674 & 0.01643 & 4.42 & 0.352 \\
\hline 5 & 0.0323 & 0.00574 & 0.01414 & 5.78 & 0.460 \\
\hline 6 & 0.0312 & 0.00523 & 0.01334 & 7.61 & 0.606 \\
\hline 7 & 0.0294 & 0.00381 & 0.01028 & 9.93 & 0.790 \\
\hline 8 & 0.0286 & 0.00378 & 0.01052 & 12.82 & 1.020 \\
\hline 9 & 0.0281 & 0.00282 & 0.00800 & 16.57 & 1.319 \\
\hline 10 & 0.0273 & 0.00236 & 0.00687 & 21.34 & 1.698 \\
\hline 11 & 0.0267 & 0.001795 & 0.00534 & 27.38 & 2.18 \\
\hline 12 & 0.0263 & 0.001361 & 0.00412 & 35.36 & 2.81 \\
\hline 13 & 0.0259 & 0.001080 & 0.00332 & 45.23 & 3.60 \\
\hline 14 & 0.0256 & 0.000913 & 0.00284 & 58.10 & 4.62 \\
\hline 15 & 0.0252 & 0.000745 & 0.00235 & 74.20 & 5.90 \\
\hline 16 & 0.0248 & 0.000678 & 0.00217 & 94.71 & 7.54 \\
\hline 17 & 0.0243 & 0.000566 & 0.001857 & 121.03 & 9.63 \\
\hline 18 & 0.0238 & 0.000512 & 0.001714 & 154.55 & 12.30 \\
\hline 19 & 0.0235 & 0.000427 & 0.001444 & 197.00 & 15.68 \\
\hline 20 & 0.0233 & 0.000383 & 0.001308 & 251.25 & 19.99 \\
\hline & & & & & \\
\hline
\end{tabular}

Table 22. Data for case $\mathrm{KCH} 2006-010$.

\begin{tabular}{|c|c|c|c|c|c|}
\hline Point & $\begin{array}{c}\text { Viscosity } \\
\text { Poise }\end{array}$ & $\begin{array}{c}\text { Elasticity } \\
\text { Poise }\end{array}$ & $\begin{array}{c}\text { Relax.Time } \\
\text { s }\end{array}$ & $\begin{array}{c}\text { ShearRate } \\
1 / \mathbf{s}\end{array}$ & Strain \\
\hline 1 & 0.0573 & 0.0220 & 0.0306 & 1.704 & 0.1356 \\
\hline 2 & 0.0580 & 0.0206 & 0.0283 & 2.19 & 0.1744 \\
\hline 3 & 0.0568 & 0.01875 & 0.0263 & 3.14 & 0.250 \\
\hline 4 & 0.0549 & 0.01829 & 0.0265 & 4.22 & 0.336 \\
\hline 5 & 0.0523 & 0.01538 & 0.0234 & 5.51 & 0.439 \\
\hline 6 & 0.0497 & 0.01329 & 0.0213 & 7.35 & 0.585 \\
\hline 7 & 0.0477 & 0.01119 & 0.01867 & 9.49 & 0.755 \\
\hline 8 & 0.0440 & 0.00880 & 0.01591 & 12.44 & 0.990 \\
\hline 9 & 0.0429 & 0.00751 & 0.01394 & 16.11 & 1.282 \\
\hline 10 & 0.0422 & 0.00601 & 0.01133 & 20.82 & 1.657 \\
\hline 11 & 0.0415 & 0.00520 & 0.00997 & 26.70 & 2.12 \\
\hline 12 & 0.0408 & 0.00433 & 0.00844 & 34.53 & 2.75 \\
\hline 13 & 0.0398 & 0.00343 & 0.00687 & 44.22 & 3.52 \\
\hline 14 & 0.0384 & 0.00268 & 0.00555 & 56.95 & 4.53 \\
\hline 15 & 0.0368 & 0.00204 & 0.00442 & 72.91 & 5.80 \\
\hline 16 & 0.0354 & 0.001672 & 0.00375 & 93.20 & 7.42 \\
\hline 17 & 0.0343 & 0.001307 & 0.00304 & 119.29 & 9.49 \\
\hline 18 & 0.0332 & 0.001012 & 0.00243 & 152.52 & 12.14 \\
\hline 19 & 0.0322 & 0.000836 & 0.00207 & 194.62 & 15.49 \\
\hline 20 & 0.0313 & 0.000682 & 0.001732 & 248.37 & 19.76 \\
\hline
\end{tabular}

Table 23. Data for case KCH2006-011. 


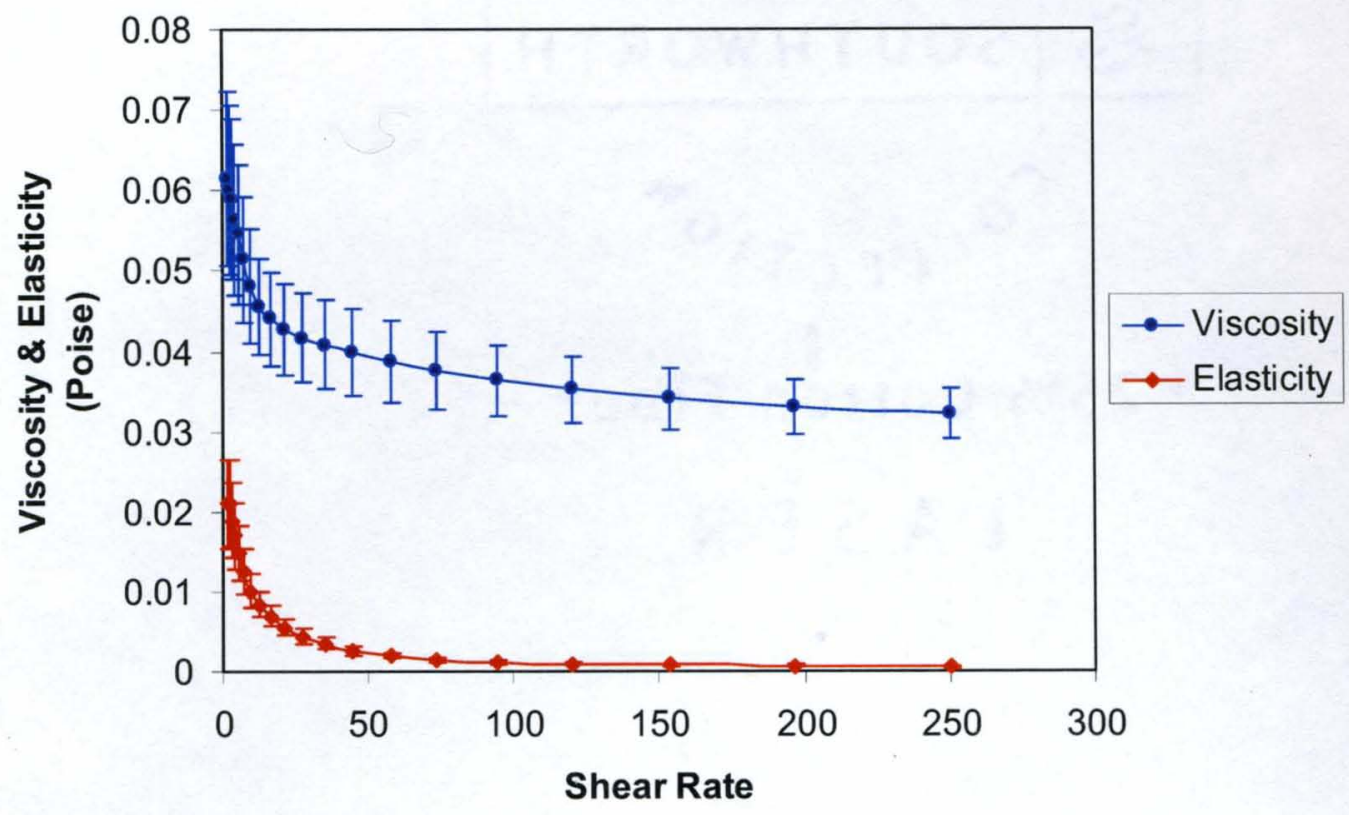

Figure 58. Viscoelasticity vs. shear rate of all pediatric data.

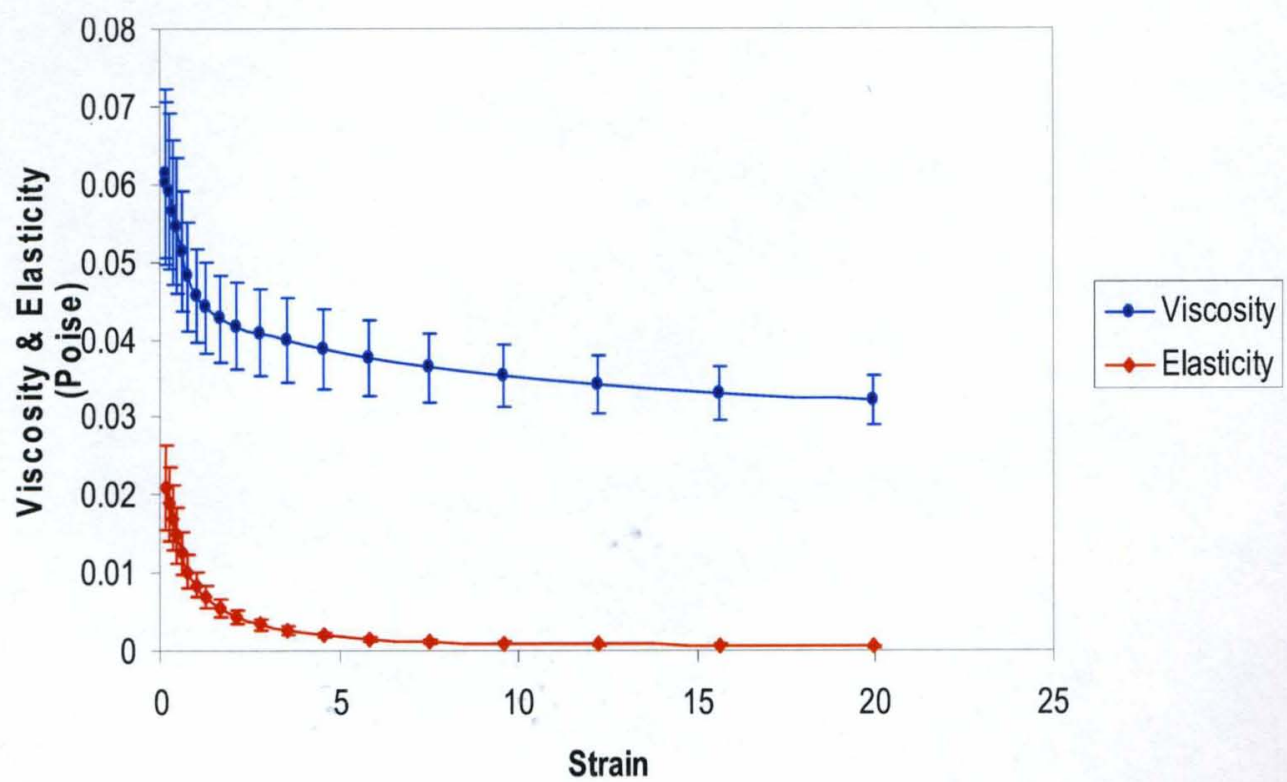

Figure 59. Viscoelasticity vs. strain of all pediatric data. 


\section{Trendlines for Hematocrit fit for Pediatric Data}

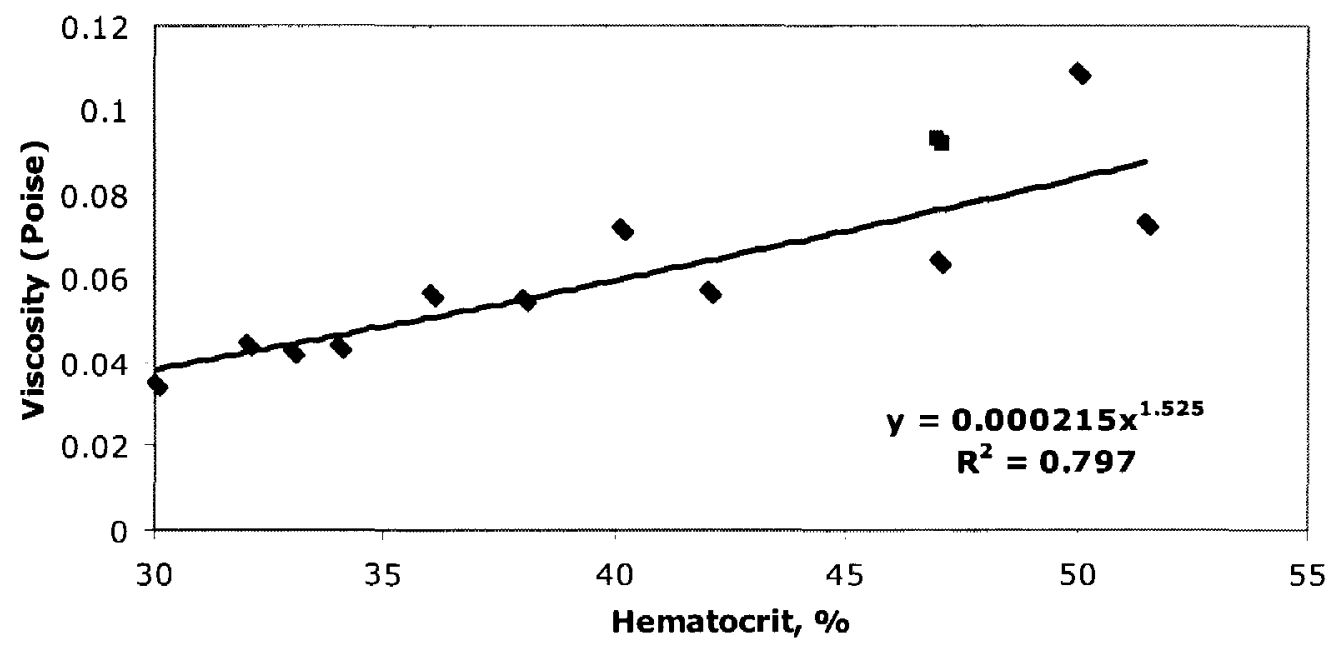

- pediatric * adult $\longrightarrow$ (Power (pediatric

Figure 60. Powercurve fit for viscosity vs. hematocrit at 0.2 strain.

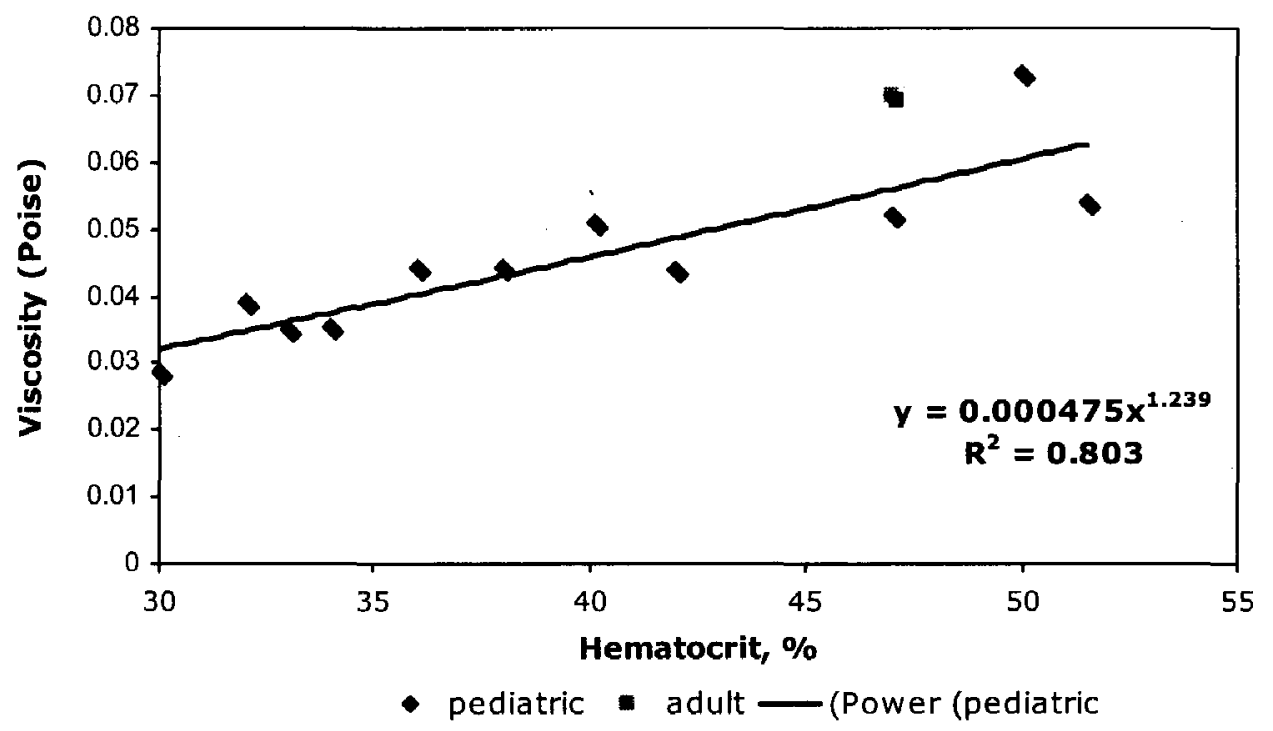

Figure 61. Powercurve fit for viscosity vs. hematocrit at 1 strain. 


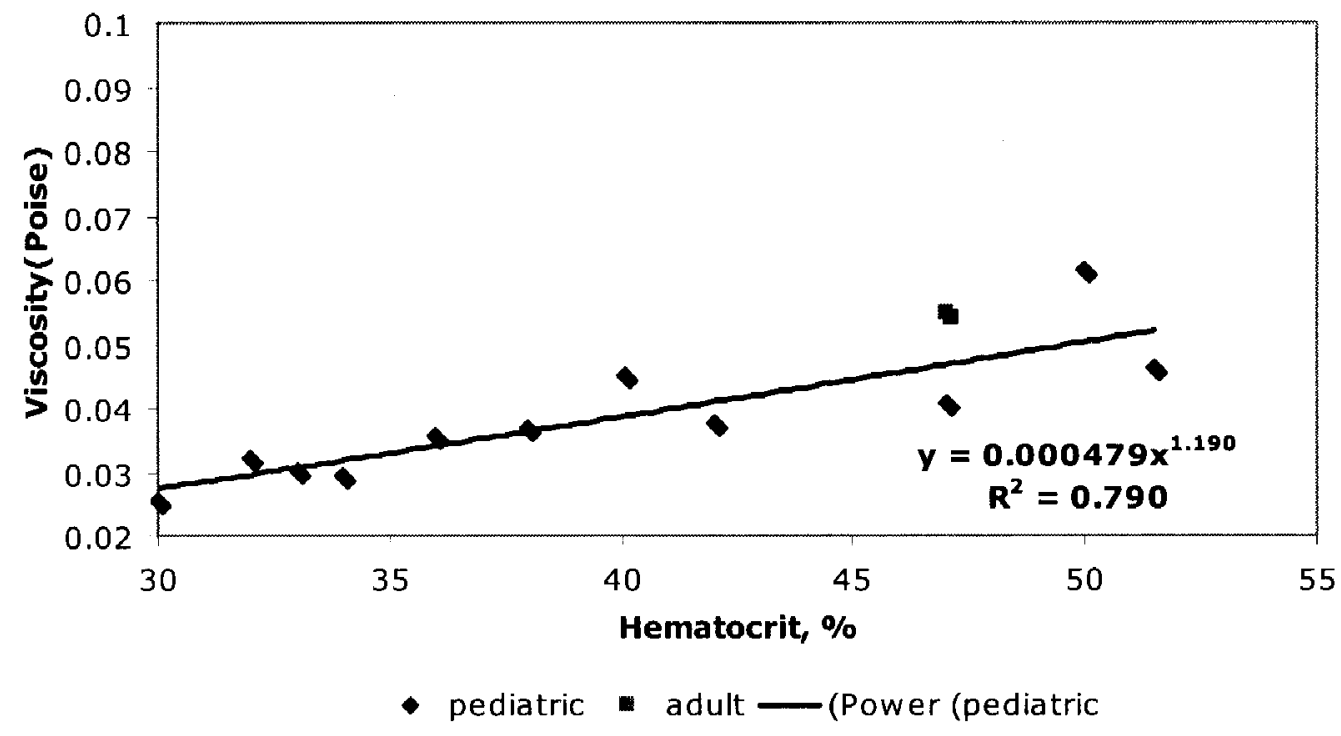

Figure 62. Powercurve fit for viscosity vs. hematocrit at 5 strain.

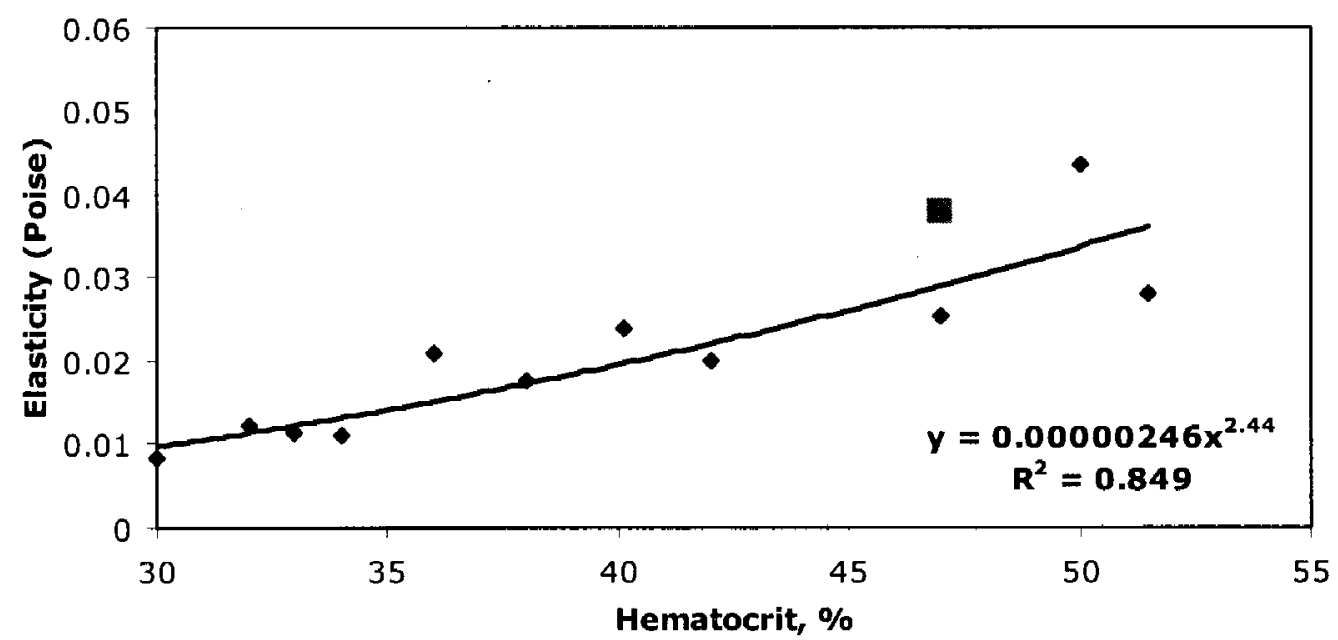

- pediatric a adult $\longrightarrow$ (Power (pediatric

Figure 63. Powercurve fit for elasticity vs. hematocrit at 0.2 strain. 


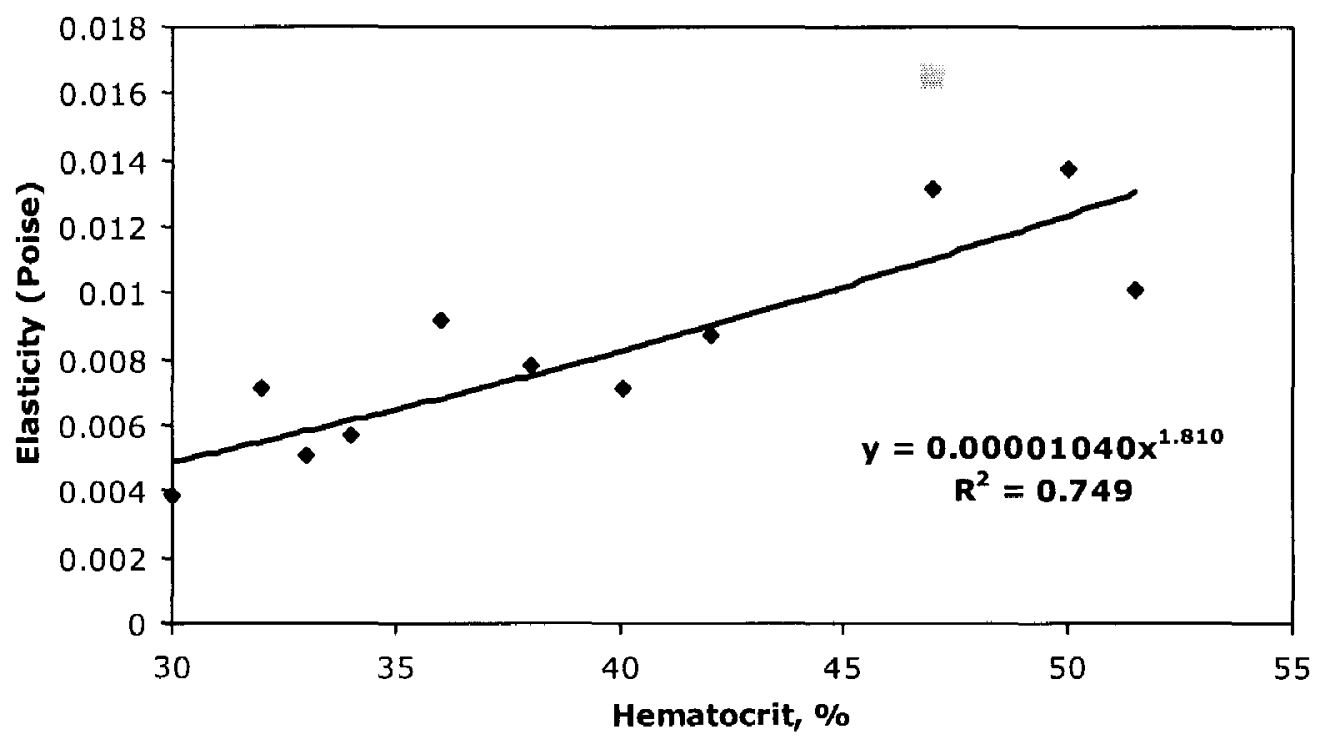

- pediatric $=$ adult $\longrightarrow$ (Power (pediatric

Figure 64. Powercurve fit for elasticity vs. hematocrit at 1 strain.

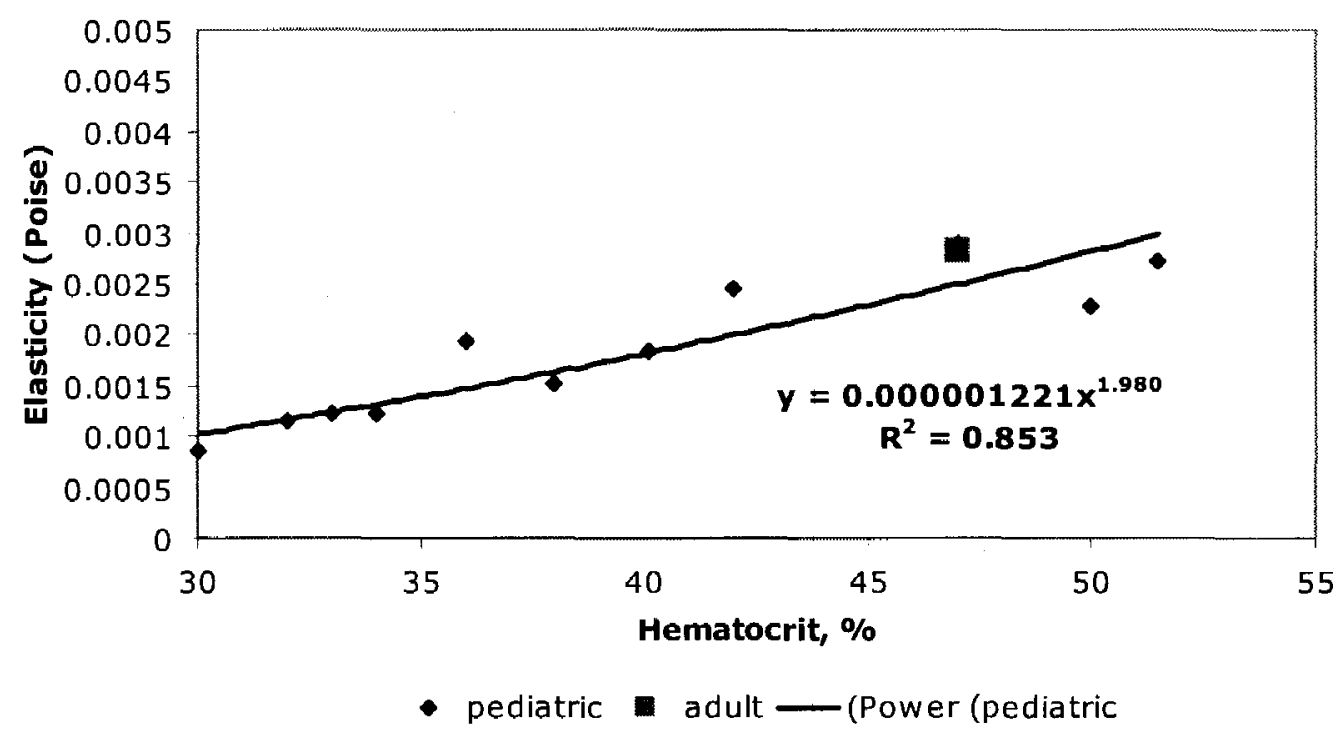

Figure 65. Powercurve fit for elasticity vs. hematocrit at 5 strain. 
This section provides the complete analysis results from the Two-way ANOVA on the adult and pediatric data.

$\underline{\text { Two-Way ANOVA }}$

\begin{tabular}{|c|c|c|c|c|c|c|}
\hline $\begin{array}{c}\text { Source of } \\
\text { Variation }\end{array}$ & SS & df & MS & F & P-value & F crit \\
\hline Rows & 0.001346 & 5 & 0.000269 & 3.665146 & 0.090167 & 5.050329 \\
\hline Columns & 0.00249 & 1 & 0.00249 & 33.90262 & 0.002111 & 6.607891 \\
\hline Error & 0.000367 & 5 & $7.34 \mathrm{E}-05$ & & & \\
\hline & & & & & & \\
\hline Total & 0.004203 & 11 & & & & \\
\hline
\end{tabular}

Table 24. Two-way ANOVA results for comparison of viscosity of pediatric and adult blood.

\begin{tabular}{|c|c|c|c|c|c|c|}
\hline $\begin{array}{c}\text { Source of } \\
\text { Variation }\end{array}$ & SS & df & MS & F & P-value & F crit \\
\hline Rows & 0.000124 & 5 & $2.48 \mathrm{E}-05$ & 1.039384 & 0.483611 & 5.050329 \\
\hline Columns & 0.000985 & 1 & 0.000985 & 41.24924 & 0.001359 & 6.607891 \\
\hline Error & 0.000119 & 5 & $2.39 \mathrm{E}-05$ & & & \\
\hline & & & & & & \\
\hline Total & 0.001229 & 11 & & & & \\
\hline
\end{tabular}

Table 25. Two-way ANOVA results for comparison of elasticity of pediatric and adult blood. 


\section{Statistical Test Analysis Results - Pediatric data at $37^{\circ} \mathrm{C}$ vs. $22^{\circ} \mathrm{C}$}

This section provides the complete analysis results from the Two-way ANOVA on the pediatric data tested at $37^{\circ} \mathrm{C}$ vs. $22^{\circ} \mathrm{C}$.

$\underline{\text { Two-WaV ANOVA }}$

\begin{tabular}{|c|c|c|c|c|c|c|}
\hline $\begin{array}{c}\text { Source of } \\
\text { Variation }\end{array}$ & SS & df & MS & F & P-value & F crit \\
\hline Rows & 0.001316 & 4 & 0.000329 & 4.62377 & 0.083612 & 6.388233 \\
\hline Columns & 0.001898 & 1 & 0.001898 & 26.68579 & 0.006671 & 7.708647 \\
\hline Error & 0.000285 & 4 & $7.11 \mathrm{E}-05$ & & & \\
\hline & & & & & & \\
\hline Total & 0.003498 & 9 & & & & \\
\hline
\end{tabular}

Table 26. Two-way ANOVA results for comparison of viscosity at 0.2 strain of pediatric data measured at $37^{\circ} \mathrm{C}$ vs. $22^{\circ} \mathrm{C}$.

\begin{tabular}{|c|c|c|c|c|c|c|}
\hline $\begin{array}{c}\text { Source of } \\
\text { Variation }\end{array}$ & SS & df & MS & F & P-value & F crit \\
\hline Rows & 0.000995 & 4 & 0.000249 & 2.852357 & 0.167165 & 6.388233 \\
\hline Columns & 0.00294 & 1 & 0.00294 & 33.71788 & 0.004376 & 7.708647 \\
\hline Error & 0.000349 & 4 & $8.72 \mathrm{E}-05$ & & & \\
\hline & & & & & & \\
\hline Total & 0.004284 & 9 & & & & \\
\hline
\end{tabular}

Table 27. Two-way ANOVA results for comparison of viscosity at 1 strain of pediatric data measured at $37^{\circ} \mathrm{C}$ vs. $22^{\circ} \mathrm{C}$.

\begin{tabular}{|c|c|c|c|c|c|c|}
\hline $\begin{array}{c}\text { Source of } \\
\text { Variation }\end{array}$ & SS & df & MS & F & P-value & F crit \\
\hline Rows & 0.000609 & 4 & 0.000152 & 3.154811 & 0.145902 & 6.388233 \\
\hline Columns & 0.002503 & 1 & 0.002503 & 51.87512 & 0.00197 & 7.708647 \\
\hline Error & 0.000193 & 4 & $4.83 \mathrm{E}-05$ & & & \\
\hline & & & & & & \\
\hline Total & 0.003305 & 9 & & & & \\
\hline
\end{tabular}

Table 28. Two-way ANOVA results for comparison of viscosity at 5 strain of pediatric data measured at $37^{\circ} \mathrm{C}$ vs. $22^{\circ} \mathrm{C}$. 


\begin{tabular}{|c|c|c|c|c|c|c|}
\hline $\begin{array}{c}\text { Source of } \\
\text { Variation }\end{array}$ & $\mathrm{SS}$ & $\mathrm{df}$ & $\mathrm{MS}$ & $\mathrm{F}$ & P-value & F crit \\
\hline Rows & 0.001118 & 4 & 0.00028 & 2.15762 & 0.23736 & 6.388233 \\
\hline Columns & 0.001099 & 1 & 0.001099 & 8.4813 & 0.043579 & 7.708647 \\
\hline Error & 0.000518 & 4 & 0.00013 & & & \\
\hline & & & & & & \\
\hline Total & 0.002736 & 9 & & & & \\
\hline
\end{tabular}

Table 29. Two-way ANOVA results for comparison of elasticity at 0.2 strain of pediatric data measured at $37^{\circ} \mathrm{C}$ vs. $22^{\circ} \mathrm{C}$.

\begin{tabular}{|c|c|c|c|c|c|c|}
\hline $\begin{array}{c}\text { Source of } \\
\text { Variation }\end{array}$ & SS & df & MS & F & P-value & F crit \\
\hline Rows & 0.000639 & 4 & 0.00016 & 1.489294 & 0.354479 & 6.388233 \\
\hline Columns & 0.001267 & 1 & 0.001267 & 11.81433 & 0.026361 & 7.708647 \\
\hline Error & 0.000429 & 4 & 0.000107 & & & \\
\hline & & & & & & \\
\hline Total & 0.002335 & 9 & & & & \\
\hline
\end{tabular}

Table 30. Two-way ANOVA results for comparison of elasticity at 1 strain of pediatric data measured at $37^{\circ} \mathrm{C}$ vs. $22^{\circ} \mathrm{C}$.

\begin{tabular}{|c|c|c|c|c|c|c|}
\hline $\begin{array}{c}\text { Source of } \\
\text { Variation }\end{array}$ & SS & df & MS & F & P-value & F crit \\
\hline Rows & $8.36 \mathrm{E}-05$ & 4 & $2.09 \mathrm{E}-05$ & 1.406186 & 0.374596 & 6.388233 \\
\hline Columns & 0.000334 & 1 & 0.000334 & 22.49224 & 0.00902 & 7.708647 \\
\hline Error & $5.95 \mathrm{E}-05$ & 4 & $1.49 \mathrm{E}-05$ & & & \\
\hline & & & & & & \\
\hline Total & 0.000478 & 9 & & & & \\
\hline
\end{tabular}

Table 31. Two-way ANOVA results for comparison of elasticity at 5 strain of pediatric data measured at $37^{\circ} \mathrm{C}$ vs. $22^{\circ} \mathrm{C}$. 


\section{APPENDIX B}

The ceritificate of completion for Basic CITI and HIPAA is attached in this section. 


\section{CITI / HIPAA Certificate}

\section{CITI Course in The Protection of Human Research Subjects}

Sunday, October 16, 2005

\section{CITI Course Completion Record for Neema Nair}

To whom it may concern:

On 10/16/2005, Neema Nair [username=neenai; Employee Number=1404756] completed all CITI Program requirements for the Basic CITI Course in The Protection of Human Research Subjects.

Learner Institution: University of Louisville

Learner Group: Group 1.

Learner Group Description: Biomedical Research Investigators and Key Personnel. Investigators with VA appointments conducting research at the Louisville VAMC should complete the optional modules on SBR and on conducting "Research at the VA" and the Good Clinical Practice module: http://www.va.gov/resdev/fr/stand_down/instructions.cfm

\section{Contact Information:}

Gender: Female

Department: Mechanical Engineering

Which course do you plan to take?: Biomedical Investigator Course Only

Role in human subjects research: Student Researcher

Email: n0nair01@louisville.edu

Office Phone: 502-777-5769

The Required Modules for Group 1. are:

Date
completed

Introduction 09/27/05

History and Ethical Principles $10 / 16 / 05$

Basic Institutional Review Board [IRB] Regulations and Review Process
10/16/05 
Informed Consent

$10 / 16 / 05$

Social and Behavioral Research for Biomedical Researchers

$10 / 16 / 05$

Records-Based Research

$10 / 16 / 05$

Genetic Research in Human Populations

$10 / 16 / 05$

Research With Protected Populations - Vulnerable Subjects: An Overview

$10 / 16 / 05$

Vulnerable Subjects- Research With Prisoners

$10 / 16 / 05$

Vulnerable Subjects- Research Involving Minors

10/16/05

Vulnerable Subjects- Research Involving Pregnant Women and

$10 / 16 / 05$

Fetuses in Utero

Group Harms: Research With Culturally or Medically Vulnerable Groups

$10 / 16 / 05$

FDA-Regulated Research

$10 / 16 / 05$

University of Louisville

$10 / 16 / 05$

Date

Additional optional modules completed: completed

HIPAA and Human Subjects Research

10/16/05

For this Completion Report to be valid, the learner listed above must be affiliated with a CITI participating institution. Falsified information and unauthorized use of the CITI course site is unethical, and may be considered scientific misconduct by your institution.

Paul Braunschweiger Ph.D.

Professor, University of Miami

Director Office of Research Education

CITI Course Coordinator 


\section{CURRICULUM VITAE}

NAME:

ADDRESS:

DOB:

EDUCATION

\& TRAINING:
Neema Nair

Cummins Inc.

MC\#50232

1900 Mckinley Ave

Columbus, IN 47201

Mumbai, India - January $24^{\text {th }} 1983$

B. E. Mechanical Engineering

Mumbai University

2000-2004

M.S. Mechanical Engineering

University of Louisville

2004-2008

WORK

EXPERIENCE: $\quad$ Sr. Performance Development Engineer, Class II VPI Lead Automotive Customer Engineering

Cummins Inc.

May 2008-Present

Performance Development Engineer

Automotive Customer Engineering

Cummins Inc.

October 2006-April 2008

SCHOLARSHIPS/

AWARDS:
International Student Scholarship

International Center, University of Louisville

2006

Department Student Assistantship

Mechanical Engineering, University of Louisville 2004 